\title{
Feasibility of Establishing An Enzyme-Linked Immunosorbent Assay (ELISA) Laboratory for the Detection of Dioxins in Economically Marginalized and Developed Countries
}

By

Adrienne Kristin Lee

B.Sc. (Hons), McMaster University, 2007

\author{
A thesis \\ presented to Ryerson University \\ in partial fulfillment of the \\ requirements for the degree of \\ Master of Applied Science \\ in the Program of \\ Environmental Applied Science and Management
}

Toronto, Ontario, Canada, 2011

(C) (Adrienne Kristin Lee) 2011 


\section{AUTHOR'S DECLARATION}

I hereby declare that I am the sole author of this thesis or dissertation. I authorize Ryerson University to lend this thesis or dissertation to other institutions or individuals for the purpose of scholarly research.

I further authorize Ryerson University to reproduce this thesis or dissertation by photocopying or by other means, in total or in part, at the request of other institutions or individuals for the purpose of scholarly research. 


\section{ABSTRACT}

Feasibility of Establishing An Enzyme-Linked Immunosorbent Assay (ELISA) Laboratory for the Detection of Dioxins in Economically Marginalized and Developed Countries

Adrienne Kristin Lee Master of Applied Science

Environmental Applied Science and Management

Ryerson University

2011

Finding a low cost and accessible means of detecting for dioxins in contaminated soil is a necessary step to ensure the health and safety of humans and the environment worldwide. Conventional technologies based on mass spectrometry are expensive and inaccessible. A minimally resourced laboratory and the use of ELISA will be discussed as a feasible, accessible, low cost alternative. The correlation between a minimally resourced laboratory (Ryerson University) and a fully resourced laboratory (Ontario Ministry of the Environment) was strong $\left(\mathrm{n}=13, \mathrm{r}^{2}=0.888\right.$, slope $\left.=0.87\right)$. To demonstrate the functionality of the minimally resourced laboratory, a supplemental site was characterized using ELISA. Results from the Ryerson and OMOE laboratories produced similar dioxin concentrations of undetectable to $120.26 \mathrm{pgTEQg}^{-1}$ and 32.38 to $163.2 \mathrm{pgTEQg}^{-1}$, respectively. This study illustrates an alternative for evaluating contaminated soil that could serve as a technology transfer for marginalized economies, and provide an accessible form of sample analysis in developed countries. 


\section{ACKNOWLEDGEMENTS}

I would like to gratefully acknowledge my supervisors Dr. Ching Lo and Dr. James Li for their guidance and support throughout the course of my thesis work. My acknowledgements also extend to members of the Ryerson University community: Maureen Cooper, Robin Luong and Meng Bo - thank you for providing me with technical support and being the answers to my many questions. A very special thanks goes out to my thesis defence committee members Dr. Lynda McCarthy, Dr. Li He and the chair of my committee, Dr. Michal Bardecki, for their interest and vast input in my work, and most importantly, joining me on my journey.

This research could not have been possible without the funding provided by Dr. James Li and the Ryerson Graduate Scholarship program. Support in terms of laboratory facilities and chemicals provided by the Ministry of the Environment, Laboratory Services Branch is acknowledged.

Finally, a great deal of thanks goes to my mother Pera Lee, and to all my family and friends for their encouragement and support of all kinds. 


\section{DEDICATION}

This thesis is dedicated to my late father Paul Lee and to the many faces and friends I met in Vietnam. 


\section{TABLE OF CONTENTS}

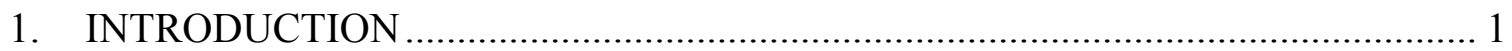

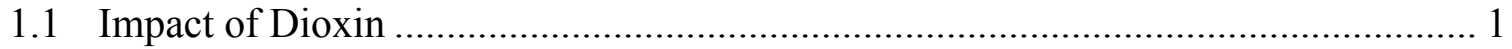

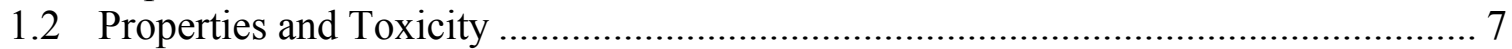

1.3 Anthropogenic Sources of Dioxin Entry into the Environment............................... 10

1.4 Health Implications to the Human Population .................................................... 16

1.5 Methods of Analysis of Dioxins in the Environment........................................... 19

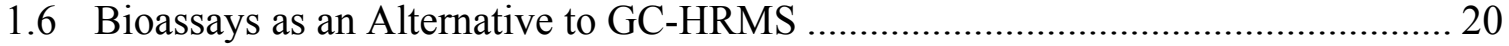

1.6.1 Chemically Activated Luciferase Gene Express (CALUX) Bioassay .............. 21

1.6.2 Enzyme-linked Immunosorbent Assay (ELISA) ............................................. 23

1.7 Dioxin-Contaminated Sites in Canada in Need of Remediation............................... 26

1.7.1 Federal Contaminated Sites Inventory 10 Step Process ..................................... 28

1.8 State of Detection in Economically Marginalized Countries..................................... 31

1.8.1 The Stockholm Convention on Persistent Organic Pollutants.......................... 31

1.8.2 Current Detection Methods Utilized in Economically Marginalized Countries 33

1.8.3 Utilization of ELISA in Economically Marginalized Countries ........................ 41

1.9 Utilization of ELISA in Developed Countries ………........................................... 46

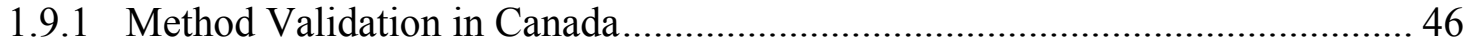

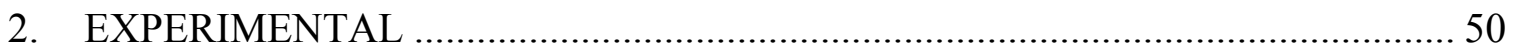

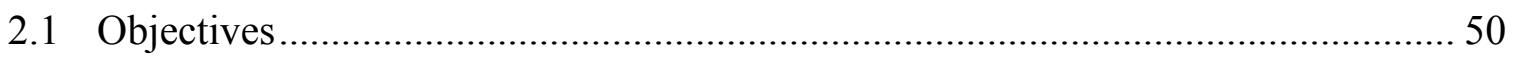

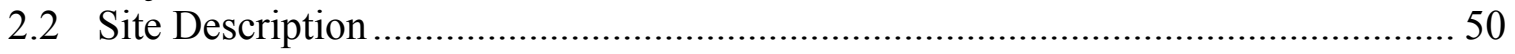

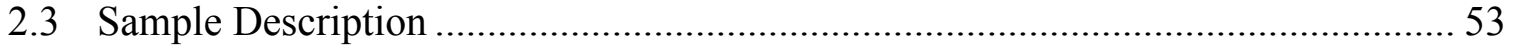

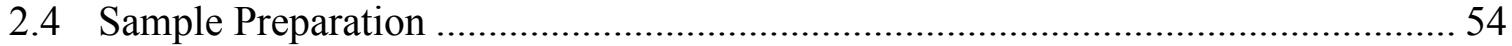

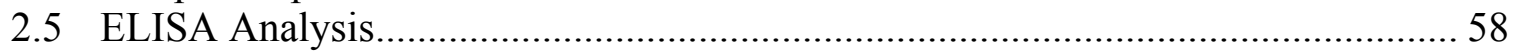

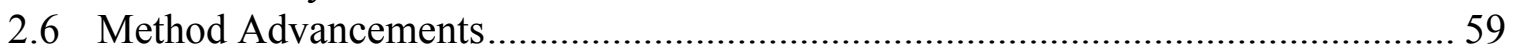

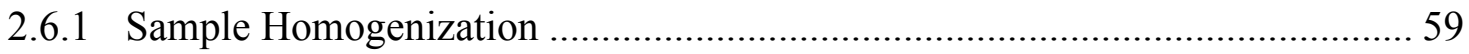

2.6.2 Bioassay Plan for a Minimally Resourced Laboratory....................................... 60

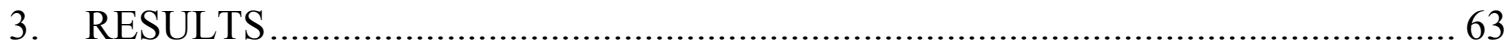

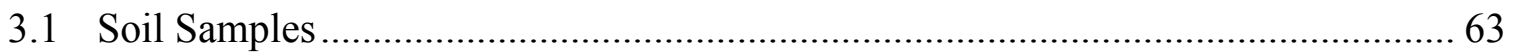

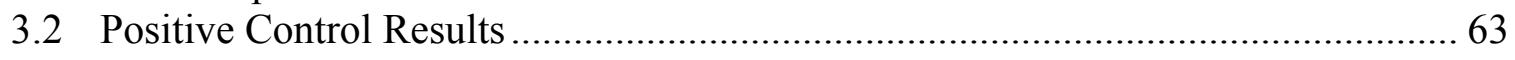

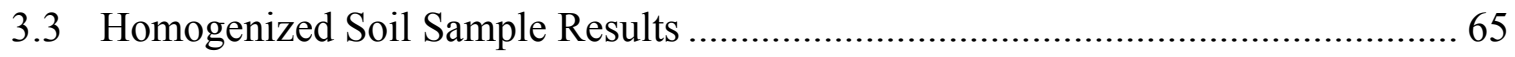

3.4 Relationship Between the OMOE and Ryerson University Lab Results .................. 67

3.5 Evaluating the Costs and Feasibility of a Bioassay Laboratory ................................ 77

3.6 Optimal Bioassay Laboratory Conditions and Laboratory Portability..................... 82

3.6.1 Optimal Conditions for a Stationary Laboratory ………….............................. 82

3.6.2 Optimal Conditions for a Portable Laboratory .................................................. 86

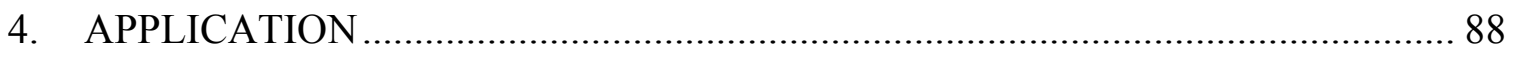

4.1 Application of ELISA in Marginalized Economies …………………………........ 88

4.2 Application of ELISA in Developed Economies ………......................................... 90 


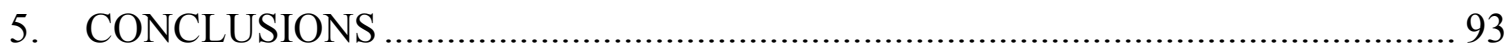

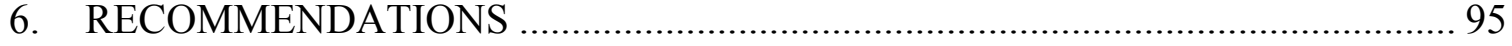

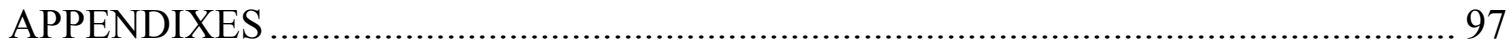

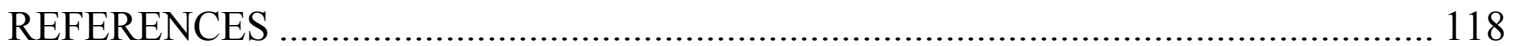




\section{LIST OF TABLES}

Table 1. Most common internationally recognized toxic equivalency schemes. ........... 10

Table 2. Dioxin contaminated sites categorized by the CCME classification system..... 31

Table 3. Marginalized economies that have conducted dioxin analysis........................ 36

Table 4. Dioxin Source-Specific Correction Factors .................................................... 48

Table 5. Summary of the three methodologies used in Mexico, Uruguay and Canada... 49

Table 6. Procedural differences between the OMOE and Ryerson University. .............. 57

Table 7. Capital cost comparison of laboratories. ......................................................... 78

Table 8. Recovery of ELISA standards prior to and post optimization.......................... 81

Table 9. Optimized equipment, specifications and costs......................................... 84 


\section{LIST OF FIGURES}

Figure 1. General chemical structure of dioxin and furan ........................................ 8

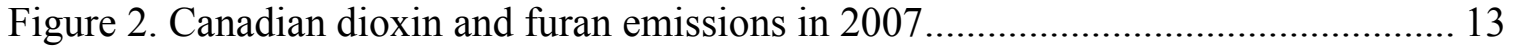

Figure 3. Canadian dioxin and furan emission trend for the last 20 years.. ................... 15

Figure 4. Schematics illustrating the influence of TCDD on the AHR pathway.............. 17

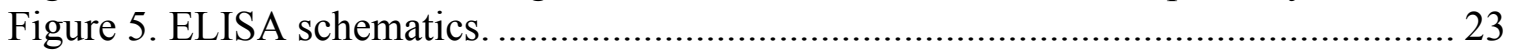

Figure 6. 304 dioxin-contaminated sites found in Canada. ......................................... 27

Figure 7. Dioxin-contaminated sites found in Ontario............................................. 28

Figure 8. Economically marginalized countries that have conducted dioxin analysis. .... 34

Figure 9. DST Consulting supplemental site description......................................... 50

Figure 10. Site description and sampling schematics........................................... 53

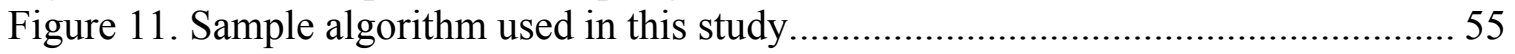

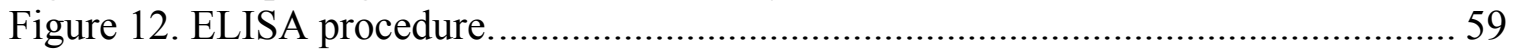

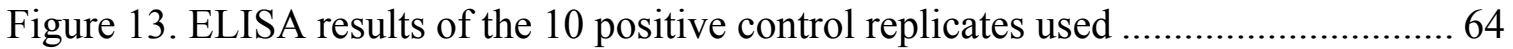

Figure 14. Homogenization results for a low concentration soil sample.........................66

Figure 15. Comparison between OMOE and Ryerson University ELISA results............ 68

Figure 16. Concentration site map for the Welland site, Canada. ................................. 72

Figure 17. OMOE spatial distribution concentration gradient trend ............................. 73

Figure 18. Ryerson University spatial distribution concentration gradient trend ............. 74 


\section{LIST OF APPENDIXES}

Appendix A. Comparison of analytical methods used to detect of dioxins...................... 97

Appendix B. High priority PCDD/F contaminated sites located in Ontario. .................. 100

Appendix C. Welland, Ontario site maps. .................................................................. 101

Appendix D. Standard operating procedure for soil samples at the MOE ..................... 103

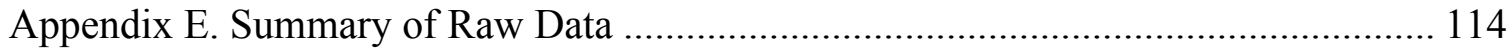

Appendix F. Statement sent requesting that No Further Action Required ...................... 117 


\section{INTRODUCTION}

\subsection{Impact of Dioxin}

At the climax of the Vietnam War, approximately 77 million liters of dioxin-tainted herbicide, Agent Orange, was sprayed across one fifth of southern Vietnam (Nguyen, 2009). Immediately following the cataclysm of the Vietnam War, an increase in the number of cancer cases, digestive ailments, neural and skin diseases had emerged amongst Vietnamese civilians. In 2001, decades after the war, a pilot project was conducted on thirty women directly affected by Agent Orange, a herbicide contaminated with the most toxic dioxin congener, 2,3,7,8-tetrachloro dibenzo-p-dioxin (TCDD). Women directly affected or whose husbands had been directly exposed to Agent Orange during the war, showed a substantial increase in the number of miscarriages and premature births, birth defects, low-weight births, and childhood cancers among offspring (Tuyet and Johansson, 2001). Two-thirds of all breast-fed infants displayed congenital malformations and developed disabilities within the first year of life. Congenital malformations associated with Agent Orange varied from conjoined twins to cleft lip and cleft palate, and mild to severe facial anomalies. American Air Force veterans employ to disperse Agent Orange during Operation Ranch Hand, the unit responsible for aerial spraying of herbicides during the Vietnam War, had an increase incidence of basal cell carcinomas when compared to reference subjects who were not exposed to the herbicide (Wolfe et al., 1990). Veterans that had served in the Vietnam War also showed a 50\% higher risk of developing non-Hodgkin's lymphoma than veterans that did not serve in the Vietnam War (Brann, 1990). 
Agent Orange was disseminated from helicopters, spray packs and boats, from 1962, and ended around 1971 (Schecter et al., 1995). The country has been described as having, "inherited the biggest chemical dumping in history," affecting anywhere between 3 to 7 million Vietnamese people (Nguyen, 2009). Nearly four decades have past and dioxin contamination in Vietnam remains a substantial issue of concern. Due to the chemical stability of dioxin in soil and sediment (Lohmann and Jones, 1998), contaminated lands have the ability to expose neighboring populations to significantly high concentrations of dioxin for extended periods of time (Dwernychuk, 2005). This not only affects where the person resides, be it on or off contaminated soil, it has also been documented that food sources in contaminated areas in Vietnam have been impinged upon (Olie, et al., 1989; Schecter, et al., 2003), affecting civilians through the consumption and bioaccumulation of contaminated fish (Baughman and Meselson, 1973) and animal products (Minh et al., 2009).

Dioxin exposure has impacted other human populations worldwide. The first case of dioxin exposure in humans was reported in 1949 after a Monsanto Company plant manufacturing trichlorophenol (TCP) reactor exploded in Nitro, West Virginia, USA (Sweeney and Mocarelli, 2000). One hundred and twenty-one workers developed chloracne immediately after the incident. Exposed workers were studied over the course of thirty years and thirty-two deaths were observed.

In 1968, a "strange disease" occurred in Japan, which involved more than 1800 people. This "disease," later referred to as "Yusho" disease was determined to have originated 
from contaminated rice oil that had been tainted with Kanechlor 400 (KC 400), a commercial mixture of polychlorinated biphenyls (PCBs) used as a heat transfer medium in rice oil production (Yao et al., 2002). Kanechlor 400 was unstable, and some PCB congeners were converted to more toxic polychlorinated dibenzo- $p$-furan (PCDF) congeners (Aoki, 2001). The total number of registered Yusho patients was 1860 in 1990, of which 149 of them had died (Masuda, 1996). Death from liver cancer was increased in both males and females exposed during the Yusho incident, although only found significant in males. Mortality from respiratory cancer was also significantly increased in males impacted by the Yusho incident (Aoki, 2001). A similar incident, "Yucheng" disease occurred in Taiwan from 1978 to 1979, impacting approximately 2000 people. People developed chloracne, hyper pigmentation and peripheral neuropathy (Guo et al., 2004). Children of exposed women were born with retarded growth, dysmorphic physical characteristics, delayed cognitive development, and behavioral problems (Rogan et al., 1988).

In 1976, an accidental industrial chemical explosion occurred in Seveso, Italy, which released a cloud of TCDD over an area of $2.8 \mathrm{~km}^{2}$ (Homberger et al., 1979). The Industrie Chemiche Meda Societa Azionaria (ICMESA), a subsidiary of Givaudan was responsible for the manufacturing of TCP. Trichloropheonol was being manufactured to produce hexachlorophene, a local antiseptic used to combat gram-positive bacteria. On the evening of July $10^{\text {th }}, 1976$, a runaway reaction occurred releasing $1 \mathrm{~kg}$ of TCDD into the atmosphere. Ten days after analytical results of TCDD contamination were confirmed, 736 people were evacuated with a total of 220000 estimated people under 
health surveillance. Immediately subsequent to the explosion, over 2000 animals within the vicinity had died within the first two months. As a precautionary to negative consequences that may be imposed upon the food chain, all other animals (nearly 78 000) in the area were slaughtered. In humans, elevated cardiovascular mortality in the first years after the event and suggestive increases in diabetes and chronic lung disease were observed (Consonni et al., 2008). Ten years after observation, a moderate increase in mortality from all cancers and digestive cancers were visible, with stomach cancer illustrating the largest and clearest increase (Bertazzi et al., 1997). Cohort studies conducted 25 years after the incident illustrated notable increases in mortality from cancers of the lymphatic and hematopoietic tissues in the areas closest to the contaminated site (Consonni et al., 2008). Suggestions of mortality increases for several types of cancer (rectum, lung) and non-cancer (circulatory diseases, chronic obstructive pulmonary disease, and diabetes mellitus) causes were also observed. Between the years 1977 to 1985 , a change to sex ratios was also observed among children born to parents with high TCDD serum concentrations (Bertazzi et al., 1998).

For over 10 years, residents of Times Beach Missouri had undergone exposure to dioxincontaminated soil. In 1971, TCDD contaminated sludge waste was mixed with waste oil and sprayed throughout the area at the Quail Run Mobile Home Park in Gray Summit, Missouri to combat a local dust problem (Hoffman et al., 1986). Three recreational riding arenas were also sprayed in the area (Kimbrough et al., 1977). Soil sample levels measured 2200 parts per billion (ppb), the highest level measured in a residential area at the time. Residents of the area had an average duration of exposure of $2.8 \pm 1.9$ years 
and an average period from first exposure to the time of the study of $6.7 \pm 3.4$ years (Evans et al., 1988). Studies on individual residents illustrated that there was a significant depression in cell-mediated immunity with 18 of the 51 persons exposed showing signs of anergy, an absence of a normal immune response. Wildlife and domestic animals living within the contaminated areas were also affected. Hundreds of birds, and domesticated dogs and cats were found dead within weeks of the first spraying in May 1971 (Kimbrough et al., 1977). Within one month of the initial spraying, horses ridden in the area were showing signs of illness. Eventually $70 \%$ of the horses exposed to contaminated soil would become ill and $51 \%$ of them would die through wasting syndrome. The area has since been remediated with a total of 265000 tonnes of TCDD contaminated material incinerated (Evans et al., 2000).

Dioxin contaminated food sources have also led to a global recall of food products, a loss to several economies and a reduction in the public's trust in authorities. In 1999, a Belgium dioxin incident found high levels of dioxin in poultry and eggs (Kennedy et al., 2010). The cause was traced to animal feed contaminated with illegally disposed of PCB-based industrial waste oil. This incident cost the Belgian economy over one billion euro. Public scrutiny over the way this issue was handled caused a decrease in confidence of authorities leading to the resignation of both the Minister of Agriculture and the Minister of Health, which was followed by the entire collapse of the Belgian government. In 2008, dioxin present in pork fat was discovered through a routine monitoring of PCB markers in Ireland (Kennedy et al., 2010). It was found that animals had been given PCB-contaminated feed with detection levels of $5200 \mathrm{pg} / \mathrm{g}$, whereby the 
maximum feed limit was set at $0.75 \mathrm{pg} / \mathrm{g}$. The European Union's legal limit for dioxin in pig fat is set at $1 \mathrm{pg} / \mathrm{g}$ for consumption; animals were tested positive with a detected limit of $80-200 \mathrm{pg} / \mathrm{g}$. It was estimated that $10 \%$ of the pig meat from the Republic of Ireland was contaminated with dioxin laced feed. As all Irish pigs are slaughtered in a small number of large processing plants, the difficulty of determining which animals were contaminated or not contaminated led to the slaughter and disposal of all pigs in Ireland from September $1^{\text {st }}$ to December $6^{\text {th }}, 2008$.

In 2011, it was acknowledged that Ontario, Canada was the latest in a string of dioxincontamination cases. Hydro One, formally Ontario Hydro, had admitted to using Agent Orange from 1950 to 1979 to clear power line corridors across the province, through city backyards and thick rural brush (Ziomislic, February $26^{\text {th }}, 2011$ ). All-terrain vehicles, helicopters, army trucks, swamp tractors, and horses were used to distribute hundreds of gallons of Agent Orange across hundreds of thousands of kilometers in Ontario. Students and junior rangers were employed to disseminate the herbicide, some acting as "human markers holding red, helium-filled balloons on fishing lines," so that low-flying planes could spray the herbicide directly on the brush below (Ziomislic, February $17^{\text {th }}, 2011$ ). Four of the five supervisors that had worked on the spraying programs in Northern Ontario have since been diagnosed with or have died of cancer.

The persistency and toxicity of dioxin has remained a legacy for millions worldwide. The impact of dioxin amongst civilian populations is a growing list of issues that should be readdressed by the public and scientific community. As dioxin half-lives in 
contaminated soil and sediment are unknown, with estimated half-lives are upwards of greater than 30 years (Lohmann and Jones, 1998), and as several incidences illustrate an impact to human health (Aoki, 2001; Bertazzi et al., 1997; Consonni et al., 2008; Masuda, 1996; Nguyen, 2009), food sources (Minh et al., 2009; Kennedy et al., 2010), and the health of unborn children (Bertazzi et al., 1998; Rogan, et al., 1988; Tuyet \& Johansson, 2001); the human population and surrounding environment continue to be at risk in areas that have been contaminated by dioxin in the past, and remain contaminated to this day.

\subsection{Properties and Toxicity}

Polychlorinated dibenzo- $p$-dioxins (PCDDs) and polychlorinated dibenzo- $p$-furans (PCDFs) are a group of polychlorinated hydrocarbons that are persistent and bioaccumulative in the environment (Lohmann and Jones, 1998). These compounds are poorly water-soluble and possess high octanol-water partition coefficients $\left(\mathrm{K}_{\mathrm{ow}}\right)$. The $\log$ $\mathrm{K}_{\mathrm{ow}}$ of PCDDs and PCDFs range from 4.75 for mono-substituted compounds and are as high as 8.2 for octa-substituted compounds. These compounds will more readily partition to soils and sediments than enter the aqueous phase. PCDDs and PCDFs are colloquially called "dioxins and furans" as both share a common chemical structure and serve similar modes of action within the human body (Ahlborg et al., 1994). Dioxins consist of two benzene rings connected by two oxygen atoms, whereas furans consist of two benzene rings connected by one oxygen atom (Figure 1) (Kulkarni et al., 2008). 


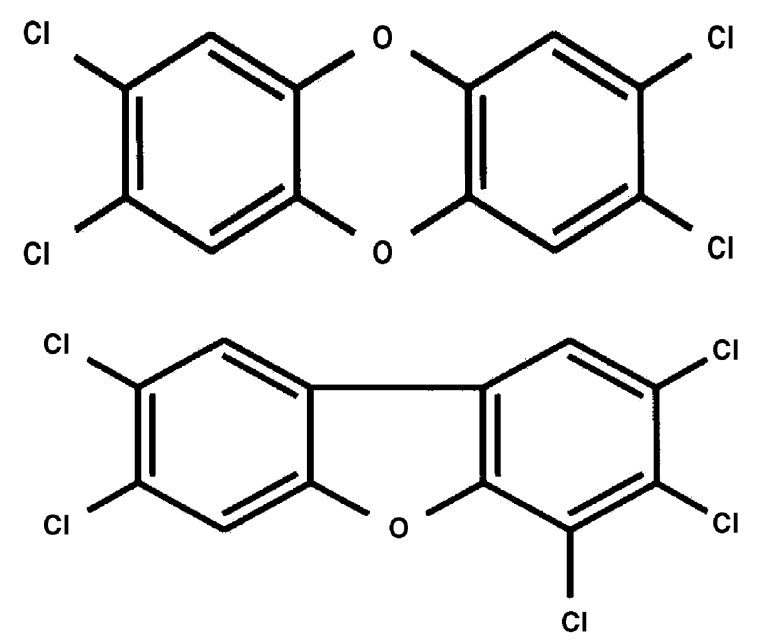

Figure 1. General chemical structure of dioxin (top) and furan (bottom).

Source: Schecter et al., 2006

Former toxicological data focused on conventional risk assessment techniques of estimating the heath hazards compared to the most toxic congener, TCDD. As real-world exposure involves a complex mixture of dioxin congeners, toxicology schemes were redeveloped to include compounds that exhibit dioxin-like activity (Eadon et al., 1986). For a compound to have dioxin-like activity, four prerequisites are required, the compound must: (i) show a structural relationship to PCDDs and PCDFs; (ii) bind to the aryl hydrocarbon receptor (AHR), which is a cytosolic receptor present in most vertebrate; (iii) elicit an AHR-mediated biochemical and toxic response; and (iv) be persistent and accumulative in the food chain (Van den Berg et al., 2006).

The structures of dioxins involve the substitution of anywhere between four to eight chlorine atoms onto the two benzene rings. Hence, there are a total of 75 dioxin congeners and 135 furan congeners; 7 dioxin congeners and 10 furan congeners are labeled as having dioxin-like toxicity (Kulkarni et al., 2008). The most toxic congeners 
are those with four to eight chlorine atoms, and in particular, those in which positions 2 , 3, 7, 8 are chlorinated (Elijarrat and Barcelo, 2002).

Individual toxicity of each congener varies in magnitude, which is determined by a number of different international decision-making bodies as a mechanism of simplifying risk assessment and regulatory control (Ahlborg et al., 1994). The scheme was developed, as although TCDD is the most toxic of all congeners, it is generally present in real-world samples in much lower concentration than less toxic congeners (McKay, 2002). The "toxic equivalent" value is based on the comparative toxicity of each dioxin congener present in a gas (Ahlborg et al., 1994). Congeners that exhibit dioxin-like toxicity are assigned a Toxic Equivalency Factor (TEF) based on their relative potency to TCDD, which is given a TEF of 1 (Kimbrough et al., 2010). All congeners are then a fraction of 1 .

The TEFs are determined based on in vitro and in vivo studies (Ahlborg et al., 1994). The toxicity of the mixture of congeners, relative to TCDD, is then expressed by multiplying the concentration of each individual congener with their respective TEFs (McKay, 2002). These are then added to produce a total Toxic Equivalent (TEQ), which expresses the concentration of dioxin as if the mixture were composed of pure TCDD. A major assumption to this scheme, and often a limitation, is that it assumes components in a mixture are additive, neglecting the possibility of synergistic or antagonistic effects (Ahlborg et al., 1994). Two of the most common internationally recognized toxic equivalency schemes are presented in Table 1. Both the World Health Organization 
(WHO) and the North Atlantic Treaty Organization (NATO) schemes are used to determine human exposure to dioxin (McKay, 2002).

Table 1. Most common internationally recognized toxic equivalency schemes. World Health Organization (WHO) dioxin toxic equivalency factors (TEFs) $(1994,1998,2005)$ and NATO I-TEFs for PCDDs and PCDFs.

\begin{tabular}{|c|c|c|c|c|c|}
\hline & Congener & $\begin{array}{c}\text { WHO } \\
1994 \text { TEF }\end{array}$ & $\begin{array}{c}\text { WHO } 1998 \\
\text { TEF }\end{array}$ & $\begin{array}{c}\text { WHO } \\
2005 \text { TEF }\end{array}$ & $\begin{array}{l}\text { NATO } \\
\text { I-TEF }\end{array}$ \\
\hline \multirow{7}{*}{ PCDDs } & 2,3,7,8-Tetra-CDD & 1 & 1 & 1 & 1 \\
\hline & 1,2,3,7,8-Penta-CDD & 0.5 & 1 & 1 & 0.5 \\
\hline & $1,2,3,4,7,8-$ Hexa-CDD & 0.1 & 0.1 & 0.1 & 0.1 \\
\hline & $1,2,3,6,7,8$-Hexa-CDD & 0.1 & 0.1 & 0.1 & 0.1 \\
\hline & $1,2,3,7,8,9-$-Hexa-CDD & 0.1 & 0.1 & 0.1 & 0.1 \\
\hline & $1,2,3,4,6,7,8$-Hepta-CDD & 0.01 & 0.01 & 0.01 & 0.01 \\
\hline & OCDD & 0.001 & 0.0001 & 0.0003 & 0.001 \\
\hline \multirow{10}{*}{ PCDFs } & $2,3,7,8$-Tetra-CDF & 0.1 & 0.1 & 0.1 & 0.1 \\
\hline & 1,2,3,7,8-Penta-CDF & 0.05 & 0.05 & 0.03 & 0.5 \\
\hline & $2,3,4,7,8-$ Hexa-CDF & 0.5 & 0.5 & 0.3 & 0.05 \\
\hline & $1,2,3,4,7,8-$ Hexa-CDF & 0.1 & 0.1 & 0.1 & 0.1 \\
\hline & $1,2,3,6,7,8-$ Hexa-CDF & 0.1 & 0.1 & 0.1 & 0.1 \\
\hline & $1,2,3,7,8,9-$-Hexa-CDF & 0.1 & 0.1 & 0.1 & 0.1 \\
\hline & $2,3,4,6,7,8-$ Hexa-CDF & 0.1 & 0.1 & 0.1 & 0.1 \\
\hline & $1,2,3,4,6,7,8$-Hepta-CDF & 0.01 & 0.01 & 0.01 & 0.01 \\
\hline & $1,2,3,4,7,8,9-H e p t a-C D F$ & 0.01 & 0.01 & 0.01 & 0.01 \\
\hline & OCDF & 0.001 & 0.0001 & 0.0003 & 0.001 \\
\hline
\end{tabular}

Source: Chandler, 2007; McKay, 2002

\subsection{Anthropogenic Sources of Dioxin Entry into the Environment}

Dioxins were never produced intentionally but occur as trace contaminants in a variety of industrial and thermal processes (Fiedler, 1999). Dioxins are emitted into the environment through a number of sources. Combustion systems release dioxins and furans through different types of waste incineration (e.g. municipal solid waste, sewage sludge waste, medical waste, and hazardous waste) (McKay, 2002). Three possibilities 
lead to the formation of dioxins and furans through incineration processes, PCDD/Fs: (i) may already be present in incoming waste; (ii) are produced from related chlorinated precursors (e.g. PCB, chlorinated phenols and benzenes); or (iii) are formed via de novo synthesis through the pyrolysis of polyvinyl chloride (PVC) in various plastics and other chlorocarbons (Fiedler, 1999). Metal industries contribute to dioxin emissions through metal smeltering, refining iron ore and steel production (McKay, 2002), as dioxins can be formed in thermal processes in which chlorine-containing substances (e.g. PVC residues, chloroparaffins in waste oils or inorganic carbon) are burnt together with carbon and a suitable catalyst (such as copper) in the presence of excess oxygen at temperatures above $300^{\circ} \mathrm{C}$ (Fiedler, 1999). A number of different chemical manufacturing industries have also lead to dioxin emissions through chlorine bleaching of wood pulp and through the making of certain herbicides and pesticides (McKay, 2002).

Reservoir sources have also been listed as an emission source for dioxins; whereby previously formed dioxins, are deposited, and have the potential to re-circulate from matrixes in to the environment (McKay, 2002). Dioxins and furans found in these reservoirs are not newly generated compounds, but concentrated from other sources. Products that may act as reservoirs for dioxins include pentachlorophenol (PCP)-treated wood, PCB-containing transformers and sewage sludge, compost, and liquid manure used in agriculture and gardens (Fiedler, 1999). Chlorophenols are contaminated with trace quantities of dioxin congeners, specifically hexa-, hepta- and octachloro congeners, during the manufacturing process (Eduljee, 1999). Highly contaminated areas often act 
as reservoir sources; these areas include landfills, contaminated soils and contaminated sediments.

In Canada, emission sources are often grouped into three broad categories: (i) industrial, (ii) combustion/non-industrial and (iii) incineration sources (Figure 2) (Environment Canada, 2007). In 2007, the main aquatic emitters of dioxins through industrial sources were from pulp and paper mill activities, the metal industry, cement and concrete industry and through chemical manufacturing. Dioxins and furans are also emitted through non-industrial sources by release through diesel-fueled vehicles, electric power generation and the use of coal fuel utilities. The greatest contributor of dioxins emission in Canada; however, are predominantly observed through incineration activities (Environment Canada, 2007). These include hazardous and non-hazardous (municipal) waste incinerators (Environment Canada, 2010). 


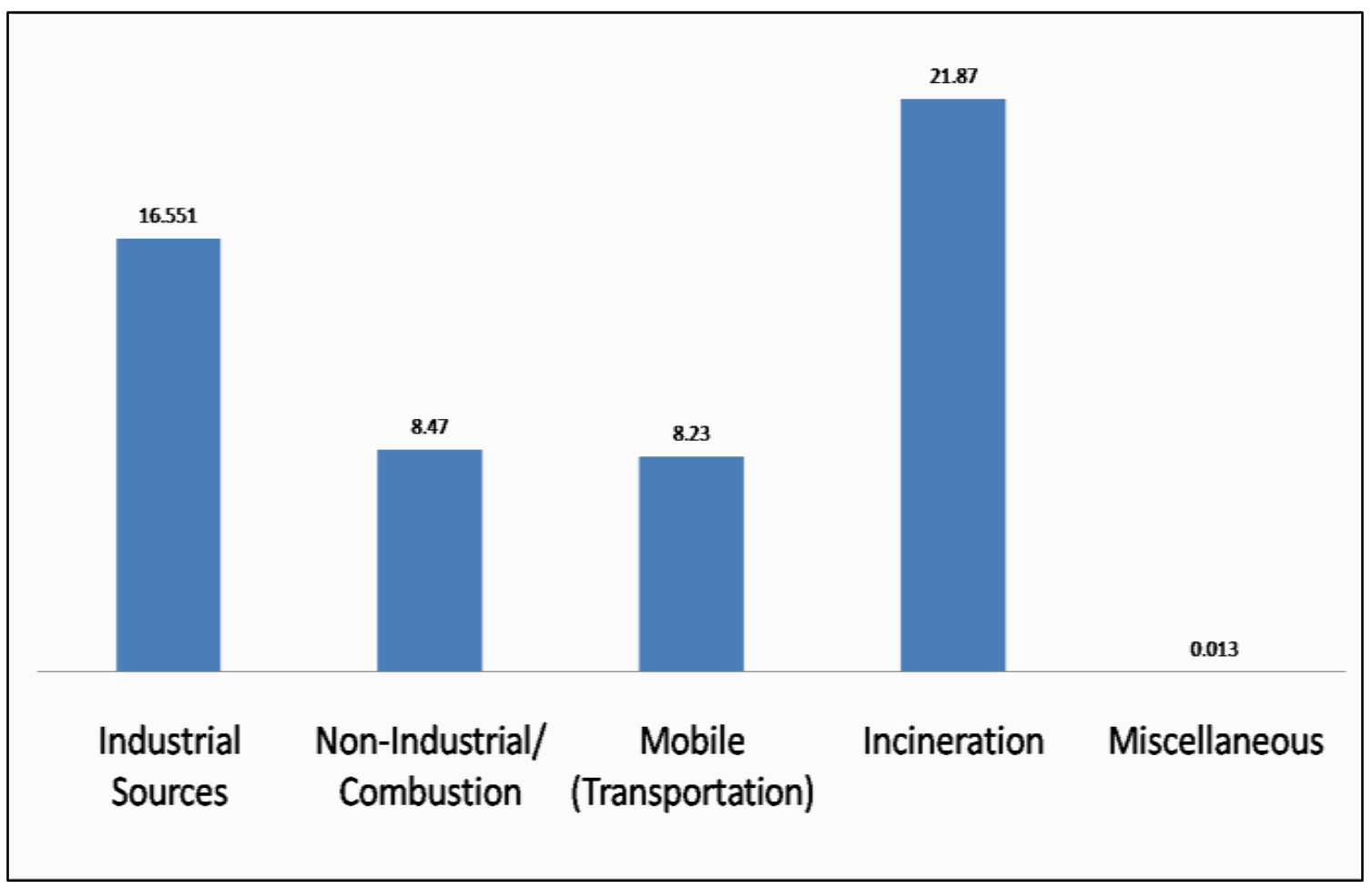

Figure 2. Canadian dioxin and furan emissions in 2007. All data are stated in gramsTEQ.

Data source: Environment Canada, 2007

Once emitted into the atmosphere, dioxins sorb strongly onto particulate matter and settle in the environment through wet or dry deposition. The ultimate sink of dioxins is the sorption to soil and sediment; dioxins will strongly adhere to soil particles with little leaching or volatilization (Kulkarni et al., 2008). Dioxins are also highly water insoluble and persistent in soil, and will consequently partition more strongly to soil and sediment in comparison to entering the aqueous phase (Lohmann and Jones, 1998). This is problematic as once dioxins have sorbed onto soil, dioxins become more stable and as a result, more difficult to remediate. Dioxins are inherently difficult to treat due to their low vapor pressures, low water solubilities, and high octanol-water partitioning coefficients, which allows these chemicals to acquire a high affinity for particulate matter 
(Haglund et al., 2007). In soil and sediment, dioxins have an estimated half-life of greater than 30 years.

The overall trend of dioxin emissions has decreased over the last 20 years in Canada (Figure 3). This is largely due to the 1998 Canada-Wide Accord on Environmental Harmonization and its role in the development of the Canada-Wide Standards on Dioxins and Furans. The purpose of the accord was to "provide the highest level of environmental quality for all Canadians (Alcantara, 2005)." Under this policy, dioxins were slated towards virtual elimination and have been targeted under six priority sectors, these include: (i) waste incineration (e.g. municipal solid waste, hazardous waste, sewage sludge and medical waste); (ii) pulp and paper mill boilers; (iii) iron sintering; (iv) electric arc furnace steel manufacturing; (v) conical municipal waste combustion; and (vi) residential wood combustion (Canadian Council of Ministers of the Environment [CCME], 2001). All sectors have had Canada-Wide Standards developed for the elimination of dioxins except residential wood burning (Canadian Council of Ministers of the Environment [CCME], 2011). 


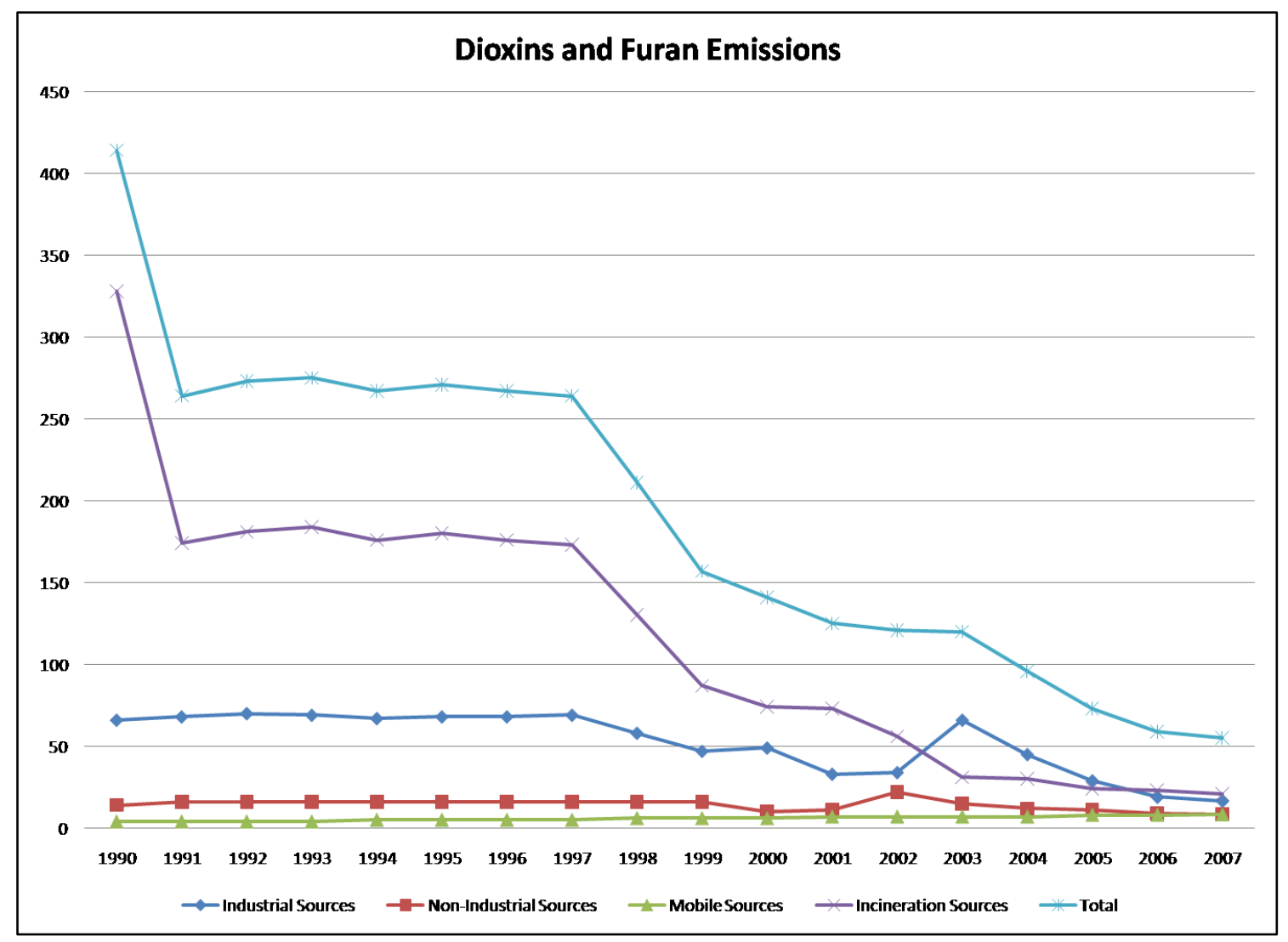

Figure 3. Canadian dioxin and furan emission trend for the last 20 years. Data are reported in gTEQ.

Data source: Environment Canada, 2007

Despite the reduction and efforts to eliminate dioxins in the Canadian context, dioxin contamination remains a prominent and substantial concern. Due to dioxins' recalcitrant properties, its lengthy life span within soil and sediment, and being that reservoir sources still contribute to dioxin emissions, dioxins continue to persist and remain present within the Canadian environment to this day. 


\subsection{Health Implications to the Human Population}

Dioxins are known to induce a broad spectrum of biological functions that disrupt normal hormone signaling pathways. This causes a cascade of heath problems that have lead to reproductive and developmental defects, immunotoxicity, liver damage, wasting syndrome, and cancer (Mandal, 2005). The primary exposure pathway of dioxins to the human population is over $90 \%$ through dietary intake (Liem et al., 2000); where it accumulates in body tissue after recurrent exposure (Kimbrough et al., 1977). Dioxins are highly lipophilic, bioaccumulative, and persistent in the human body. Due to dioxins lipophilicity, dioxins diffuse freely across cellular membranes and bind with high affinity to transcription factors, specifically the aryl carbon receptor (AHR) within liver cells (Mandal, 2005). Toxicity associated with TCDD is achieved through disruption of signaling pathways or through the production of secondary toxicants that are capable of reacting with macromolecules like DNA. This causes an array of cellular responses as the activation of the AHR disrupts a number of regulatory proteins that are specific for cell cycle control and apoptosis (Sorg et al., 2009).

The AHR mediates the mechanism of cell cycle control in the cytoplasm, which is a ligand-activated transcription factor acting in concert with the AHR nuclear translocator (ARNT) (Figure 4). The AHR nuclear translocator is a complex with two chaperone heat shock proteins (Hsp90s). After diffusion through the cellular membrane, TCDD binds to the AHR and acts as an inducer for the AHR-dependent cytochrome P-450 1A1 (CYP1A1). This dissociates the Hsp90 allowing the TCDD/CYP1A1 complex to translocate into the nucleus to act as a transcription factor by binding to the promoter 
region of CYP1A1 gene, which is directly controlled by the AHR (Mandal, 2005). As a result, TCDD disrupts gene regulation required for protein synthesis, leading to early cellular responses (cell grow stimulation) and delayed tissues responses, ultimately leading to cancer.

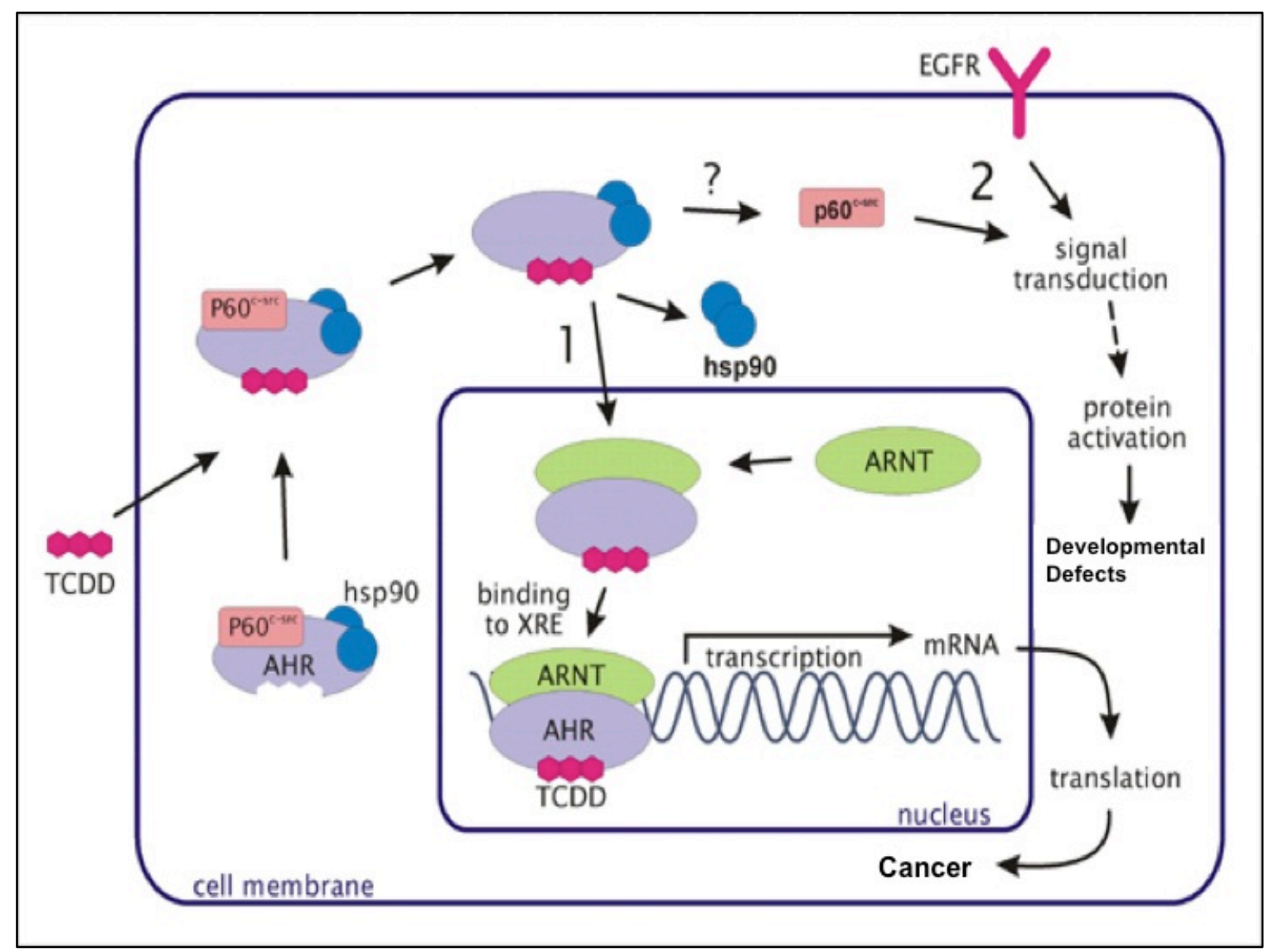

Figure 4. Schematics illustrating the influence of TCDD on the AHR pathway. Source: Thesleff et al., 2008

Dioxins are recognized as endocrine disruptors and influence thyroid hormone metabolism (Mandal, 2005). The thyroid hormone is essential for normal human development and impacts the intelligence of children if mothers have low levels of 
thyroid hormone in their first trimester of pregnancy. Even at low does, dioxins influence normal development through a broad range of brain to reproduction-controlling functions. Humans exposed to doses just above background level ( $5 \mathrm{ng} / \mathrm{kg})$, increase their risk of cancer tenfold (Steenland and Deddens, 2003). TCDD has been determined to cause a broad range of immunologic impacts including decreased host resistance to infectious disease and suppressed humoral and cell-mediated immune responses. TCDD is also a tumor promoter, which affects the rate of division and terminal differentiation or death of a cell.

Dioxins have long elimination half-lives, which are variable depending on the concentration and the composition of fat in the body (Sorg et al., 2009). The chlorine atoms play a large role in the extended half-lives of these compounds. The chlorine atoms, which are in lateral positions to each other, when bound to the AHR receptor, prevent the bioconversion into polar metabolites needed for elimination. Bioconversion through oxidation may occur only when two hydrogen atoms are adjacent to each other. When dioxin exposure has occurred, the chlorine-substituted atoms prevent this pathway from taking place.

Surprisingly, at very high concentrations of exposure, dioxins have a decreased elimination half-life (Sorg et al., 2009). For concentrations of $10000 \mathrm{pgTEQg}^{-1}$ or greater, the half-life of elimination is less than five years. For concentrations of 50 $\operatorname{pgTEQg}^{-1}$ or less, the half-life has been estimated to be greater than 10 years. At very high concentrations, it has been hypothesized that TCDD may actually induce 
cytochrome monooxygenases, which allows for faster elimination from the body, primarily through the digestive system.

\subsection{Methods of Analysis of Dioxins in the Environment}

Current methods of analysis used for the determination of dioxins in the environment utilize gas chromatography-high resolution mass spectrometry (GC-HRMS), as it is highly accurate and capable of providing congener specific concentrations. Since the 1980s, GC-HRMS has been considered the gold standard for dioxin sample analysis (Reiner et al., 2006). The basic methodology employed for GC-HRMS has been described previously (Reiner et al., 2006). In brief, dioxins and other organics are extracted several times from the sample matrix. The extract is run through a series of cleanup columns, each used to target specific potential cross contaminants. These cleanup columns can include silica, alumina and reversed-phase High Performance Liquid Chromatography (HPLC) (Hites, 1997). Dioxin congeners are separated sequentially according to mass, with tetrachlorinated compounds eluting from the chromatographic columns first, followed by penta-, hexa-, hepta-, and octachlorinated congeners (Reiner et al., 2006). The eluted congeners are then fed through a mass spectrometer that determines the molecular fragments of each, and quantifies their concentration using mathematical software.

A number of studies have utilized this methodology for detection of dioxins in various environmental matrixes including; soil and sediment (Kishida et al., 2010; Miyawaki et al., 2008; Popp et al., 1997), fish (Baughman and Meselson, 1973; Haglund et al., 2007; 
Schecter et al., 2003) and foods (Kleinhenz et al., 2006; Olie et al., 1989; Papadopoulos et al., 2004; Schecter et al., 2003). This method provides an accurate, minimum detection limit that is capable of detecting substances in the low pg/g (or ppt) concentration range (Schrock et al., 2009).

Despite being the gold standard, GC-HRMS as a method of analysis is costly, laborious, and requires highly trained technicians to employ the complex instrumentation (Van Emon et al., 2008). This often limits the number of samples that can be analyzed as the large number of samples needed for environmental monitoring is affected by the high costs of equipment and time-consuming preparation required for sample analysis (Chuang et al., 2009). The need for an alternative approach for screening has been discussed and other forms of analysis have been explored to find a more economical and time efficient means of investigation (Appendix A).

\subsection{Bioassays as an Alternative to GC-HRMS}

The U.S. Environmental Protection Agency's Superfund Innovative Technology Evaluation Monitoring and Measurement Technologies Program (EPA SITE MMT) has encouraged the development and implementation of finding alternatives for screening of contaminated sites (Billets, 2004). Finding an alternative method of screening would be of great interest for regulatory agencies as new technologies would expedite and expand the process in which remediation occurs, relieving regulatory agencies of some major costs in chemical evaluation and possibly increasing and initiating the number of sites being remediated (Schrock et al., 2009). 
Bioanalytical methods such as bioassays have been evaluated to either replace GCHRMS or to partially alleviate some of the analysis costs through preliminary screening practices (Nichkova et al., 2004). Attempts have been initiated to develop a sensitive and selective immunochemical technique; however, due to dioxins' lipophilic properties, method sensitivity, and the nature of environmental samples, limited studies have been reported with mixed results (Van Emon et al., 2008). The major downside of bioassays is that they are unable to provide congener specific concentration profiles, which may be useful for site characterization and contamination source identification (Chuang et al., 2009). However, in terms of producing an alternative screening methodology, independent of individual congener concentrations, bioassays remain the leading method for a sustainable, simple and low cost means of analysis (Trindade et al., 2008). Bioassays have the ability to handle large numbers of samples simultaneously and require a relatively simple sample preparation and clean up procedure (Harrison and Eduljee, 1999). Rapid and automated extraction and clean up technologies have expanded this technology to make it an efficient and precise method with high sample throughput while retaining the cost and time saving benefits.

\subsubsection{Chemically Activated Luciferase Gene Express (CALUX) Bioassay}

Chao et al. (2011) combined a fast coupled-column cleanup system with a dioxinresponsive element (DRE)-driven luciferase bioassay to test for dioxins in soil and sediment. Ten grams of solid sample was extracted using $300 \mathrm{~mL}$ of toluene through Soxhlet extraction. Samples were evaporated to near dryness and then loaded onto commercially available coupled carbon acid-silica columns for cleanup. Final extracts 
were evaporated to dryness and reconstituted using $100 \mathrm{~mL}$ of dimethyl sulfoxide (DMSO) in preparation for the luciferase assay. The luciferase assay utilized Huh7DRE-Luc cells coated on a 96 well plate that were treated with environmental extracts for 24 hours. Cells were also subjected to different known concentrations of TCDD treatments for the development of a calibration curve. After treatment, a lysis buffer was applied and luciferase activity was measured. Concentrations for PCDD/Fs ranged from 75.1 to 2670 pgDRE-driven Luciferase activity (DL)-TEQg ${ }^{-1}$ dry weight. This technique was also validated against GC-HRMS with a correlation of $\mathrm{r}^{2}=0.962$ (Chao et al., 2011).

There are several advantages with using this technique in comparison to GC-HRMS. It utilizes a fast cleanup system that is effective and meets the criteria of U.S. EPA methods $1613 \mathrm{~B}, 1668 \mathrm{~A}$ and 1614 . It is capable of being applied to other environmental matrixes including fish, breast milk, sediments and soil, and most importantly, it provides a costeffective high-throughput screening method for highly contaminated dioxin samples (Chao et al., 2011). The disadvantages of this technique is that it is unable to provide congener specific concentrations for samples and does require a clean up methodology that makes use of one time use, commercially constructed clean-up columns. This can often add to the financial costs of sample analysis as well as the environmental costs of disposable equipment. 


\subsubsection{Enzyme-linked Immunosorbent Assay (ELISA)}

The ELISA is a type of bioassay that exploits the use of antibodies to detect for the presence of dioxins (Figure 5) (Chuang et al., 2009).

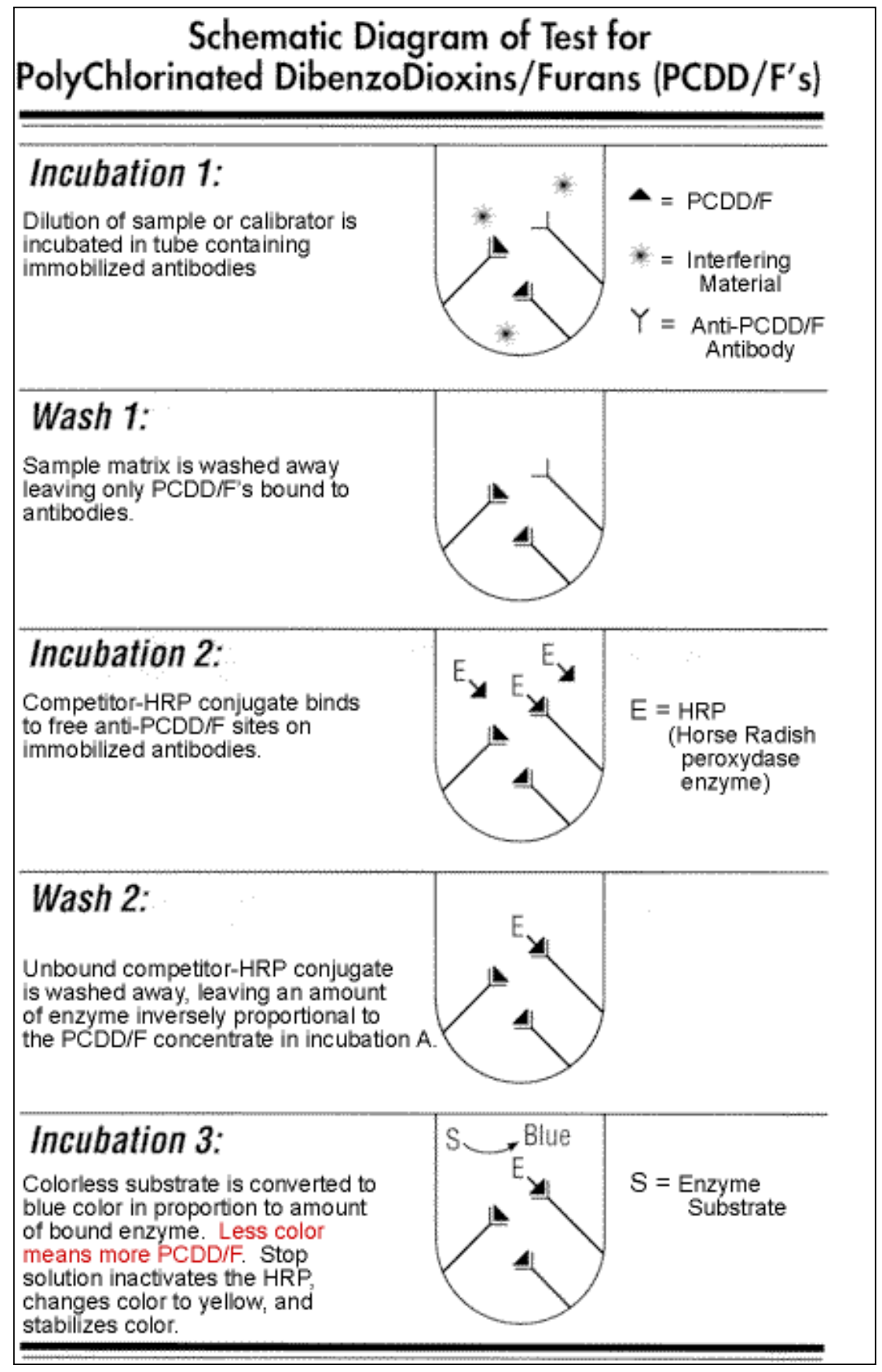

Figure 5. ELISA schematics.

Source: CAPE-Technologies 
The ELISA is conducted by using analyte-specific antibodies, which have been immobilized on the sides of specially engineered test tubes (Billets, 2005). These test tubes specifically bind analyte molecules, in this case dioxin. Unbound material is washed away, and bound analyte molecules remain. A competitor-enzyme conjugate is added and occupies vacant antibodies unoccupied by the analyte. Unbound conjugate is then washed away. Lastly, a solution of chromogenic substrate and hydrogen peroxide is added to the test tubes. The enzyme from the conjugate cleaves the hydrogen peroxide, which releases a water molecule and an oxygen free radical. The oxygen free radical then reacts with the chromogen, whereby color production or optical density (OD) can be measured using a spectrophotometer.

Chuang et al. (2009) developed one of the most recent and promising immunoassays for soil and sediment. The authors developed a methodology that combined pressurized liquid extraction (PLE) in conjunction with an immunoassay to detect for dioxins and furans. Pressurized liquid extraction was used with an ELISA to produce a high throughput screening method for sediment and soil samples. Chuang et al. (2009) tested different parameters to determine optimized conditions for sample preparation and analysis, these included: (i) clean-up adsorbents, (ii) extraction solvents, and (iii) extraction temperatures. Optimal conditions for this methodology described extracting samples with dichloromethane (DCM) at $100^{\circ} \mathrm{C}$ or $120^{\circ} \mathrm{C}$ while using $10 \%$ silver nitrate and acidic silica as the most efficient clean up absorbents. PLE-ELISA performances showed high recoveries of greater than $80 \%$ for two reference materials (SRM 1944 and WMS-01). PLE-ELISA method produced similar precision $( \pm 30 \%)$ and accuracy 
$(>70 \%)$ as the conventional method, which utilized Soxhlet extraction followed by multicolumn clean up and analyzed with GC-HRMS. The estimated method detection limit was $10 \mathrm{pgTEQg}^{-1}$ for a $4 \mathrm{~g}$ sample. PLE-ELISA was also validated against GC-HRMS showing the relationship between ELISA BEQs (bioanalytical equivalents) and GCHRMS TEQs, which were plotted to produce a highly linear correlation between the two methods $\left(r^{2}=0.9707\right)$. The two methods each yielded similar ranges of concentrations with ELISA producing a range of 26 to $17700 \mathrm{pgEQg}^{-1}$ and GC-HRMS producing a range of 12.3 to $13700 \mathrm{pgTEQg}^{-1}$.

The authors also validated PLE-ELISA in regards to precision, detection limit, sample throughput, and estimated costs. Both methods produced similar precisions; however GC-HRMS produced a more sensitive method detection limit of $2 \mathrm{pg} / \mathrm{g}$. Despite this, the method detection limit of $10 \mathrm{pg} / \mathrm{g}$ for PLE-ELISA is sensitive enough to be employed for testing of dioxin-contaminated sites. The estimated sample throughput of PLE-ELISA was found to be three times greater than GC-HRMS as the extraction and clean up method was much faster and simpler for PLE-ELISA. PLE-ELISA was able to produce results for 20 samples per day, compared to GC-HRMS, which required approximately four days for 20 samples. Consequentially, costs for the PLE-ELISA method were also significantly lower (Chuang et al., 2009).

The advantages of this technique is that it utilizes an extraction process that is automated, uses less solvent and requires less time commitment when compared to traditional extraction techniques such as Soxhlet extraction. The ELISA requires less sample 
cleanup than instrumental methods because of the selective binding between an antibody and target analyte. The use of cleanup absorbents during the PLE stage eliminates the possibility of reduced sample throughput and retains the cost advantages offered by the ELISA. PLE-ELISA sample throughput was more than three times that of the conventional GC-HRMS (Chuang et al., 2009). Common disadvantages were shared with other bioanalytical methods, in that it this method was not able to produce individual congener specific profiles. Capital costs for equipment such as a pressurized liquid extractor was not stated; however, would ultimately increase the capital cost of instrumentation, potentially limiting this methodology from being an alternative for technology transfer to areas with limited resources.

\subsection{Dioxin-Contaminated Sites in Canada in Need of Remediation}

The Federal Contaminated Sites Inventory (FCSI) has listed 304 dioxin-contaminated sites in Canada. A contaminated site as defined by FCSI is "one at which substances occur at concentrations: (i) above background levels and pose or are likely to pose an immediate or long term hazard to human health or the environment, or (ii) exceeding levels specified in policies and regulations" (Treasury Board of Canada Secretariat, 2010). In Canada, background levels for dioxin in soil are set at $4 \mathrm{pgTEQg}^{-1}$ (Canadian Council of Ministers of the Environment [CCME], 1999). The upper concentration limit

for dioxin-contaminated soil in residential areas is set at $10000 \mathrm{pgTEQg}^{-1}$ (Li-Muller et al., 1996). 
Of the 304 contaminated sites, 74 have been listed as high priority meaning that the available information indicates a need for action through either further site characterization, risk management or remediation (Canadian Council of Ministers of the Environment [CCME], 2008). Eight contaminated sites are found in the region of Southern Ontario. These are summarized in terms of location, site name, reporting organization, environmental media, status and classification (Appendix B). The 304 sites in Canada (Figure 6) as well as those found in Ontario (Figure 7) have been mapped.

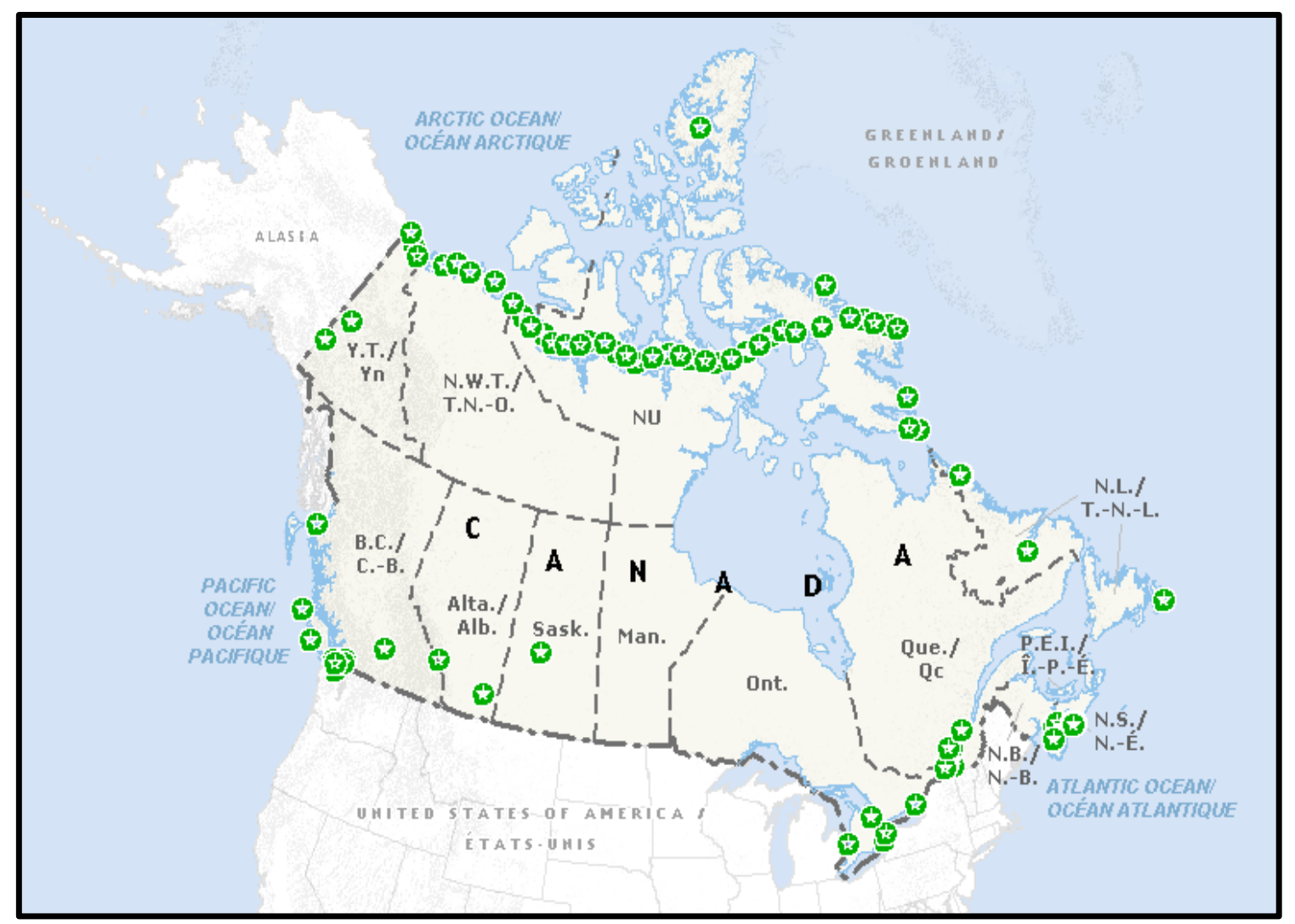

Figure 6. 304 dioxin-contaminated sites found in Canada. Source: CCME, 2008 


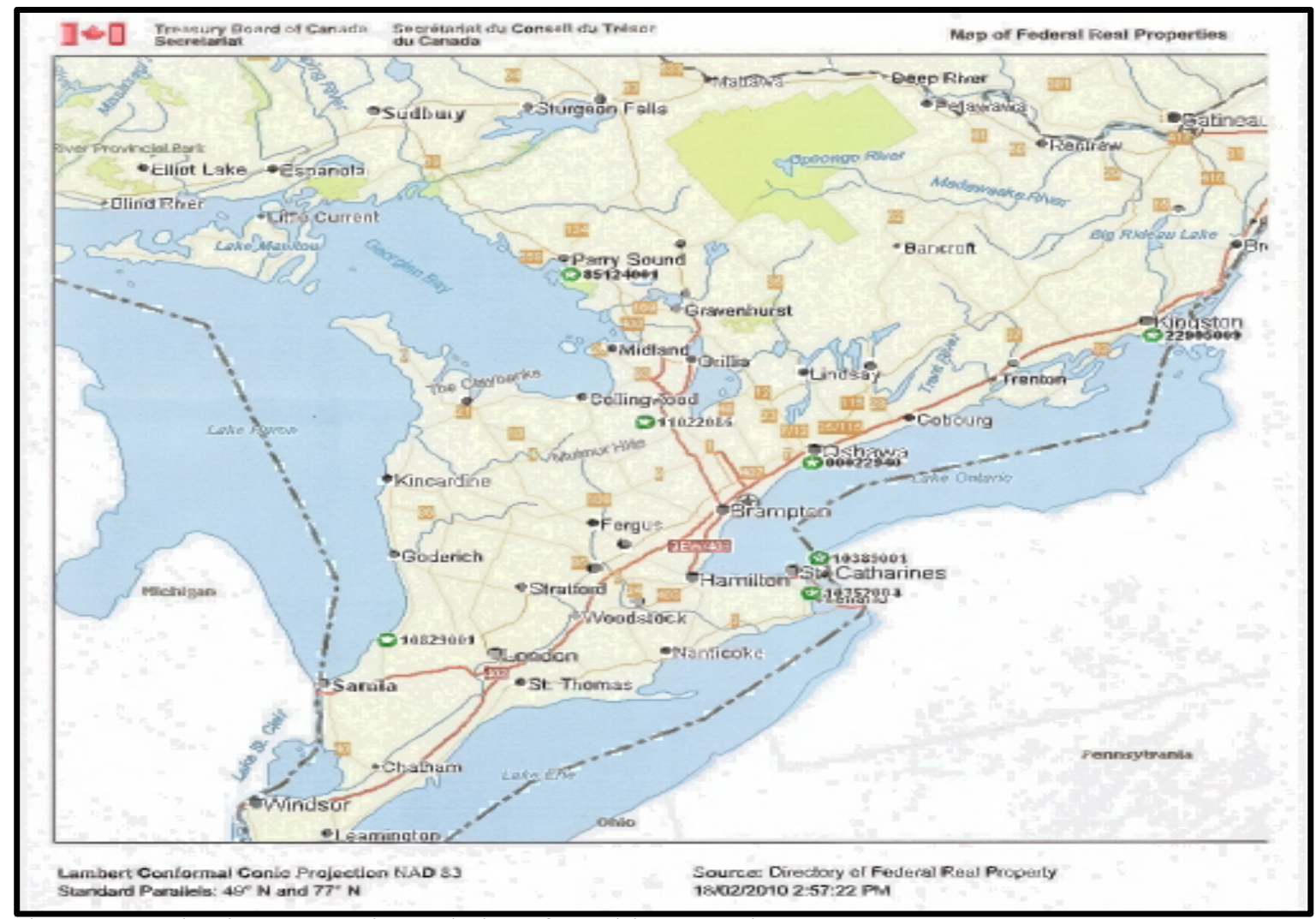

Figure 7. Dioxin-contaminated sites found in Ontario.

Source: CCME, 2008

\subsubsection{The Federal Contaminated Sites Inventory 10-Step Process}

The Canadian Council of the Ministers of the Environment (CCME) has created a National Classification System for Contaminated Sites (NCSCS) in Canada. This system was developed to assess the current or potential adverse effects to human health and the environment by providing a scientifically defensible and rational means to prioritize and investigate a remediation site (CCME, 2008). Contaminated sites in Canada must undergo a ten-step review process:

i. Identify Suspect Sites: identifies potentially contaminated sites based on activities that had occurred in the past or present near the site

ii. Historical Review: assembles and reviews all historical information pertaining to the site 
iii. Initial Testing Program: provides a preliminary characterization of contamination and site conditions

iv. Classify Contaminated Sites Using the CCME National Classification System: prioritizes the site for future investigation and/or remediation and/or risk management action. This system classifies a site as either low, medium, high priority, insufficient information, not a priority for action or not yet classified based on a quantitative marking system.

v. Detailed Testing Program: Re-testing the site based on findings from the Initial Testing Program

vi. Re-classify the Site Using CCME National Classification System

vii. Develop Remediation/Risk Management Strategy: focuses on specific areas of concern indentified in Step 3 and provides further in depth investigation and analysis

viii. Implement Remediation/Risk Management Strategy: addresses contamination issues

ix. Confirmatory Sampling and Final Reporting: verifies and documents the success of the remediation and or risk management strategy

x. Long-Term Monitoring (Optional): ensures remediation and long term risk management goals are achieved

Lab analysis is conducted in five of the ten steps in this process: (i) initial testing program, (ii) detailed testing program, (iii) development of remediation/ risk management strategy, (iv) confirmatory sampling and final reporting, and (v) long term monitoring. Despite the ELISA not being applicable to every step of the process, each contaminated site will eventually reach a stage in which the ELISA may be implemented. Therefore, the ELISA may potentially be viewed as more than a screening tool in Canada, as it may be used as a tool employed throughout the remediation process. It should be emphasized that if the implementation of the ELISA was successful as a monitoring tool, it may also 
be applied to several steps of this approach, vastly reducing the costs and time impediments that the system is currently experiencing.

Based on the screening program or the initial testing program, the CCME classifies the contaminated site into one of six categories (Table 2). A High Priority for Action Site is classified as a Class 1 site. Under this classification, action (further site characterization, risk management, remediation) is required to address the current concerns. Several reasons that have been observed or documented may contribute to this site as being of high concerned. A Medium Priority for Action Site is classified as a Class 2 site. Under this classification; information gives evidence that there is a high potential for adverse impacts; however, the threat to humans and the environment is not generally imminent. Medium Priority sites do not tend to have off-site contamination and contaminants tend to remain stationary, migration of contaminants would most likely deem the site as High Priority. A Low Priority for Action Site is classified as a Class 3 site. Under this classification; the site is not of high concern; however, likely more information is required to confirm the site characterization. Sites that are Not a Priority for Action are classified as a Class $\mathrm{N}$ site. Under this classification, sites are likely to have no environmental impacts or effects to human health. There is likely no need to proceed with said actions unless new information develops that would require the site to be reclassified. Sites that exhibit Insufficient Information are classified as Class INS. Under this classification, the site has undergone a Phase I Environmental Assessment and has shown that there is insufficient information to classify the site. Additional information and research would be required (CCME, 2008). 
Table 2. Dioxin contaminated sites categorized by the CCME classification system.

\begin{tabular}{|l|c|c|c|c|}
\hline Classification Type & \multicolumn{4}{|c|}{ Number of Sites } \\
\hline High Priority for Action & Total & Suspected $^{1}$ & Active $^{2}$ & Closed $^{3}$ \\
\hline Medium Priority for Action & 74 & 3 & 59 & 12 \\
\hline Low Priority for Action & 50 & 2 & 45 & 3 \\
\hline Insufficient Information & 32 & 0 & 25 & 7 \\
\hline Not a Priority for Action & 15 & 1 & 12 & 2 \\
\hline Site(s) Not Yet Classified & 84 & 0 & 18 & 31 \\
\hline Total & 304 & 69 & 11 & 4 \\
\hline
\end{tabular}

1 - Further assessment work is required to confirm whether the site is considered a "contaminated site."

2 - Active sites are confirmed contaminated sites where remedial action is or may be required

3 - No further action is required

Date source: Treasury Board of Canada Secretariat, 2010

Canada is in no short supply of dioxin-contaminated sites. With new emerging technologies such as ELISA, and the implementation of ELISA as a screening and monitoring tool, dioxin-contaminated sites in Ontario would benefit from the advantages ELISA has to offer. Applying the ELISA as a technology to screen and test contaminated sites would expedite and reduce costs and demands on Canadian regulatory agencies. This would benefit not only the regulatory agencies, but also the general Canadian population's health and well-being.

\subsection{State of Detection in Economically Marginalized Countries}

\subsubsection{The Stockholm Convention on Persistent Organic Pollutants}

The Stockholm Convention on Persistent Organic Pollutants, initiated by the United Nations Environment Programme (UNEP), led to a worldwide, multilateral agreement that held countries accountable in aiming to reduce and protect human and environmental 
exposure to specific persistent organic pollutants (POPs) (Bouwman, 2004). Persistent Organic Pollutants are characterized as a class of substances that share the common qualities of being persistent, bioaccumulative, having adverse effects to human health and the environment, and the potential for long-range environmental transport. These substances are categorized under three annexes under the Convention: Annex A lists substances slated for elimination, Annex B lists substances identified for restriction and Annex C lists unintentionally created POPs in which regulatory approaches focus on the ban of production and limitation of use. Dioxins and furans have both been listed under Annex C (Kohler and Ashton, 2010).

As of January 2011, 172 Parties have signed the Stockholm Convention on Persistent Organic Pollutants (Stockholm Convention on Persistent Organic Pollutants, 2011). A large majority of these Parties hail from areas that have marginalized economies and or are countries with transitional economies. Under Article 12 of the Convention, economically developed countries are stated to provide technical assistance to marginalized economies and transitional economies with reaching commitments set out in implementation plans (Secretariat of the Stockholm Convention on Persistent Organic Pollutants, 2004). The Stockholm Convention quotes:

The Parties shall cooperate to provide timely and appropriate technical assistance to developing country Parties and Parties with economies in transition, to assist them, taking into account their particular needs, to develop and strengthen their capacity to implement their obligations under this Convention. 
In this regard, technical assistance to be provided by developed country Parties, and other Parties in accordance with their capabilities, shall include, as appropriate and as mutually agreed, technical assistance for capacity-building relating to implementation of the obligations under this Convention.

Article 13 of the Convention also states that developed economies serve as part of a financial obligation with assisting marginalized economies and countries with transitional economies with reaching commitments set out in implementation plans. The Stockholm Convention quotes:

The developed country Parties shall provide new and additional financial resources to enable developing country Parties and Parties with economies in transition to meet the agreed full incremental costs of implementing measures which fulfill their obligations under this Convention ...

Financial assistance and technology transfers would be advantageous to marginalized and economies in transition as it would provide a means for developed Parties to assist in the implementation of achieving goals set out worldwide.

\subsubsection{Current Detection Methods Utilized in Economically Marginalized Countries}

There are several marginalized economies and countries with transitional economies worldwide that have taken steps in identifying and analyzing areas that may have been contaminated by dioxins (Figure 8). However, one significant trend that can be observed is that these countries often continue to export samples for analysis to a country with a well-developed economy (Table 5). 


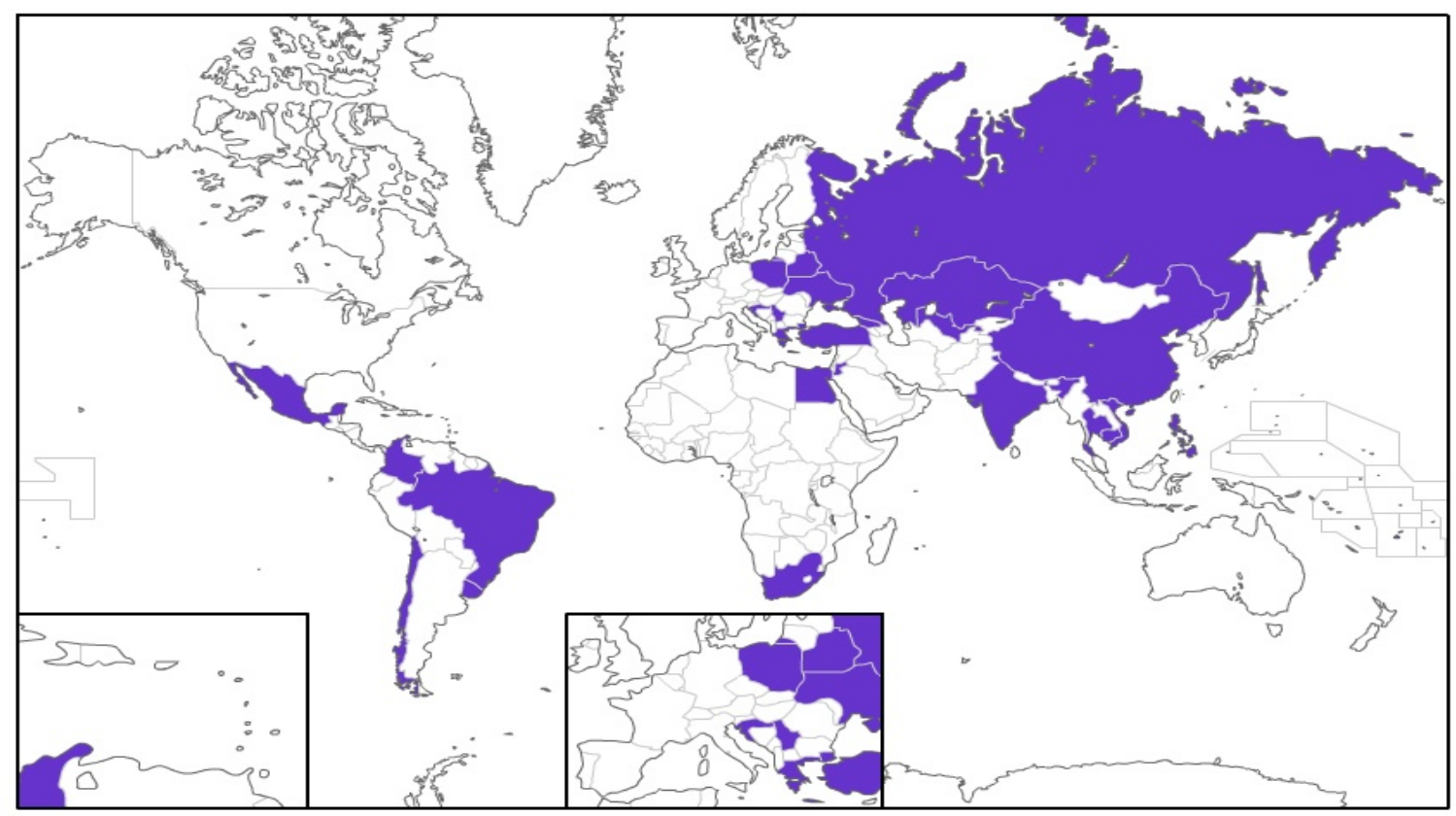

Figure 8. Economically marginalized countries that have conducted dioxin analysis.

Although the overall dioxin emissions are being reduced in economically developed areas, new sources of emissions are emerging in marginalized countries. A rapidly increasing trend observed in marginalized economies is the use of wood or coal-fuelled stoves to cook and heat houses (Garcia-Nieto et al., 2009). Dioxin has been found as an impurity within PCP treated wood, which is used as a fungicide and herbicide (Vollmuth et al., 1994). This has created a significant new source of dioxins that are emitted, and have left communities highly exposed on an unknowingly and continuous basis (GarciaNieto et al., 2009).

Several marginalized economies have reported that dioxins and furans are a contaminant in several environmental matrixes including: food (Muntean et al., 2003; Schecter et al., 2003), fly ash (Aristizabal et al., 2008; Wyrzykowska et al., 2009), soil (Minh, et al., 
2003; Takazawa et al., 2004; Alawi et al., 1996) and sediment (Tundo et al., 2004). Several Parties have also conducted research on dioxins as part of an implementation plan towards fulfilling obligations towards the Stockholm Convention (Bouwman, 2004; Ishankulov, 2008; Legashvili, 2008). Although the emissions of dioxins have decreased in economically stable regions, new sources of dioxins are emerging in marginalized areas (Garcia-Nieto et al., 2009). A meaningful way to mitigate and prevent further exposure would be valuable. 
Table 3. Marginalized economies that have conducted dioxin analysis.

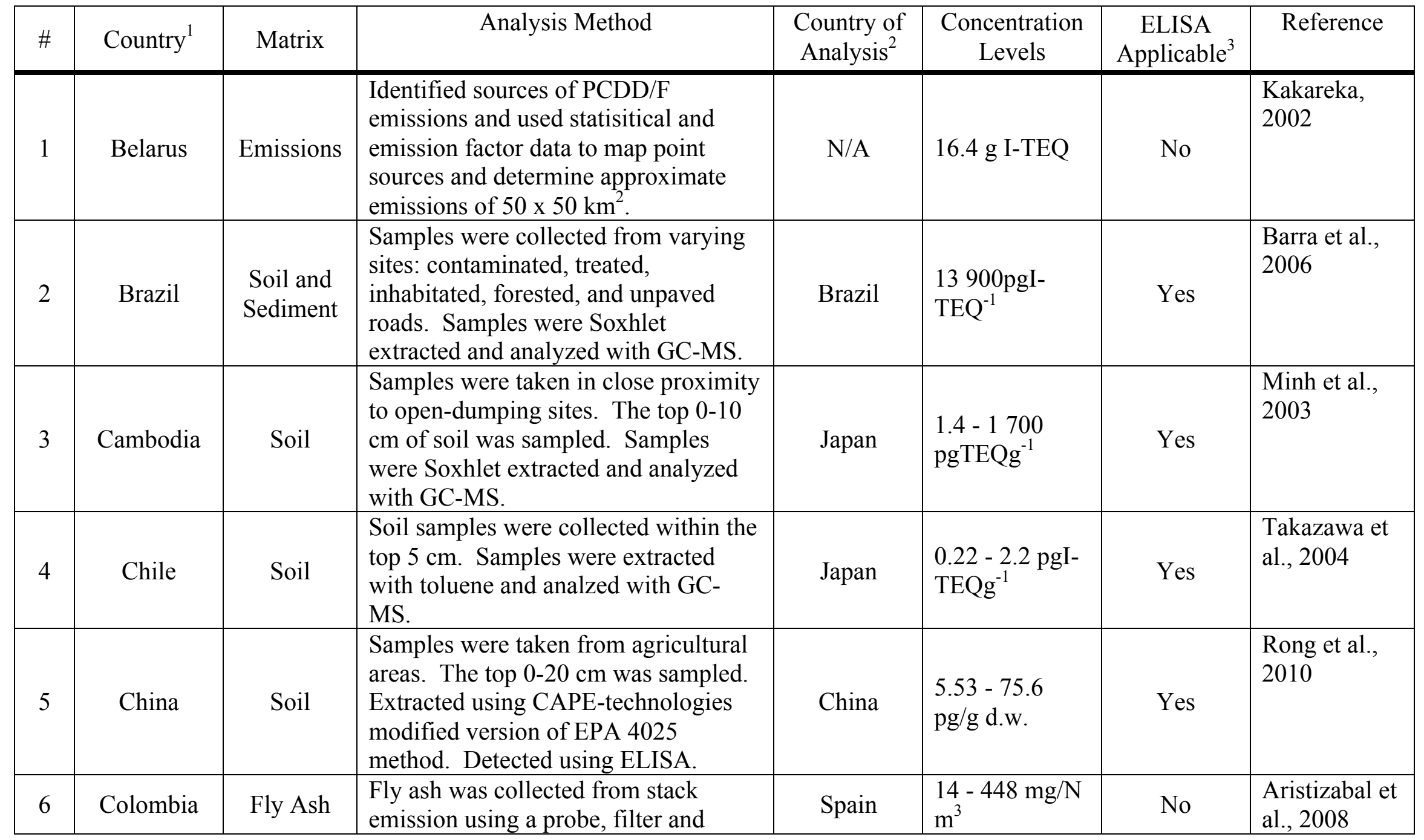




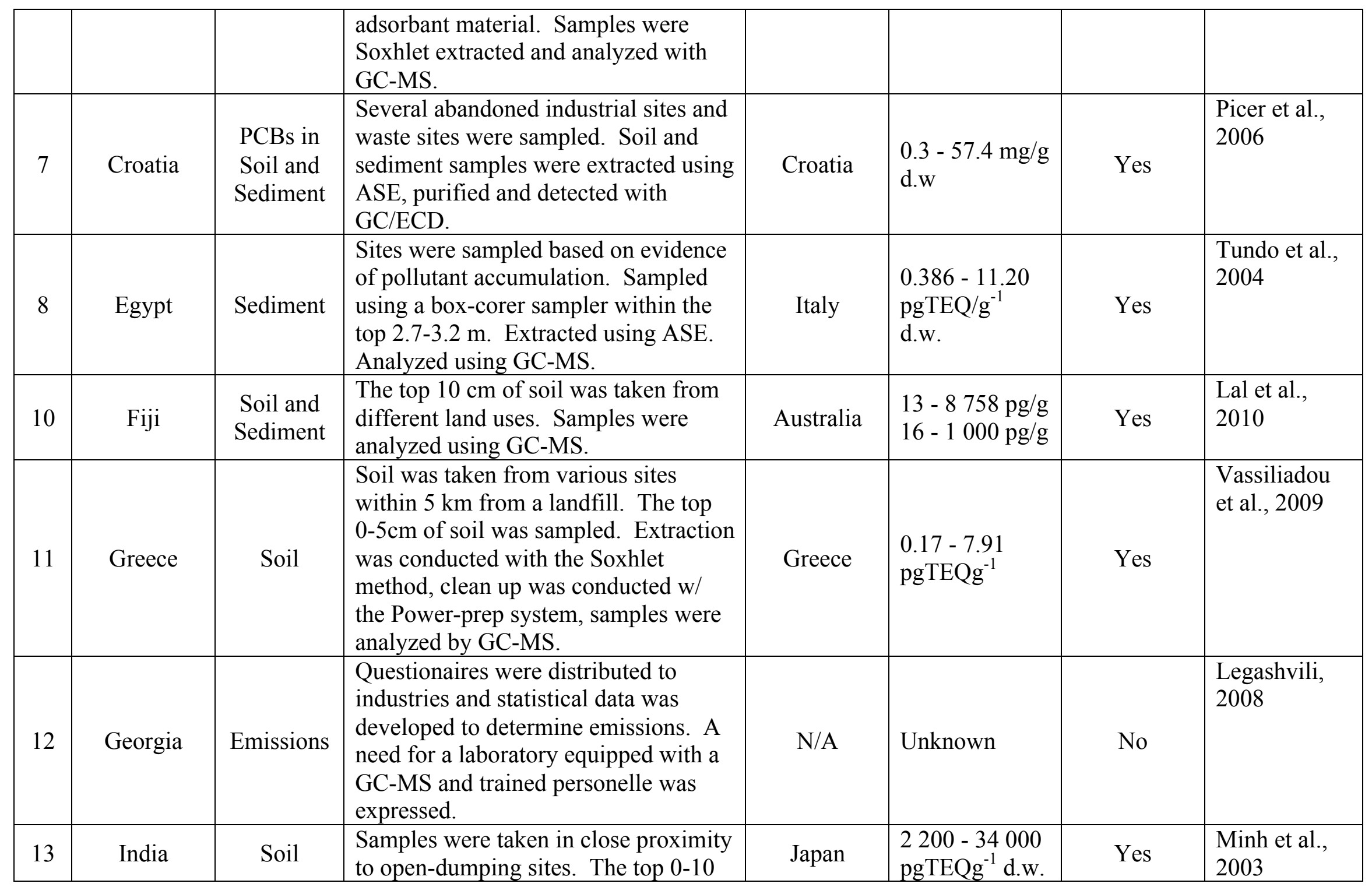




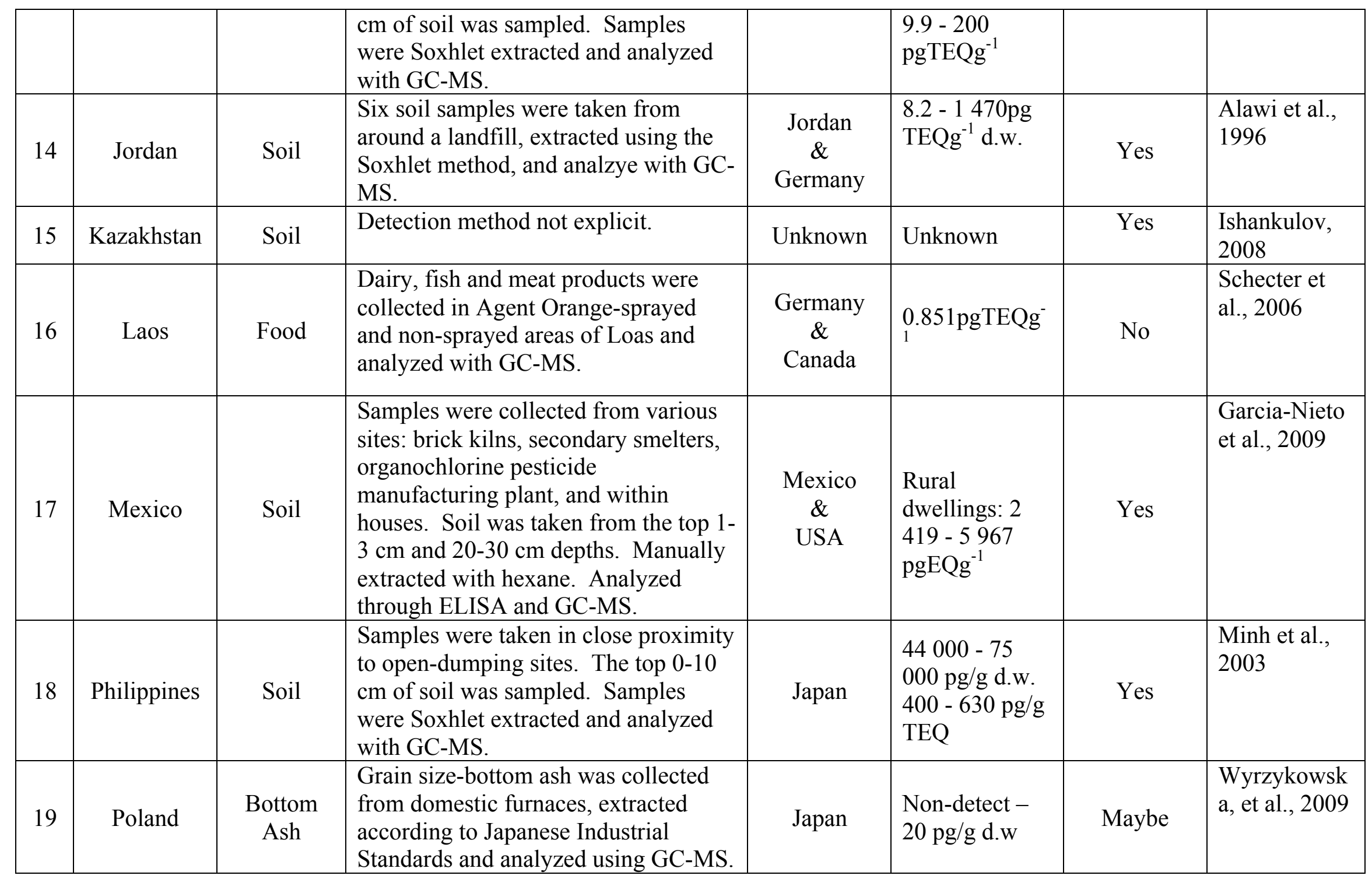




\begin{tabular}{|c|c|c|c|c|c|c|c|}
\hline 20 & Russia & Soil & $\begin{array}{l}\text { The top } 5 \mathrm{~cm} \text { of soil was sampled } \\
\text { from different functional zones in } \\
\text { Moscow. Samples were liquid } \\
\text { extracted, purified and analzyed with } \\
\text { GC-MS. }\end{array}$ & Russia & $\begin{array}{l}3.4-48.66 \\
\text { pgI-TEQg }\end{array}$ & Yes & $\begin{array}{l}\text { Agapkina et } \\
\text { al., } 2010\end{array}$ \\
\hline 21 & $\begin{array}{l}\text { South } \\
\text { Africa }\end{array}$ & $\begin{array}{l}\text { Soil and } \\
\text { Sediment }\end{array}$ & $\begin{array}{l}\text { Samples were taken from high-income } \\
\text { and low-income residental areas and } \\
\text { farmland. The top } 1-5 \mathrm{~cm} \text { were } \\
\text { sampled. Extracted using ASE. } \\
\text { Analyzed using H4IIE-luc bio-assay } \\
\text { and confirmed with GC-MS. }\end{array}$ & Norway & $\begin{array}{l}0.34-20 \\
\text { pgTEQg }^{-1}\end{array}$ & Yes & $\begin{array}{l}\text { Nieuwoudt et } \\
\text { al., } 2009\end{array}$ \\
\hline 22 & Serbia & Soil & $\begin{array}{l}\text { Soil samples from an oil refinary were } \\
\text { analyzed using GC/ECD. }\end{array}$ & Serbia & $\begin{array}{l}1.91-122.65 \\
\mathrm{ng} / \mathrm{g}\end{array}$ & Maybe & $\begin{array}{l}\text { Kaisarevic et } \\
\text { al., } 2007\end{array}$ \\
\hline 23 & Thailand & $\begin{array}{c}\text { Marine } \\
\text { mammals }\end{array}$ & $\begin{array}{l}\text { Dugong muscle tissue were sampled. } \\
\text { Tissue was extracted using Soxlet } \\
\text { method. Analyzed using GC-MS. }\end{array}$ & Japan & Unstated & No & $\begin{array}{l}\text { Kumar et al., } \\
2003\end{array}$ \\
\hline 25 & Uruguay & Soil & $\begin{array}{l}\text { Superficial }(0-5 \mathrm{~cm}) \text { soil samples were } \\
\text { taken from slums. Extracted through } \\
\text { the Soxhlet method and anaylzed by } \\
\text { ELISA and GC-MS. }\end{array}$ & $\begin{array}{l}\text { Sweden } \\
\qquad \begin{array}{l}\& \\
\text { USA }\end{array}\end{array}$ & $1790 \mathrm{pg} / \mathrm{g}$ & Yes & $\begin{array}{l}\text { Trindade et } \\
\text { al., } 2008\end{array}$ \\
\hline 26 & Uzbekistan & Food & $\begin{array}{l}\text { Samples of plant based foods were } \\
\text { analyzed in Germany and Italy using } \\
\text { GC-MS. }\end{array}$ & $\begin{array}{l}\text { Germany } \\
\& \\
\text { Italy }\end{array}$ & $\begin{array}{l}0.01-0.05 \\
\text { pgTEQg }^{-1}\end{array}$ & Maybe & $\begin{array}{l}\text { Muntean et } \\
\text { al., } 2003\end{array}$ \\
\hline 27 & Vietnam & $\begin{array}{l}\text { Soil and } \\
\text { Sediment }\end{array}$ & $\begin{array}{l}\text { Samples were taken around a from a } \\
\text { former Agent Orange storage depot }\end{array}$ & Switzerland & $\begin{array}{l}4.6-184 \\
\operatorname{pgTEQg}^{-1}\end{array}$ & Yes & $\begin{array}{l}\text { Mai et al., } \\
2007\end{array}$ \\
\hline
\end{tabular}




\begin{tabular}{|l|l|l|l|l|l|}
\hline & $\begin{array}{l}\text { within 2 depths (0-20 cm and 50-80 } \\
\text { cm). Samples were extracted using } \\
\text { Soxhlet method, purified through } \\
\text { series of columns and analyzed using } \\
\text { GC-MS. }\end{array}$ & & \\
& \multicolumn{1}{|l|}{$18 / 27$} & \\
\hline
\end{tabular}

1 - The World Bank has classified all countries listed as either low-income of middle-income economies (The World Bank, 2010)

2 - Country of Analysis signifies where samples were exported to for GC-MS analysis

3 - ELISA applicable indicates that ELISA analysis would be feasible with given the environmental matrix indicated, cleanup method described and sample concentration levels stated in study 
Affordable means of analysis are limited, which has led to either the dependence of using GC-HRMS in countries where it is available, or having limited analysis and detection conducted within these countries. As a result, this leads to a dependence on resources, causing a backlog in sample analysis, and a limitation on the number of areas that can be identified as safe or unsafe. If there were a focus on lessening the dependence of costly technology, but increasing the accessibility and knowledge transfer of affordable technology, several countries would be unhampered by depending on developed economies for environmental testing and assistance.

There are a limited number of cases in which ELISA is currently being implemented as a tool to enable and assist economically developing countries in determining dioxin soil contamination. These will be discussed in the next section.

\subsubsection{Utilization of ELISA in Economically Marginalized Countries}

ELISA analysis that has been employed in the past for dioxin determination in soil and sediment has focused on method validation between the comparison of ELISA and GCHRMS (Buan, 2009). It was not until recently that this methodology emerged as a viable screening tool for contaminated sites in marginalized economies (Garcia-Nieto et al., 2009; Trindade et al., 2008). ELISA analysis has recently been implemented in literature as a means of providing an affordable screening tool for dioxin-contaminated soils in economically developing countries where GC-HRMS laboratories are not accessible or financially available. Two cases in which the ELISA was employed as screening tools are described below. 


\section{Uncontrolled Combustion Practices in Uruguay}

Trindade et al. (2008) used the ELISA as a sustainable and simple mean to develop a low-cost monitoring program to assess the toxicological impacts of uncontrolled combustion practices that were occurring in slums in Uruguay. In Uruguay, biomass incineration, such as sugar cane fields and rice skins are seen to largely contribute to the sources of dioxin emissions, which are mostly unaccounted for. The objective of the study was twofold: (i) to develop a screening tool to estimate the occurrence of toxic PCDD/Fs in slum soils where there has been unregulated combustion of waste, and (ii) to perform an inter-laboratory validation of the immunochemical dioxin analysis of these soils.

Trindade et al. (2008) took 16 soil samples and extracted each using Soxhlet extraction. Extracts were split and internal standards were added to one part, which was designated for GC-HRMS validation. Sample clean up was conducted using multi-layer silica and carbon columns. The ELISA (Nunc, Denmark) employed a 96 well microtiter plate using 2,3,7-trichloro-8-methyl-dibenzo-p-dioxin (TMDD) as a surrogate standard. This is advantageous as it is less toxic than using TCDD as a standard; however, TMDD possesses a cross-reactivity factor of $130 \%$, which leads to an overestimation of results compared to GC-HRMS when plotted on a standard curve. A major issue the authors encountered was the ineffective attempt to simplify the sample clean up procedure by omitting carbon column cleanup. This attempt was unsuccessful, as results did not correlate with GC-HRMS results. It was stressed that sample preparation and simplification were necessary in order to obtain results comparable to the traditional 
method as well as maintaining efficiency and cost reducing advantages of the ELISA (Trindade et al., 2008).

Due to the high costs of GC-HRMS, a screening level was generated to determine which samples would go on for further analysis. Trindade et al. (2008) used the United States Agency for Toxic Substances and Disease Registry (ATSDR) recommendations that had established three different guidance levels for soil contaminated with dioxins on residential property. These are: (i) screening level (TEQ value $\leq 50 \mathrm{pgTEQg}^{-1}$ ), (ii) evaluation level (TEQ value between 51 and 999 pgTEQg $^{-1}$ ) and (iii) action level (TEQ value $\geq 1000 \mathrm{pgTEQg}^{-1}$ ). If a soil sample exceeds the screening level, further sitespecific evaluations are needed. If a soil sample exceeds the evaluation level, sitespecific actions and prohibition of exposure are required to be implemented.

Over $70 \%$ of the samples processed by Trindade et al. (2008) were above the screening level. Three of the samples (19\%) contained concentrations above the action level for residential soil, indicating that risk to these areas was serious. Analyses of hundreds of samples would be required for this area; which would be an unaffordable task if GCHRMS were employed. Trindade et al. (2008) had suggested using ELISA to determine samples that are above the action level, so that remediation can be implemented in these areas.

\section{Industrial Sectors in Mexico}

In Mexico, a preliminary soil assessment program had been implemented for the detection of dioxins at different contaminated sites. The same ELISA (Nunc, Denmark) 
utilized by Trindade et al. (2008) was employed in five different industrial sectors of Mexico where dioxin release had occurred. Areas that were studied included: (i) an area in which accidental pesticide released from a dichlorodiphenyltrichloroethane (DDT) production plant had occurred, (ii) areas around secondary smelters, (iii) areas around brick kilns, and (iv) rural dwellings. Garcia-Nieto et al. (2009) collected 37 surface and sub-surface soil samples, which were homogenized by mortar and pestle and sieved through a $600 \mathrm{~mm}$ sieve. Samples were extracted manually with hexane and white sand, filtered with Whatman filter paper, evaporated and then cleaned with a three-layered sulfuric acid silica-gel column. The extract was then solvent exchanged into DMSOTriton-X and then ELISA detection was conducted. Due to the high costs of GC-HRMS, only one soil sample was analyzed for ELISA validation, which was composed of a pooled sample from the area around the DDT production plant. The ELISA was validated against GC-HRMS; GC-HRMS had a concentration of $220 \mathrm{pgTEQg}^{-1}$ for soil from the DDT chemical production plant and the ELISA had a concentration of 241 pgTMDD-EQg ${ }^{-1}$ (Garcia-Nieto et al., 2009).

To evaluate the relevancy of employing the ELISA as a screening tool, the same evaluation criterion used in the Uruguay case, the ATSDR Soil Guidelines, was used here. Garcia-Nieto et al. (2009) found that none of the soil samples taken from the industrial sector were above the action level; however, a large majority of the samples tested fell within the evaluation level. In this case, four out of the five industrial sectors tested required further studies, and the only areas deemed safe were the brick kilns. Shockingly, all of the samples taken from within rural dwellings employing coal, 
unprocessed biomass and crop residues for fuel were within the action level. In Mexico, up to $90 \%$ of rural households rely on and utilize these forms of fuel. This is problematic as it illustrates that numerous individuals have exposed themselves to dioxins on a daily basis and a detailed assessment plan and/or remediation is urgently needed.

These two cases illustrate that the use of ELISA as a screening tool is achievable and feasible for soil remediation screening purposes in economically developing countries, and that there is a need for multiple sample analyses and detailed assessments in order to protect vulnerable communities. These two cases can be used as arguments in favour of the use of ELISA to remediate not only Canadian contaminated soil sites, but also sites located within other marginalized economies. Remediation may be expedited and expanded to include immunochemical techniques as an alternative to GC-HRMS or by using GC-HRMS only as a confirmation source for when action is required. Both cases emphasize the cost savings provided by ELISA, as neither site possessed the accessibility or financial budget to have ongoing employment of a GC-HRMS laboratory. It was also illustrated that there is a serious need for an alternative screening method within these areas. Both cases illustrate that areas believed to be safe, such as in highly populated residential areas, were largely contaminated by dioxin exposure.

There were barriers experienced in both scenarios that required a means to be corrected for. First, both cases used TMDD as a less toxic standard than TCDD; however, it was found to have a higher cross-reactivity than TCDD, producing results that needed to be corrected based on the $130 \%$ cross-reactivity to the ELISA antibodies. In both cases, 
neither study discussed how samples were compensated in regards to the stronger cross reactivity of standards versus samples and whether this led to an overestimation for the ELISA results. Second, both cases used series of columns to clean up soil samples. This may have possibly led to the loss of analyte and an increase in monetary cost and waste generation from one-time use columns. Lastly, microtiter plate ELISAs were also used, which may not provide samples with as much surface area for contact with anti-dioxin antibodies as a test tube ELISA format.

\subsection{Utilization of ELISA in Developed Countries}

\subsubsection{Method Validation in Canada}

Although Canada is far from a marginalized economy, work conducted at home is worth mentioning to produce a feasible means of developing the ELISA as an analysis tool worldwide. A different methodology was used in the immunoassay procedure performed by Buan (2009). The author utilized an ELISA (CAPE-Technologies, USA) that required manual extraction and clean up without the use of disposable columns. A highly potent, pure standard of TCDD was employed and the ELISA was conducted using a test tube format. In this study, the author used the ELISA to map a two contaminated site in Canada using the ELISA that had been previously mapped using GC-HRMS. The primary goal here was to illustrate the validation of ELISA to GC-HRMS for a contaminated soil site in Canada.

Buan (2009) increased the efficiency of the ELISA by making it practical to analyze large groups of samples where the concentrations were unknown and highly variable. The 
author developed an algorithm to determine the proper volume of sample extract that would accurately determine the amount of PCDD/Fs introduced into an ELISA tube, thereby eliminating sequential runs on a trial and error basis, and thus retaining the ELISA efficiency and cost savings. In brief, the sample algorithm optimizes the amount of dioxin sample introduced into the ELISA tube to produce accurate results that are neither over-estimating dioxin concentration nor producing under-sensitive results.

The author created three concentrations levels that have varying sample preparation procedures dependent on the concentration of the sample. These levels are: (i) low sensitivity (50 to $899 \mathrm{pgTEQg}^{-1}$ ), (ii) mid-range sensitivity (900 to $5999 \mathrm{pgTEQg}^{-1}$ ) and (iii) upper-sensitivity $\left(>6000 \mathrm{pgTEQg}^{-1}\right)$. Each sample is first analyzed at the mid-range sensitivity level (900 to $5999 \mathrm{pgTEQg}^{-1}$ ) and than re-determined if the sample falls out of the range of 4 to $35 \mathrm{pg}$ TEQ per tube. Samples below $4 \mathrm{pg}$ are re-determined using the low-sensitivity procedure (50 to $899 \mathrm{pgTEQg}^{-1}$ ) and samples above $35 \mathrm{pg}$ per tube are redetermined using the upper-sensitivity procedure (>6000 pgTEQg $\left.^{-1}\right)$.

Raw results are then multiplied by a "Congener Correction Factor," a concept developed by the author to relate ELISA BEQs directly with GC-HRMS TEQs. It should be noted that the ELISA still gives results based on biological potency of the extract; however, when corrected, ELISA BEQ values can be directly compared to TEQ values. The Congener Correction Factor takes each of the 17 toxic congener's individual TEFs into account by considering each TEF $\div$ (cross-reactivity) to the ELISA. All toxic congeners can be taken into account by determining the composite cross-reactivity and composite 
TEF values by considering each congener's percent composition in a real sample. As individual congener concentrations are difficult to determine without at least one GCHRMS sample, Buan (2009) developed Site-Wide Congener Correction Factors for a number of different industrial sources. Examples of these Site-Wide Congener Correction Factors are listed in Table 4. For the particular site mapped by Buan et al., the Congener Correction Factor determined for the soil sample surrounding the spill source happed to be 1.01 .

Table 4. Dioxin Source-Specific Correction Factors

\begin{tabular}{|l|c|}
\hline Source & Source-specific Correction Factor \\
\hline Soil and Sediment Samples at Study Site & 1.01 \\
\hline Secondary Copper Refinery & 2.68 \\
\hline Incinerator-Hazardous Wastes & 1.93 \\
\hline Medical Waste Incineration & 1.84 \\
\hline Barrel Burning for House Waste & 1.71 \\
\hline Secondary Aluminum Smelters & 1.70 \\
\hline Coal Fired Plants & 1.49 \\
\hline Municipal Solid Waste Incinerators & 1.31 \\
\hline Secondary Lead Smelters & 1.26 \\
\hline Cement Kilns & 1.07 \\
\hline Tire Combustion & 1.07 \\
\hline Diesel Fuelled Trucks & 1.05 \\
\hline Primary Ferrous Metal Smeltering & 1.02 \\
\hline Source: Buan, 2009 &
\end{tabular}

Source: Buan, 2009

Buan (2009) obtained the BEQ of twenty-eight soil samples provided by the Ontario's Ministry of Environment (OMOE) and superimposed each alongside previously determined GC-HRMS TEQ data on the site map. Comparison of both the ELISA and GC-HRMS results showed that areas of high and low PCDD/F concentrations were both equally identifiable. Of the 32 samples analyzed, 29 correctly fell into the proper concentration ranges as determined by GC-HRMS. A high correlation was found 
between the ELISA and GC-HRMS with an agreement of $94 \%\left(r^{2}=0.9941\right)$ (Buan, 2009). The author illustrated that using the ELISA as a screening method is feasible on Canadian soils and produces screening results comparable to GC-HRMS.

These studies showed the time and cost saving potential that regulatory agencies would gain if the ELISA was implemented as a site screening alternative to GC-HRMS. Each ELISA scenario discussed previously is summarized in Table 5.

Table 5. Summary of the three methodologies used in Mexico, Uruguay and Canada.

\begin{tabular}{|l|c|c|c|}
\hline & $\begin{array}{c}\text { Trindade et al. } \\
(2008)\end{array}$ & $\begin{array}{c}\text { Garcia-Nieto et al. } \\
(2009)\end{array}$ & Buan et al. (2009) \\
\hline Number of Samples & 37 & 16 & 32 \\
\hline $\begin{array}{l}\text { Extraction } \\
\text { Technique }\end{array}$ & Soxhlet extraction & $\begin{array}{c}\text { Manual Shaking - } \\
\text { hexane and white } \\
\text { sand }\end{array}$ & $\begin{array}{c}\text { Manual Shaking - } \\
\text { hexane and glass } \\
\text { beads }\end{array}$ \\
\hline Clean-up Technique & $\begin{array}{c}\text { Multi-layered silica } \\
\text { and carbon columns }\end{array}$ & $\begin{array}{c}\text { Three-layer } \mathrm{H}_{2} \mathrm{SO}_{4}- \\
\text { silica-gel column }\end{array}$ & $\begin{array}{c}\text { Oxidation - using } \\
\text { fuming } \mathrm{H}_{2} \mathrm{SO}_{4}\end{array}$ \\
\hline $\begin{array}{l}\text { Detection } \\
\text { Technique }\end{array}$ & $\begin{array}{c}96 \text { well microtiter } \\
\text { ELISA (Nunc, } \\
\text { Denmark) }\end{array}$ & $\begin{array}{c}\text { 96 well microtiter } \\
\text { ELISA (Nunc, } \\
\text { Denmark) }\end{array}$ & $\begin{array}{c}\text { Test tube ELISA } \\
\text { (CAPE- } \\
\text { Technologies, } \\
\text { USA) }\end{array}$ \\
\hline Standard Used & TMDD & TMDD & TCDD \\
\hline $\begin{array}{l}\text { Number of Samples } \\
\text { Validated }\end{array}$ & 16 & pooled & 28 \\
\hline Validation & $\mathrm{r}^{2}=0.693$ & unstated & $\mathrm{r}^{2}=0.994$ \\
\hline
\end{tabular}




\section{EXPERIMENTAL}

\section{$2.1 \quad$ Objectives}

The purpose of this study is twofold. First, this study will expand on work conducted previously at the Ontario Ministry of the Environment (OMOE) on dioxin contaminated soil by applying the ELISA to a real dioxin contaminated site in Canada and determining whether ELISA results obtained are acceptable to the terms utilized by Canadian regulatory agencies. By achieving this, the goal is to use the ELISA as an alternative technology for mapping and screening contaminated soil sites, independent of GCHRMS. Second, this study will illustrate the feasibility of initiating an ELISA laboratory as a model that may be implemented in areas where GC-HRMS laboratories are not financially available or accessible. This will be achieved if results are obtained with similar concentration ranges as those produced at the OMOE using limited resources, dated equipment and financially less capital costs.

\subsection{Site Description}

Surface samples were extracted from a supplemental investigative site in Welland, Ontario in the summer of 2010. The Ontario Ministry of Transportation (OMOT) granted access to the site, as well as provided rudimentary site descriptions (Appendix C) from DST Consulting. DST Consulting had found dioxin contamination at one of four boreholes onsite (Figure 9). Investigations were put forth to determine whether the reason for contamination was due to air deposition or caused by a subsurface source in the groundwater. 


\section{EXPERIMENTAL}

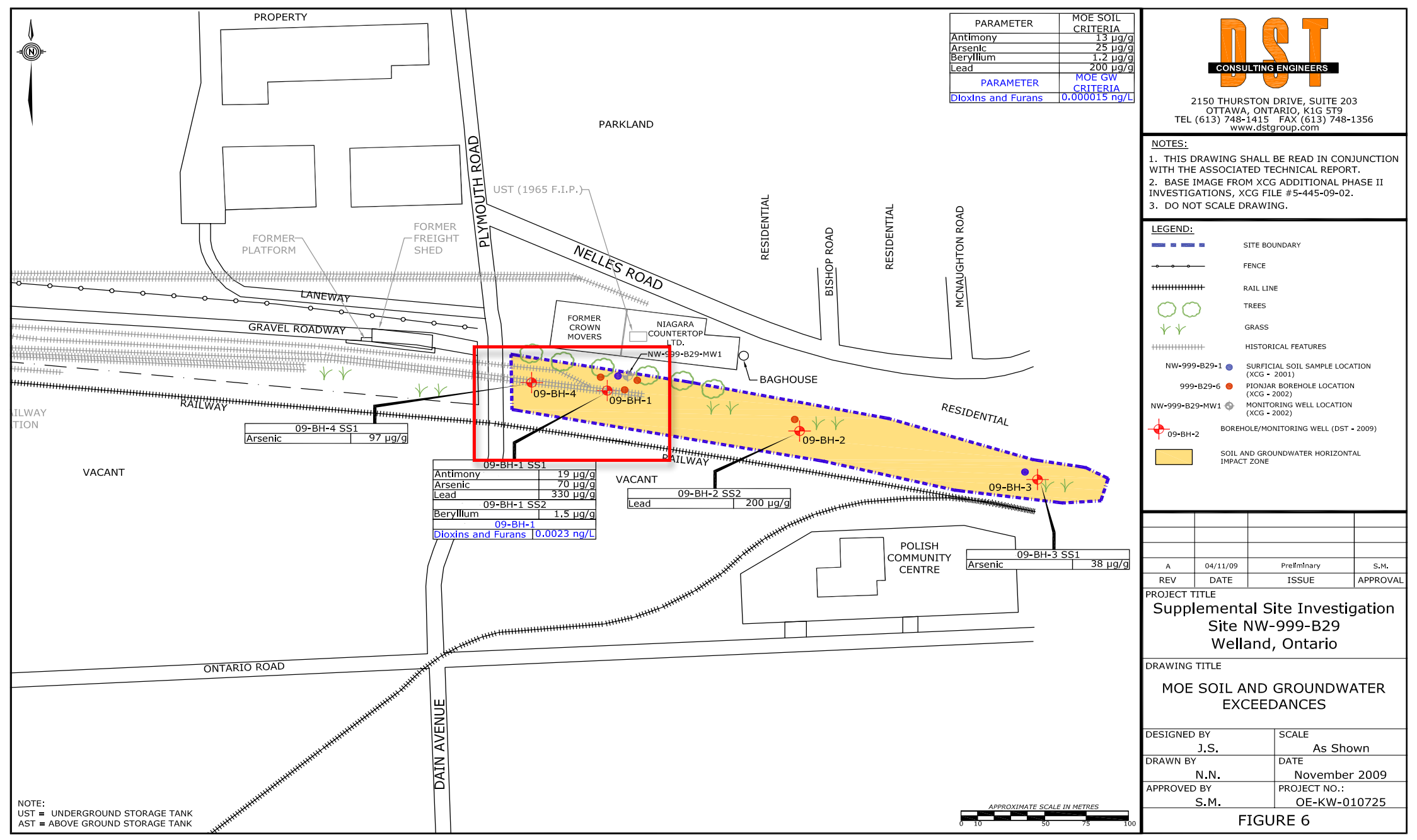

Figure 9. DST Consulting supplemental site description. The red boundary encompasses the sampling site for this study. Source: OMOT personal communication, 2010 
The sampling area was a small stretch of grass-laden land. Signs were posted that trespassing was prohibited; however, there were no fences to restrict public access. A set of railroad tracks terminated to the south of the sampling site and ran parallel to this area. A public walking trail ran through the sampling site and was located north of the railroad tracks. It was not determined whether the railroad tracks were still in commission or whether this area was a decommissioned route utilized previously. South of the sampling site and railroad tracks was a community centre. North of the sampling site was a series of small commercial estates that were separated from the sampling site by a wire fence (Figure 10).

A strategic sampling grid (Marsh et al., 1996) was constructed using the site description provided by the OMOT. From the borehole, determined to be PCDD/F positive by DST Consulting, a grid of 5 meters by 5 meters was plotted (Figure 10). Using detergentscrubbed (Alconox Powered Precision Cleaner) and solvent-rinsed (methanol, HPLC grade) sampling equipment (Marsh et al., 1996), samples were taken within the upper 10 $\mathrm{cm}$ of the soil bed and transferred into solvent rinsed amber glass jars. Jars were labeled with quadrant numbers and stored on ice back to the laboratory in Toronto. 


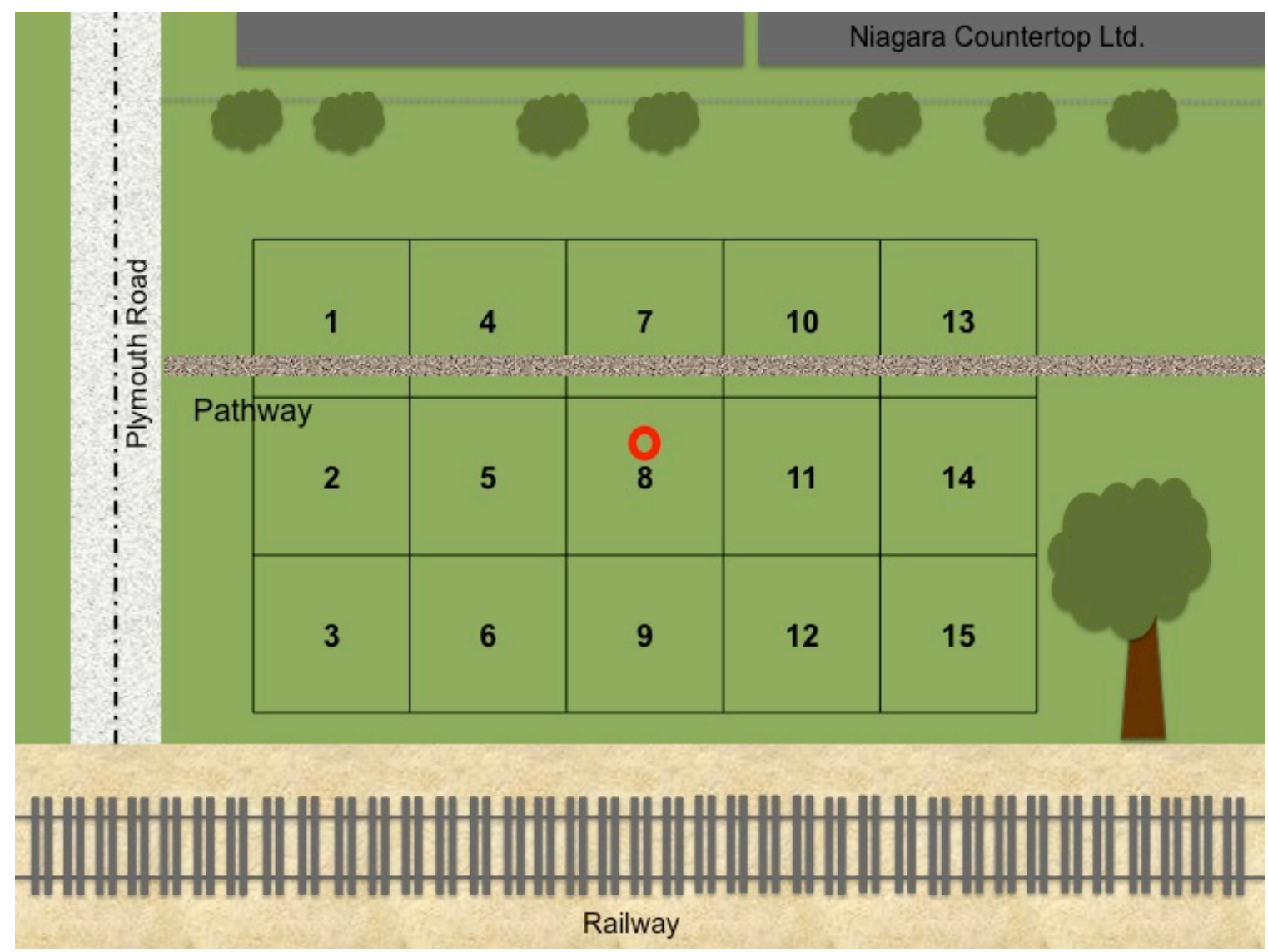

Figure 10. Site description and sampling schematics. Samples were taken 5 meters apart. The blue dot is an indication of where the contaminated borehole was located.

\subsection{Sample Description}

Fifteen soil samples were taken from the Welland Site and transferred to laboratories at the OMOE and Ryerson University. Dioxin concentrations were determined by ELISA analysis at the laboratories at the OMOE and Ryerson University as parallel samples.

A previously analyzed soil sample was used as a positive control in lieu of certified reference materials (CRMs) for all experiments. This sample was obtained by the OMOE from Pringle Creek, Ontario in 2006. The Pringle Creek (PC) sample, used as a positive control for all experiments, had been previously determined by both GC-HRMS and 
ELISA. The sample concentration was determined to be $1300 \mathrm{pgTEQg}^{-1}$ and 665.7 $\operatorname{pgTEQg}^{-1}$, respectively. This sample had been previously determined without sample homogenization. The PC sample was homogenized and the concentration was redetermined using the ELISA in this study. This sample was run through the entire procedure and was repeated for each experiment.

A negative control was also used for each experiment. This sample was composed of $4 \mathrm{~g}$ of anhydrous sodium sulphate and contained no soil. This sample was run through the entire procedure and was repeated for each experiment. The soil samples were used to test the ability of the OMOE laboratory to determine the concentrations of an undetermined site. The samples were also used to correlate with parallel samples analyzed at the preliminary Ryerson University laboratory to determine whether creating a bioassay laboratory plan with limited resources was feasible and transferrable.

\subsection{Sample Preparation}

The sample homogenization procedure was obtained from the OMOE (Marsh et al., 1996). Each soil sample was air-dried for 48 hours in individual aluminum foil bins at room temperature at the OMOE. The aluminum foil bins were loosely covered with a sheet of aluminum foil to reduce cross contamination of dust. Using an acetone-rinsed mortar and pestle, each sample was disaggregated and passed through a $2 \mathrm{~mm}$ sieve (US standard $10 \mathrm{mesh})$. Particles that were larger than $2 \mathrm{~mm}$ were discarded. The sample was then transferred back into the mortar, and ground using a pestle until all contents were able to pass through a $355 \mu \mathrm{m}$ sieve (US standard 45 mesh). The sample was then 
stored in a solvent-rinsed amber glass jar in a refrigerated environment until sample analysis. This research utilized the methodology previously described by Buan, 2009 . The sample algorithm developed by the author was used throughout this procedure.

Schematics of the sample algorithm used in this study are illustrated in Figure 11. Sample \#1 (Quadrant \#1) was first run at the mid-sensitivity level. The concentration fell below the lower threshold of 4 pgTEQg $^{-1}$ and therefore, was re-determined with all other samples at the low-sensitivity level.

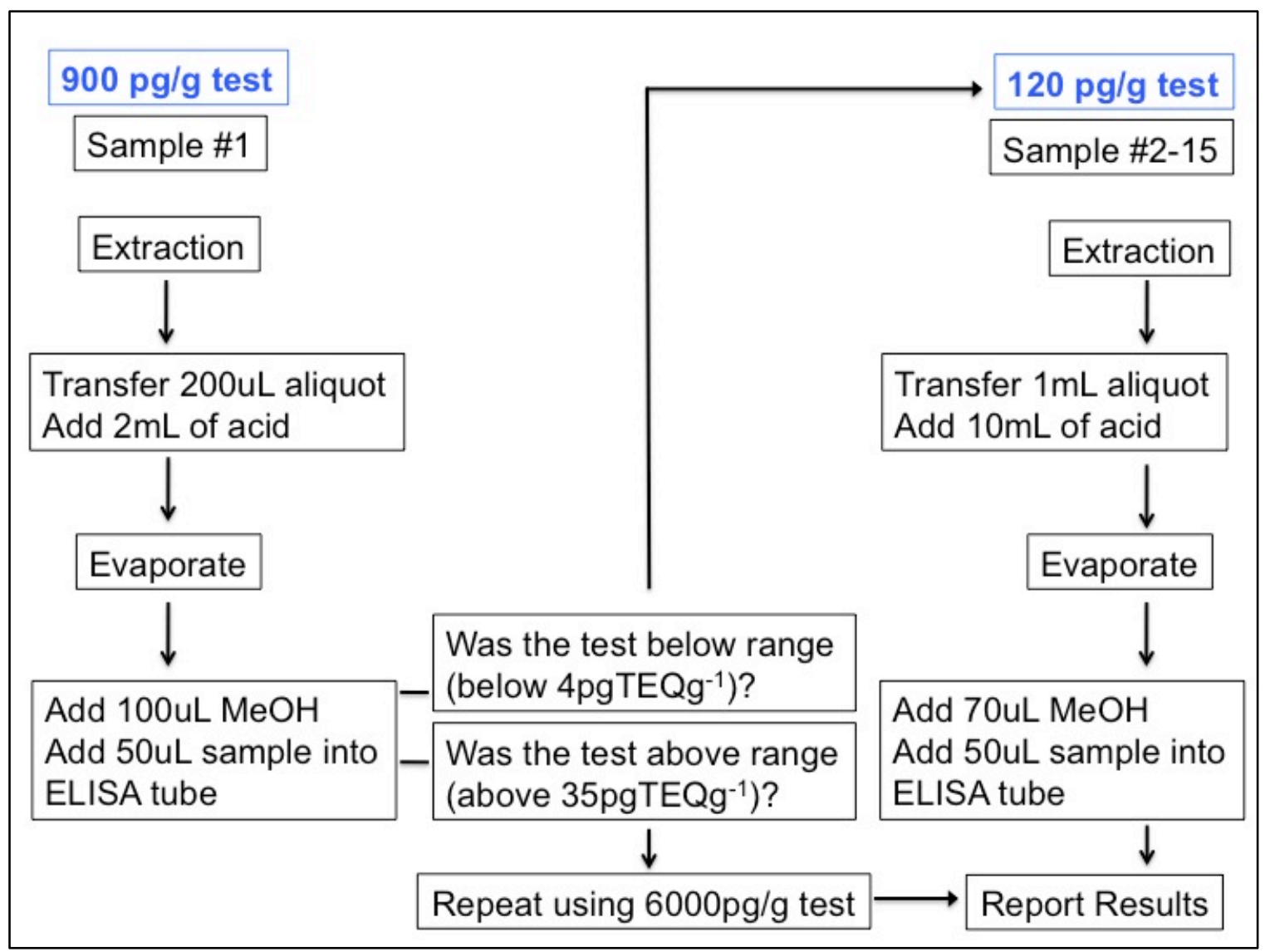

Figure 11. Sample algorithm used in this study. 
A full description of the sample preparation and ELISA procedure may be found in Appendix D. In brief, at the OMOE, a 5 g portion of homogenized sample was weighed out into a $50 \mathrm{~mL}$ borosilicate glass centrifuge tube. A $4 \mathrm{~g}$ portion of anhydrous sodium sulphate was added to the $5 \mathrm{~g}$ soil sample to ensure the sample was dried. The mixture was shaken to ensure contents were homogenous. Dioxins were extracted from the sample using $15 \mathrm{~mL}$ of dimethylformamide (DMF) and shaken on a rugged rotator for 2 hours. The sample was then centrifuged for 15 minutes at $1000 \mathrm{x} g$ to separate the soil particles from the DMF. After extraction, either a $200 \mu \mathrm{L}$ or $1 \mathrm{~mL}$ aliquot of each dioxin sample in DMF was transferred into $6 \mathrm{~mL}$ of hexane (the aliquot amount was dependent on the sensitivity level as determined by the sample algorithm). The remaining DMF extract was stored in a refrigerated environment for further experiments. The sample, the solution of DMF and hexane, was then oxidized using either $2 \mathrm{~mL}$ or $10 \mathrm{~mL}$ of fuming sulphuric acid. The sample was then reattached to the rugged rotator and spun for 15 minutes to ensure full oxidation had occurred. The sample was then centrifuged for 5 minutes at $2000 \mathrm{x}$ g to separate the acid layer from the hexane layer. The supernatant hexane layer was transferred into a clean borosilicate glass test tube containing $150 \mu \mathrm{L}$ of keeper solution (80:20 methanol:polyethylene glycol [PEG] + 100 ppm Triton X-100). The hexane was evaporated at $55^{\circ} \mathrm{C}$ leaving behind the detergent keeper. The keeper residue was collected to the bottom of the tube by centrifugation (2000xg, 30 minutes). The residue was reconstituted using $70 \mu \mathrm{L}$ methanol and analyzed using ELISA. CAPETechnologies recommends additional cleanup for samples that exhibit cloudiness during reconstitution. Since no cloudiness was observed, samples were tested without further clean up. 
At the minimally resourced Ryerson University laboratory, the sample preparation procedure reproduced the procedure utilized at the OMOE, as closely as possible with the resources that were available. All steps were followed; however, as the Ryerson University laboratory was absent of a centrifuge capable of accommodating $50 \mathrm{~mL}$ centrifuge tubes, incubation periods of 24 hours post extraction, and 48 hours post oxidation, were conducted in the fume hood to allow contents to separate via gravity. An orbital platform shaker was employed to shake the sample during the extraction and oxidation step. As this procedure was created to test the efficiency of dated equipment, the duration was not altered despite the rotation speed being half that of the rugged rotator used at the OMOE. Differences in sample preparation are noted in Table 6.

Table 6. Procedural differences between the OMOE and Ryerson University.

\begin{tabular}{|l|l|}
\hline \multicolumn{1}{|c|}{ Ontario Ministry of the Environment } & \multicolumn{1}{c|}{ Ryerson University } \\
\hline Sample weighing & Sample weighing \\
\hline $\begin{array}{l}\text { Sample extraction using rugged rotator } \\
(40 \text { rpm) }\end{array}$ & $\begin{array}{l}\text { Sample extraction using orbital platform } \\
\text { shaker (20rpm) }\end{array}$ \\
\hline Centrifuge for 15 minutes & Leave for 24 hours to separate via gravity \\
\hline Transfer aliquot of sample into hexane & Transfer aliquot of sample into hexane \\
\hline Oxidize sample with sulfuric acid & Oxidize sample with sulfuric acid \\
\hline Shake sample on rugged rotator (40rpm) & Shake sample on platform shaker (20rpm) \\
\hline Centrifuge for 5 minutes & Leave for 48 hours to separate via gravity \\
\hline Obtain supernatant & Obtain supernatant \\
\hline Evaporate & Evaporate \\
\hline ELISA analysis & ELISA analysis \\
\hline Total time for sample prep: 3 days & Total time for sample prep: 6 days \\
\hline
\end{tabular}




\subsection{ELISA Analysis}

ELISA analysis used the method described in Buan, 2009. The ELISA tubes and reagents were purchased from CAPE-Technologies. Eight samples were tested alongside a minimum of one method blank, a minimum of one positive control, two negative controls, and eight standards. The ELISA procedure is illustrated in Figure 12. After sample reconstitution, a $50 \mu \mathrm{L}$ aliquot of the sample was added to the ELISA tube containing $500 \mathrm{~mL}$ sample diluent. The contents were mixed by vortex for 5 seconds and the solution was allowed to incubate for two hours. After one hour of incubation time had elapsed, the tube received 5 seconds of vortex. After the two hours of incubation time had surpassed, the solution was discarded. Tubes were washed using $1 \mathrm{~mL}$ of Wash Solution I (100 ppm Triton X-100), which is available in the CAPE-Technologies kit. The tube was washed for a total of four times and then $500 \mathrm{~mL}$ of competitor horseradish peroxidase (HRP) conjugate was added. The solution was subjected to vortex for 5 seconds and then incubated for 20 minutes. After the incubation period, the solution was dumped, and washed four times with $2 \mathrm{~mL}$ of deionized distilled water (DDW). After the final wash of DDW, $500 \mathrm{~mL}$ of HRP-substrate solution was added to the ELISA tube. Vortex was applied for 5 seconds. Addition of the substrate solution allows for a blue colour to develop. The solution was allowed to incubate for 40 minutes in the dark; after the final incubation period, $500 \mathrm{~mL}$ of stop solution was added. Addition of the stop solution converts the blue solution to yellow. Colour production is inversely proportional to the amount of dioxin in the sample tube and the absorbance of the solution can be measured using a spectrophotometer (Abraxis LCC model no. 108921-500 at the OMOE and Artel Inc. model DP at Ryerson University). The final raw ELISA results are issued 
in TCDD equivalents by converting the absorbance reading through the use of a standard curve based on a four-parameter equation supplied by CAPE-technologies.

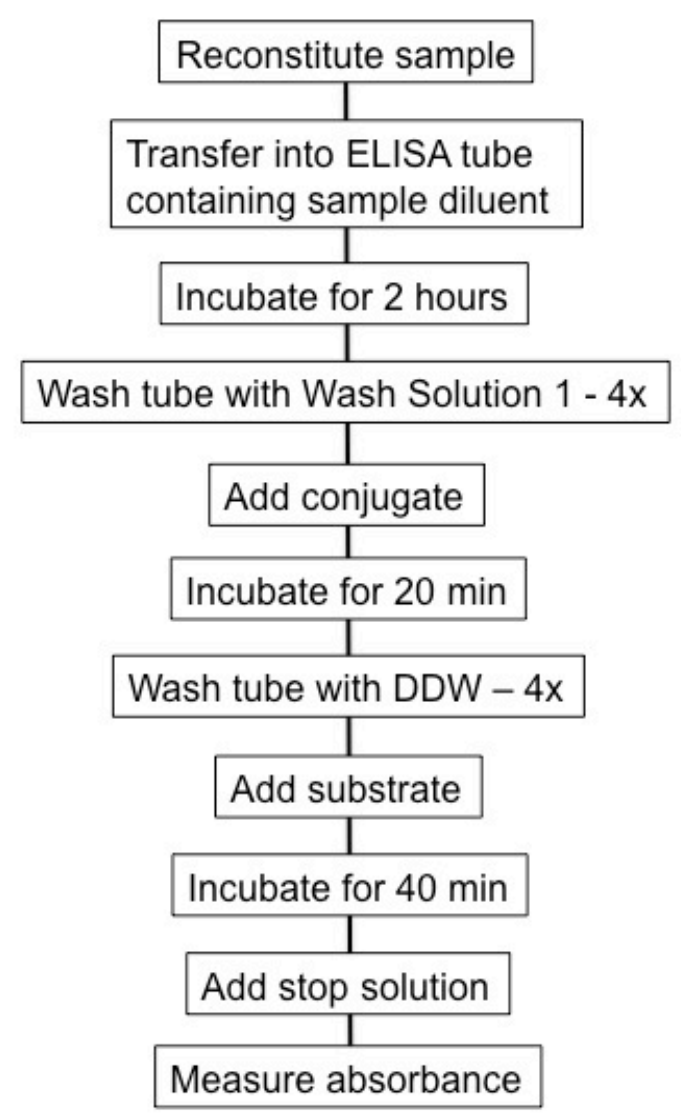

Figure 12. ELISA procedure.

\subsection{Method Advancements}

\subsubsection{Sample Homogenization}

The effects of sample homogenization were tested on dioxin-contaminated soil to determine whether the addition of sample homogenization to the sample preparation procedure altered the concentration of tested soil. One homogenization method was used to test two different concentration ranges. Experiments were conducted to determine 
whether non-homogenized and homogenized samples produced varying concentrations, as the spatial variability of the sample was likely to change.

Two cases of non-homogenized versus homogenized soil samples were analyzed. Both cases utilized samples that were previously obtained from the OMOE in 2006 from contaminated site, Pringle Creek in Ontario. The first case took one soil sample known to have a low dioxin concentration, as determined previously by GC-HRMS, and the sample was split into two aliquots. One aliquot was homogenized as stated previously and the other split was left unaltered. Each aliquot was then split into three $5 \mathrm{~g}$ replicates. Both homogenized and non-homogenized replicates went through the same sample preparation and analysis method as stated above.

The second case took one soil sample known to have a high concentration level, as determined previously by GC-HRMS. This sample was also used as a positive control in all experiments. The sample was homogenized and analyzed through each experiment as a positive control. The mean average of all replicates was taken and compared to previously determined concentrations that had been analyzed by ELISA without homogenization.

\subsubsection{Bioassay Plan for a Minimally Resourced Laboratory}

The establishment of an ELISA laboratory was initiated at Ryerson University to simulate a marginalized economy without the capacity to analyze samples using GCHRMS. The laboratory at Ryerson University was chosen to simulate an marginalized 
economy for a number of reasons: the laboratory; (i) used dated equipment and had limited resources; (ii) was viewed as financially limited with a small finite budget; (iii) lacked support and permanent staff; and (iv) was high traffic, dusty and located in a transient space. A plan to illustrate the portability and feasibility of this approach will be discussed with the ambition of applying this model to areas where GC-HRMS is not accessible and where knowledge and technology transfer may be easily applied.

An unoccupied space at Ryerson University was chosen to determine whether ELISA could be reproduced in a transient setting. The minimum requirements of the laboratory were that it contained a working chemical fume hood (minimum of 5 foot exhaust), equipped with electricity $(115 / 230 \mathrm{~V}, 60 \mathrm{~Hz})$ temperature-control $\left(21^{\circ} \mathrm{C}\right)$, and was relatively dust-free. Running water was not necessary for the laboratory; however, approximately 3 liters of deionized distilled water was stored and available for each experiment.

The laboratory, which had been previously used to investigate cement and hydraulic movements, was washed scrupulously. Previous work conducted (Zhang, 2008) illustrated that dust was a significant contributor to cross contamination of ELISA results. Therefore, all surfaces, bench tops, windows, and floors were dusted and washed three times using all-purpose cleaner. Air ducts were professionally cleaned. The fume hood was washed with all-purpose cleaner twice and then solvent-wiped with methanol. A layer of aluminum foil was used to cover the entire surface of the fume hood. 
Brand new borosilicate glass bottles were solvent-rinsed three times with DCM and were used to store opened reagents. Foil was used to cover the tops of these bottles to prevent settling dust from transferring from the lids to the reagents. The third rinse of DCM from these bottles was collected in a clean test tube for analysis of background contamination. All glassware used during the ELISA preparation procedure was solvent rinsed according to Zhang, (2008). Clean glassware was wrapped in aluminum foil and stored in airtight Rubbermaid containers in the cupboards to prevent future dust contamination.

Limited equipment was purchased in order to keep capital costs low and retain the simulation of an economically marginalized area. The majority of the equipment set up at the Ryerson University laboratory was borrowed, brought out of storage or purchased refurbished. Equipment brought out of storage and set up in the laboratory included a multi-purpose one-speed bench top centrifuge (Valuspin, Vulcon Technologies), an orbital platform shaker (Rocker Platform, Bellco Glass Inc.) and a one-speed vortex mixer (MaxiMix, Labnet VX-100). Equipment purchased refurbished included a nitrogen generator system (Parker Nitroflow Lab). As the nitrogen generator system is specific and required for ELISA sample preparation, accessories for the nitrogen generator system were purchased new. This included a digital dry bath (Labnet Digital Drybath) and two heating blocks. A photometer compatible with the specific ELISA tubes was also purchased new from Artel Inc. A mobile aluminum-sheet box, which may be used on the lab bench or in the fume hood, was made as a cost efficient alternative to purchasing a laminar flow dust cabinet. This was used to contain further dust contamination from previous projects at the Ryerson laboratory and was built to be mobile and multi-functional. 


\section{RESULTS}

\subsection{Soil Samples}

At the OMOE, the fifteen soil samples from Welland, Ontario were run in duplicate alongside a minimum of one method blank and one positive control. One sample run at mid-range sensitivity level fell below the sensitivity range of the ELISA: between 4 and 35 pgTEQ per ELISA tube. All samples analyzed after this sample were run at the lowsensitivity level and all fell within the sensitivity range.

At Ryerson University, the same fifteen soil samples from Welland, Ontario were run in parallel, alongside a minimum of one method blank and one positive control. All samples were run at the low-sensitivity level. Four samples fell below the sensitivity range of the ELISA, at the low-sensitivity level. However, to maintain sample preparation conditions identical to those used at the OMOE, samples were processed using the same preparation procedure and conditions. The samples at Ryerson University were used to examine: (i) the relationship between OMOE results and Ryerson University results, (ii) the effects of ELISA using dated and under-resourced equipment and facilities and (iii) whether feasible results were able to be produced in a provisional setting in under one year.

\subsection{Positive Control Results}

As CRMs are costly, a soil sample that had been previously determined by both GCHRMS and ELISA was chosen as a positive control. The sample was homogenized in the same manner as the samples from Welland, Ontario. ELISA analysis conducted in 
previous years on this sample did not use a homogenization procedure. Ten replicates were determined by ELISA at the two laboratories, seven at the OMOE and three at Ryerson University, one replicate for each experiment conducted. Figure 13 below shows the concentration of the positive control sample. The red line indicates the overall mean of all ELISA determinants and the blue line indicates a single GC-HRMS result obtained. The light blue line indicates the previously determined ELISA result without homogenization.

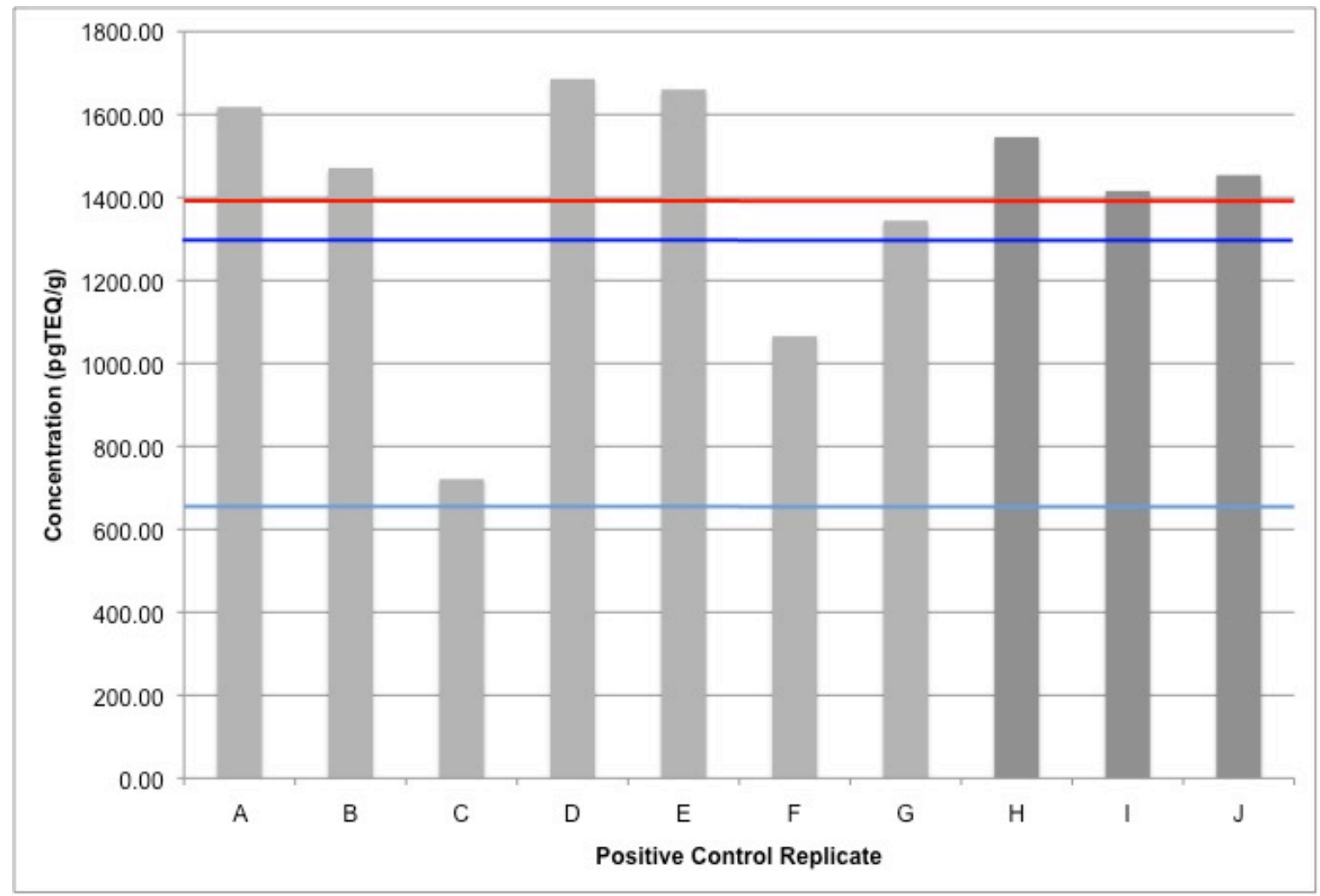

Figure 13. ELISA results of the 10 positive control replicates used. The red line indicates the mean of all ten positive control replicates determined by ELISA. The dark blue line indicates a single GC-HRMS result obtained previously. The light blue line indicates a single ELISA result obtained previously without homogenization. Light grey columns represent replicates detected at the OMOE (A-G). Dark grey columns represent replicates detected at Ryerson University (H-J). 
The mean dioxin concentration of the Positive Control (PC) was determined by ELISA to be $1398 \pm 299 \operatorname{pgTEQg}^{-1}$ (t-test, $p$-value=0.48 > 0.05). A Grubb's outlier test determined that all replicate $Z$ values were below the Critical $Z$ value of 2.29 for $n=10$. One replicate, Replicate $\mathrm{C}$, had a $\mathrm{Z}$ value of 2.27 , which was borderline to the Critical $\mathrm{Z}$ value of 2.29. This replicate had undergone a splash effect upon the addition of the conjugate during ELISA analysis. Some sample could have been lost at this point; however, as the $\mathrm{Z}$ value was still less than the Critical $\mathrm{Z}$, Replicate $\mathrm{C}$ was kept within the population and not deemed an outlier. The PC sample was previously determined by a single GC-HRMS result to be $1300 \mathrm{pgTEQg}^{-1}$. The mean ELISA positive control concentration is than approximately $8 \%$ higher than this amount.

The findings of the replicates used for a positive control implies that samples homogenized and run in replicate are able to correct for discrepancies from past ELISA analysis, as well as report concentrations within $10 \%$ of those reported by GC-HRMS. By using soil samples with a known concentration determined by GC-HRMS that have been thoroughly homogenized and analyzed repeatedly, CRMs may be substituted in situations that lack the funding to purchase high-cost positive controls.

\subsection{Homogenized Soil Sample Results}

The concentrations of soil samples without homogenization and with homogenization at low-concentration levels were $38.1 \mathrm{pgTEQg}^{-1}$ and $37.9 \mathrm{pgTEQg}^{-1}$ respectively (t-test, $p$ value $=0.998>0.05)$ (Figure 14). This illustrated that there was no significant difference in concentration between samples analyzed at low concentrations. 


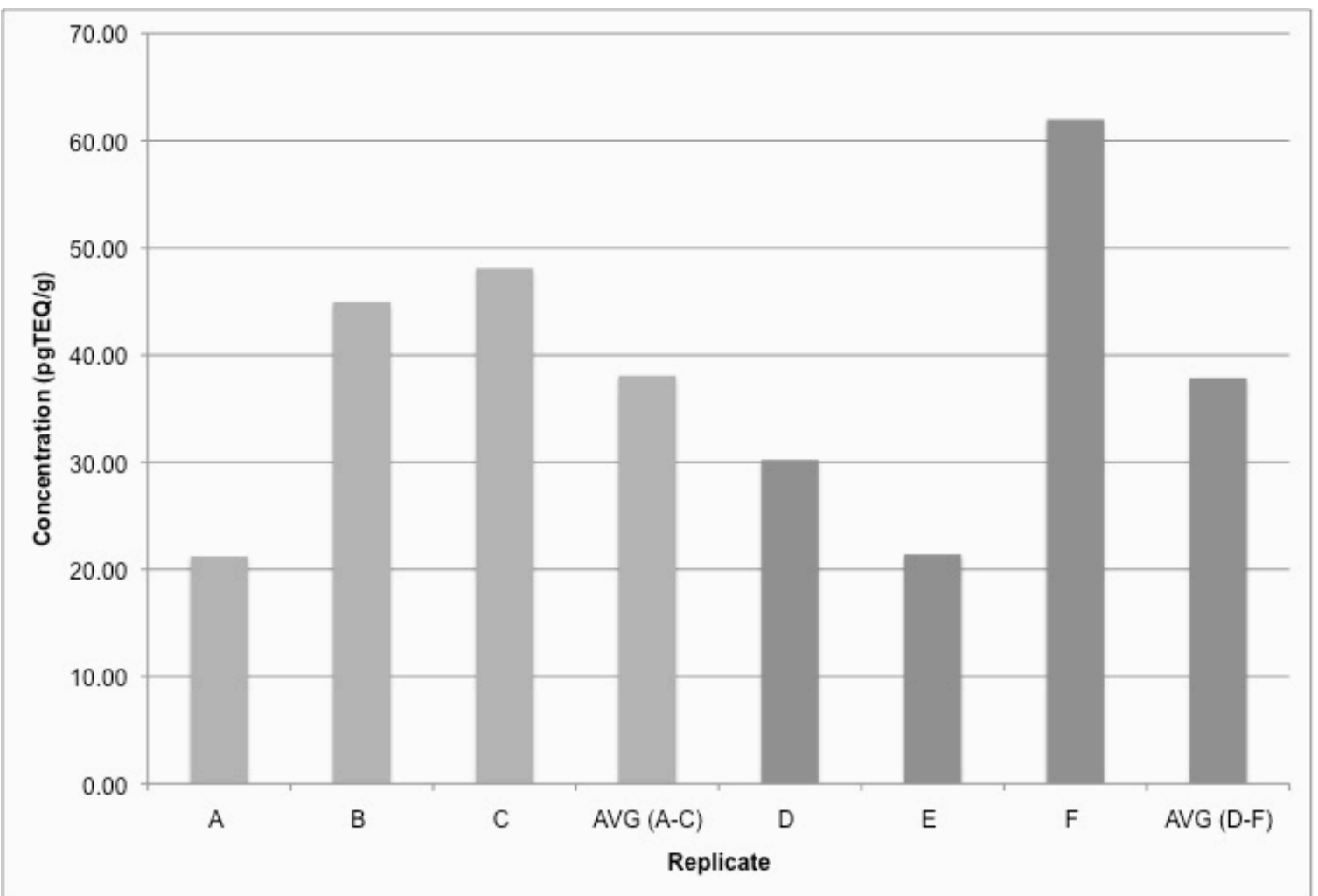

Figure 14. Homogenization results for a low concentration soil sample. Light grey bars (Replicates A-C and the mean average of Replicates A-C) represent the aliquot of the sample that did not undergo homogenization. Dark grey bars (Replicates D-F and the mean average of Replicates D-F) represent the aliquot of the sample that did undergo homogenization.

Samples analyzed at mid-range to higher concentrations illustrated that soil homogenization had a significant effect on the overall concentration (t-test, $p$-value $=$ $0.480>0.05)$. The ELISA concentrations of a soil sample without homogenization and with homogenization at mid-range to high-concentrations were $665.7 \operatorname{pgTEQg}^{-1}$ and 1398.1 pgTEQg $^{-1}$, respectively (Figure 13). The GC-HRMS concentration was previously determined to be $1300 \mathrm{pgTEQg}^{-1}$. 
These results illustrate that samples at mid-range to high concentrations may have a larger affect in terms of dioxin retention and spatial variability. This may be the case as dioxins may undergo a process called "ageing" observed in many other recalcitrant environmental contaminants (Tang et al., 2007). The process of "ageing" is variable and largely depends on the soil characteristics, particle size, porosity, and the concentration of contaminants. The binding affinity of PCDD/Fs in soil may be dependent on the concentration. As seen in other environmental contaminants, retention is affected by the concentration of related compounds as they compete for higher affinity binding sites. Over time, the pollutant will redistribute from weaker binding sites (exterior of soil particles) to higher affinity binding sites (interior pores of soil particles) (Tang et al., 2007). Therefore, soil samples with higher concentrations may have dioxin molecules within higher affinity binding sites, which may be released from interior pores through the grinding and crushing process during homogenization.

\subsection{Comparison Between the OMOE and Ryerson University Lab Results}

The overall correlation between ELISA results analyzed at the OMOE and ELISA results analyzed at the Ryerson University bioassay laboratory for soil samples with dioxin concentrations of 32.38 to $163.2 \mathrm{pgTEQg}^{-1}$, and undetectable to $120.26 \mathrm{pgTEQg}^{-1}$, respectively, are plotted in Figure $15\left(\mathrm{n}=13, \mathrm{r}^{2}=0.888\right.$, slope $\left.=0.87\right)$. A paired t-test comparing the OMOE ELISA results and the Ryerson University ELISA results was not significantly different based on a $p$-value of 0.00 , when the criteria used for statistical significance was $p$-values less than 0.05 . Included in Figure 15 is a confidence interval for the mean response of $n=13$. 


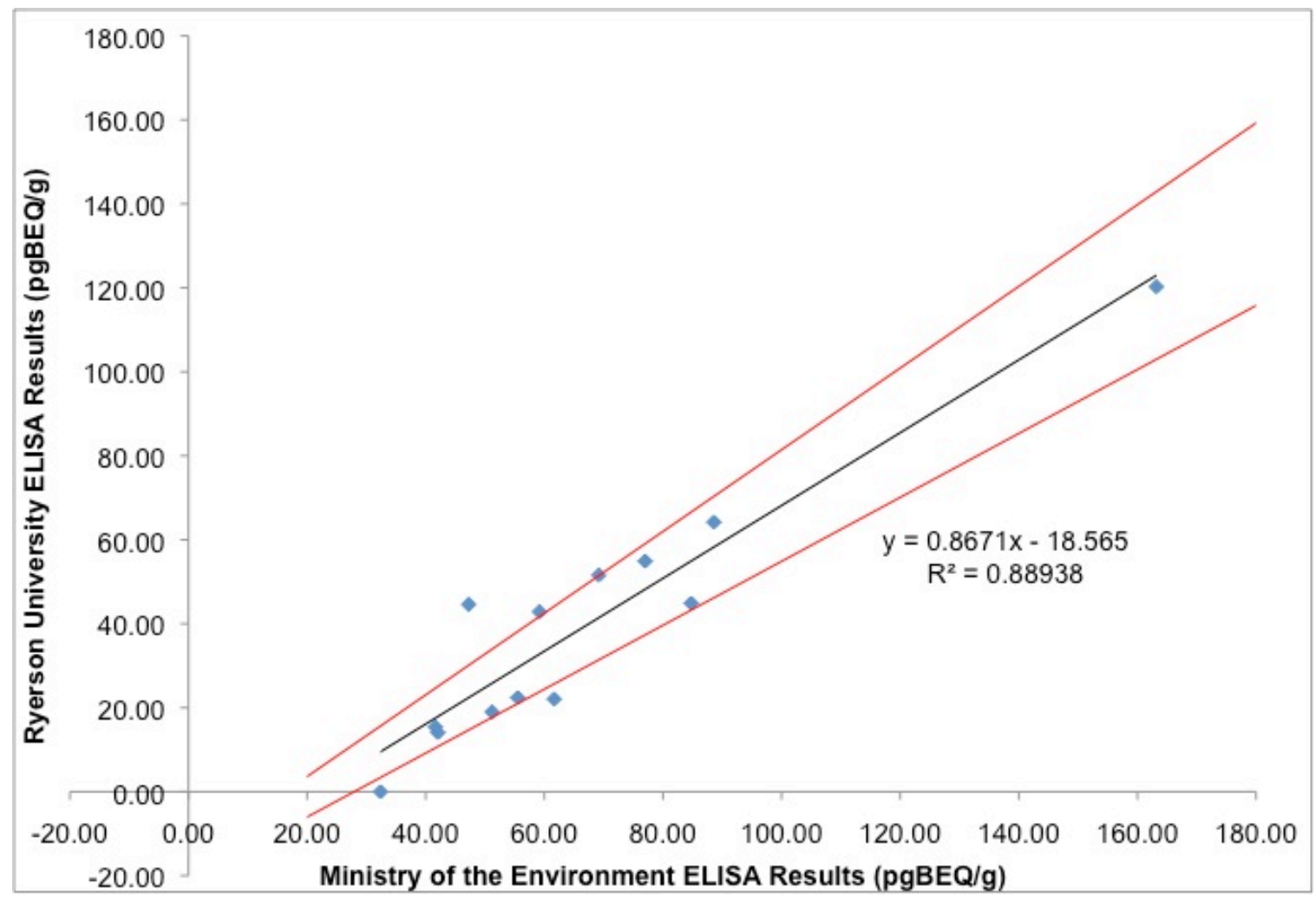

Figure 15. Relationship between OMOE and Ryerson University ELISA results. A confidence interval for the mean response is shown (red) for $\mathrm{n}=13, p$-value $<0.05$.

The first quadrant from Welland, Ontario, analyzed at the OMOE was eliminated from the figure as the results were run at the mid-sensitivity level and did not produce detectable results. All other samples were run at the low-sensitivity range and were therefore comparable to each other. The third quadrant (sample no. 3) from the Welland site was also eliminated from this data set. This was justified as all sample concentrations analyzed from the OMOE were consistently higher than those produced at Ryerson University, with exception of the third quadrant. Taking the definition of an outlier from Barnett and Lewis (1994) quoted in Hodge and Austin (2004) into account:

An observation (or subset of observations), which appears to be inconsistent with the remainder of that set of data. 
Thus it was justifiably considered as an outlier and removed from the data used in this correlation plot. The $p$-value determined by conducting a t-test using the results of the two laboratories ELISA results as paired arrays indicted that the null-hypothesis should be rejected. As the only difference in conditions between the two arrays was the equipment used for sample preparation, the t-test was an indication that the instruments used resulted in a difference between the two resulting concentrations.

The majority of data points are incorporated within the confidence interval based on the mean of the response. One significant exception being the point that fell out of detection range. When analyzed at the OMOE, this point had the lowest concentration and fell just within sensitivity range. At the OMOE, 5.4 pgTEQ per tube was introduced into the ELISA tube. This was already near the lower threshold of the sensitivity range of the ELISA tubes: 4 to 35 pgTEQ per tube. As all data analyzed at Ryerson University was consistently lower than that at the OMOE, it was anticipated that this point was likely to fall below the sensitivity range. However, as the procedure aimed to mimic the conditions of the OMOE as closely as possible, it was decided that the conditions for this point would remain consistent to those used at the OMOE to be directly comparable. The other potential outlier is the point that lies left of the confidence interval. As with all sets of data that have a normal distribution, approximately 1 in 22 observations will differ by twice the standard deviation or more from the mean (Ruan et al., 2005). A Grubb's outlier test determined that this point was not an outlier; therefore, it was not excluded from the data set. 
Two explanations as to why samples at Ryerson University were consistently lower than those obtained at the OMOE may be due to a contrast in the equipment used at both of these facilities. The rotator used at Ryerson University is a dated orbital platform shaker that is narrowly functional and produces a rotation speed of approximately $20 \mathrm{rpm}$ at the highest setting. As the soil samples were less agitated with this type of stirrer, in comparison to the rugged rotator used at the OMOE, it may be a reason that attributed the soil concentration levels to be consistently lower than those produced at the OMOE. At the OMOE, samples are rotated at a speed of 40 to $50 \mathrm{rpm}$. Soil samples at Ryerson University continuously stuck to the sides of the centrifuge tubes, preventing full mixing of the sample. The sample had to be manually shaken and rotated every 15 minutes, and reattached to the orbital platform shaker over the course of 2 hours to assist in the extraction process. It is believed that DMF may not have had optimal access to the soil particles over the course of the 2 hours. Although the instrument did work, it is recommended that extraction times be increased to either 3 or 4 hours in future experiments.

The Ryerson University laboratory also lacked a table top centrifuge capable of accommodating $50 \mathrm{~mL}$ centrifuge tubes, as well as one that possessed temperature and speed control. As a result, samples could not be centrifuged after extraction or oxidation and were left in the fumehood for several hours to separate. Although this was likely an insignificant issue post extraction, as only an aliquot of sample is taken and transferred into hexane, this may have lead to a loss in analyte post oxidation. After oxidation, the samples were left in the fume hood for at least 48 hours to separate via gravity. It was 
found that after 2 to 24 hours, there was still significant acid transfer in the sample, as the sample after evaporation contained a slight yellow coloration. After 48 hours, samples were transferred into evaporation vials with minimal to no acid transfer; however, some hexane was lost over this time frame. Volumes were compared to determine whether hexane lost had occurred and there was an average of 1.3 to $1.7 \mathrm{~mL}$ of solvent loss from samples that did not undergo a centrifugal force. This was likely due to the lack of compaction factor that is attained from the strong gravitational force through centrifugation. This was taken into account for all samples and final concentrations were re-determined by theoretically determining how much sample was lost through lack of compaction from centrifugation. Determination of sample loss should be conducted for each experiment to more accurately determine the recovery of the sample.

A concentration site map was produced of the dioxin-contaminated site in Welland, Canada (Figure 16). The map displays the soil samples analyzed at the OMOE (red) and Ryerson University (blue). The map superimposes the ELISA results found at each respective laboratory. The superimposed concentration bars are all to scale with exception to the ninth quadrant (sample no. 9) analyzed at the OMOE. This bar was truncated to fit into the figure and is designated with an arrowhead to illustrate that this concentration is in fact higher than illustrated. The numerical concentrations are also displayed alongside the concentration bars as well as the quadrant number. Concentrations are located to the right of the quadrant number. A yellow marker has been used to signify the approximate location of the dioxin-contaminated borehole determined by DST Consulting. 

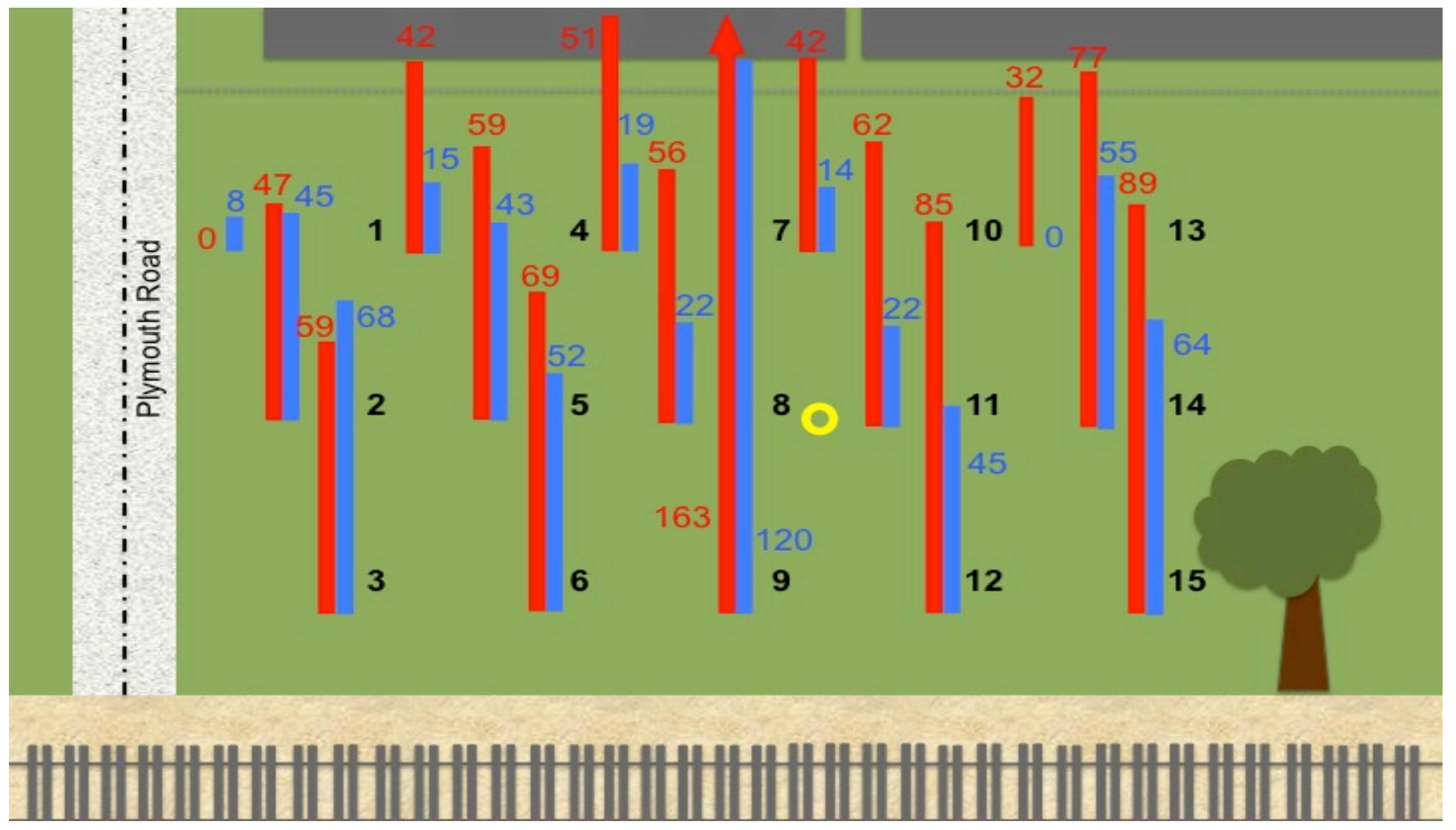

Figure 16. Concentration map for the Welland site, Canada. OMOE ELISA results (red) and Ryerson University ELISA results (blue) indicate the quadrant concentration in $\mathrm{pgTEQg}^{-1}$. Concentration bars are located to the right of each quadrant. A yellow marker in proximity to quadrant 8 represents the location of a dioxin-contaminated borehole. 
There is a major pattern shared between the superimposed concentrations from the two laboratories. The pattern observed at the OMOE can be seen in Figure 17. The pattern observed at Ryerson University can be seen in Figure 18. For both laboratories, quadrants closest to the railroad tracks (Quadrant 3, 6, 9, 12, 15) (green) all have the highest dioxin concentrations. Quadrants furthest from the railroad tracks (Quadrant 1, 4, $7,10,13)$ (blue) all have the lowest dioxin concentrations; and the quadrants located between these two areas (Quadrant 2, 5, 8, 11, 14) (red) lie somewhere in the middle.

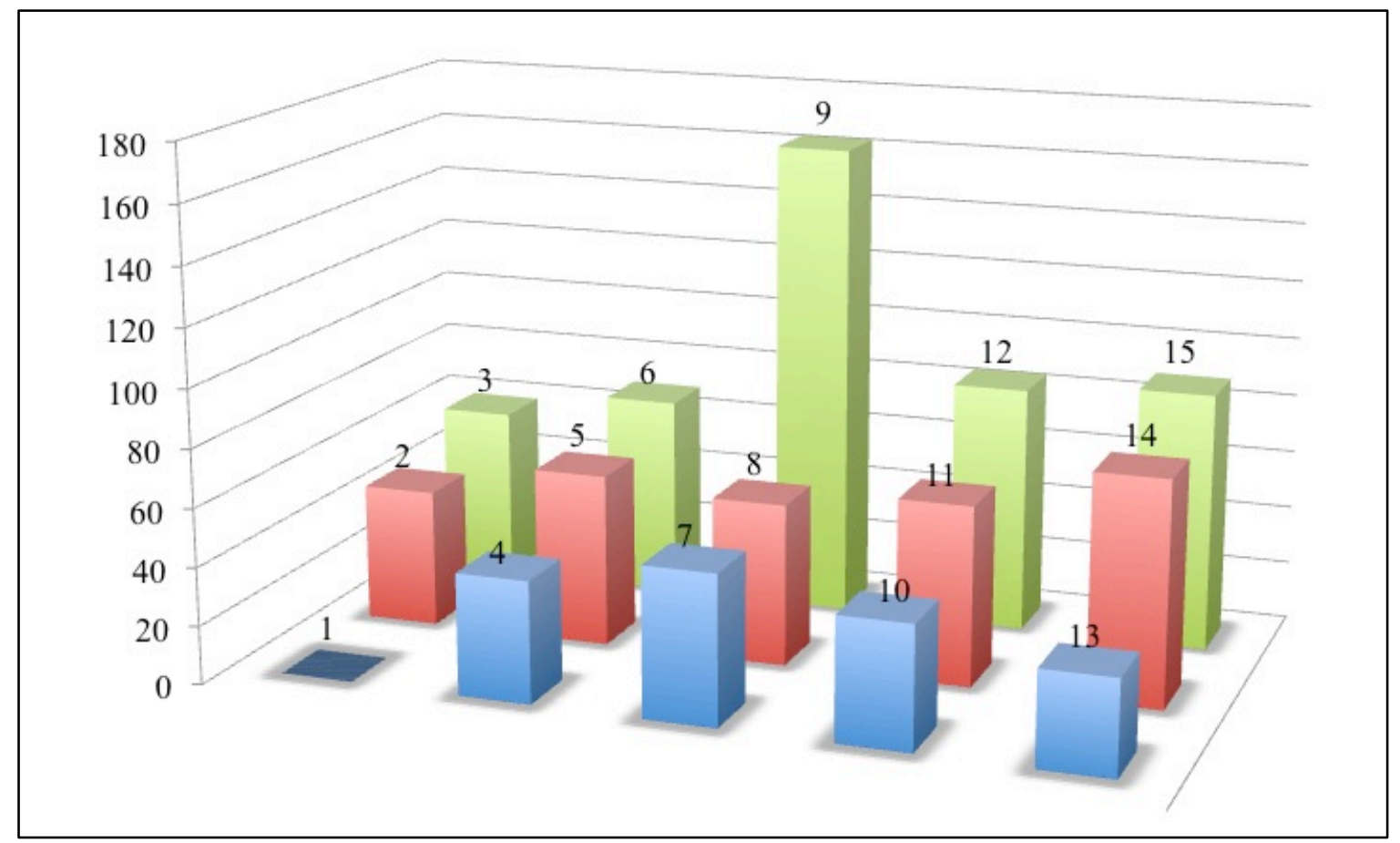

Figure 17. OMOE spatial distribution concentration gradient trend. Corresponding quadrant numbers are indicated above each concentration bar. 


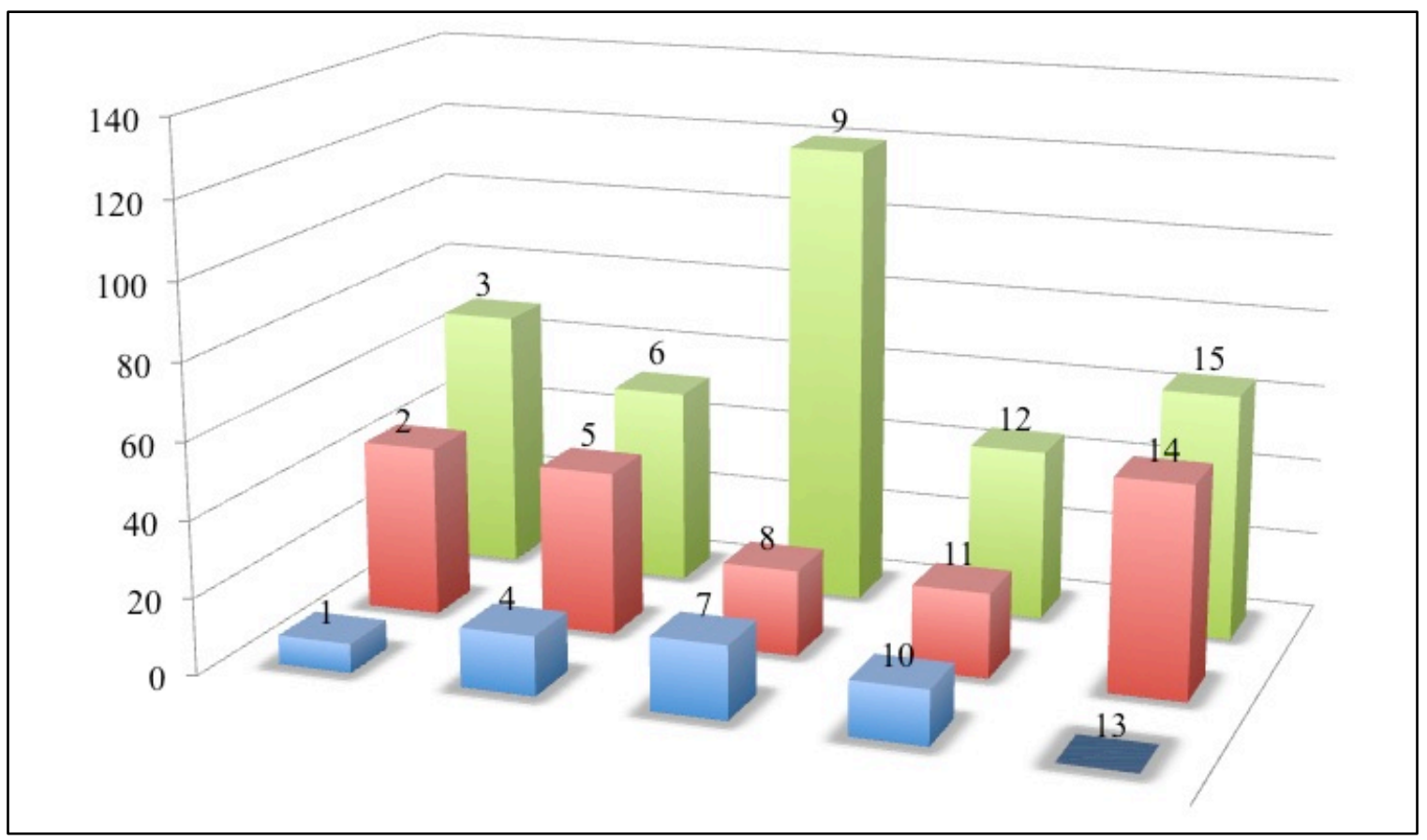

Figure 18. Ryerson University spatial distribution concentration gradient trend. Corresponding quadrant numbers are indicated above each concentration bar.

This observation follows the general concentration gradient rules in that areas of high concentration will move to areas of lower concentration. This is an indication that dioxin contamination was likely coming from a southern source and moving north. This is a consistent pattern that was not only achieved by all quadrants; however, was also reproduced between the two laboratories.

It had been hypothesized that the dioxin source had been concentrated at the borehole sample point determined by DST Consulting; however, if this were the case, a concentration gradient radiating from quadrant 8 (sample no. 8) would have been observed. As this was not the case, it was hypothesized that the source for dioxin 
contamination for this research study, was likely due to other sources discussed below rather than groundwater contamination.

A number of reasons could have lead to dioxin contamination in this area. Immediately south of the sampling site are a set of railroad tracks. Contamination may have occurred through potential emissions caused by coal-fuelled trains utilized previously throughout this area. If this was the case, the tree located within Quadrant 15 may have acted as a shield from dioxin emissions resulting in the lowest concentration at Quadrant 13.

Another potential source of dioxin contamination may have been from the degradation of PCP-treated wood used as railway ties to construct the railroad track. There were approximately 2000 commission PCP-treated rail ties used by CN Rail in the early 1970s, each having an estimated lifetime of 35 years (Canadian Environmental Protection Act [CEPA], 1999). The average release of dioxin to soil from PCP-treated wood preservatives used on rail ties in Canada prior to 1987 was $0.31 \mathrm{~g} /$ year for $70000 \mathrm{~m}^{3}$ of wood. Although this concentration is low, accumulation over the years and degradation of PCP over the course of its lifetime may have contributed to the dioxin release in this area. Railway ties have not been treated with PCP in Canada since 1992 (CEPA, 1999).

The Welland site may have also been a target of Agent Orange in the 1950's, 1960's and 1970 's, as this herbicide was also used by the Ministry of Transportation to clear roadways for infrastructure (Zlomislic and Talaga, 2011). The use of Agent Orange to 
clear way for infrastructure such as railway tracks may possibly be encompassed within these provincial-wide sprayings.

The pattern acquired also illustrates that the ELISA may be able to detect for a source of dioxin contamination. In this case, by being able to quantify dioxins in a considerable number of samples from one site, and within close proximity to each other, a pattern was elucidated that contamination most likely occurred south of the sampling site. Taken this into consideration, ELISA may partially be viewed as more than just a screening tool. It presented itself as a source tracking tool as well.

At the beginning of this assessment, it was hypothesized that dioxin contamination was likely highest around the contaminated borehole. The strategic sampling grid was created to take this into account, plotting Quadrant 8 (sample no. 8) within the centre. However, upon investigation, it can be implied that dioxin-contamination is likely coming from the south and moving north. With enough sample analysis, ELISA is beginning to take the shape of being able to be used as a source identifier for contamination, and no longer just as a screening tool used for dioxin assessment. With enough samples taken from the same site, in close enough proximately, patterns may lead to indications of where the source is located. This is feasible with ELISA as the cost per sample is significantly low compared to GC-HRMS. GC-HRMS would still be required for source confirmation; however, the number of samples would be significantly less. 
Using the screening levels set out by ATSDR Soil Guidelines (screening level $\leq 50$

$\operatorname{pgTEQg}^{-1}$, evaluation level 51 and $999 \mathrm{pgTEQg}^{-1}$ and action level $\geq 1000 \mathrm{pgTEQg}^{-1}$ ), all samples fell either within the screening level or within the low end of the evaluation level. From this it can be determined that this site is no longer a high priority for PCDD/F contamination and may be de-listed from the Federal Sites Contamination Inventory. A letter of recommendation for this action has been submitted and may be found in the Appendix E. The OMOT reporting agency for this site has accepted the ELISA results from this study and will be using the results as part of the FCSI biannual inventory update of dioxin-contaminated sites in Canada.

\subsection{Evaluating the Costs and Feasibility of a Bioassay Laboratory}

The initiation of a bioassay laboratory within a temporary and provisional setting was feasible and transferable. The total time to equip and run the laboratory, with reasonable and reproducible results, was approximately a year. This time included clearing and organizing an area to provide sufficient space; washing and flushing the laboratory, fume hood and air ducts of dust; running preliminary tests to determine which equipment was required and which equipment was nonessential; ordering and purchasing required equipment; and constructing laboratory instruments, such as a provisional dust-particle cabinet and nitrogen generator apparatus. Total cost applied for the entire set up and construction of the Ryerson University bioassay laboratory was $\$ 17354.34$. 
Capital costs of constructing a bioassay laboratory are listed in Table 7. At Ryerson University, some equipment was available for use, but was dated and in need of maintenance. The two major costs for this project are described below.

Table 7. Capital cost comparison of laboratories.

\begin{tabular}{|c|c|c|c|c|}
\hline Equipment & Type & MOE & Type & $\begin{array}{c}\text { Ryerson } \\
\text { University }\end{array}$ \\
\hline $\begin{array}{l}\text { Benchtop } \\
\text { Centrifuge }\end{array}$ & $\begin{array}{ll}\text { Sorvall Legend } \\
\text { RT }\end{array}$ & $\$ 15955$ & $\begin{array}{l}\text { Valuspin } \\
\text { Vulcon } \\
\text { Technologies } \\
\end{array}$ & $\$ 299 *$ \\
\hline Repeator Pipettor & $\begin{array}{l}\text { Eppendorf } \\
\text { Repeator Pipettor } \\
4 \times 10 \mathrm{~mL} \text { Tip } \\
2 \times 50 \mathrm{~mL} \text { Tip }\end{array}$ & $\begin{array}{l}\$ 492 \\
\$ 107 \times 4 \\
\$ 132 \times 2\end{array}$ & $\begin{array}{l}\text { Eppendorf } \\
\text { Repeator } \\
\text { Pipettor } \\
4 \times 10 \mathrm{~mL} \text { Tip } \\
2 \times 50 \mathrm{~mL} \text { Tip }\end{array}$ & $\begin{array}{l}\$ 492^{*} \\
\$ 107 \times 4^{*} \\
\$ 132 \times 2^{*}\end{array}$ \\
\hline Nitrogen Generator & $\begin{array}{l}\text { Parker Balston } \\
\text { Nitrovap System }\end{array}$ & $\$ 11174$ & $\begin{array}{l}\text { Parker Nitroflow } \\
\text { Lab }\end{array}$ & $\$ 14995$ \\
\hline $\begin{array}{l}\text { Positive } \\
\text { Displacement } \\
\text { Microdispensers }\end{array}$ & $\begin{array}{l}\text { Drummond } \\
25 \mathrm{~mL} \\
2 \times 50 \mathrm{~mL} \\
2 \times 100 \mathrm{~mL}\end{array}$ & $\begin{array}{l}\$ 794.17 \\
\$ 794.17 \times 2 \\
\$ 794.17 \times 2 \\
\end{array}$ & $\begin{array}{l}\text { Drummond } \\
25 \mathrm{~mL} \\
2 \times 50 \mathrm{~mL} \\
2 \times 100 \mathrm{~mL}\end{array}$ & $\begin{array}{l}\$ 794.17 * \\
\$ 794.17 \times 2 * \\
\$ 794.17 \times 2 *\end{array}$ \\
\hline $\begin{array}{l}\text { Sample } \\
\text { Evaporation } \\
\text { System }\end{array}$ & $\begin{array}{ll}\text { Labnet } & \text { Digital } \\
\text { Dry Bath } & \\
2 \quad x & \text { Heating } \\
\text { Blocks } & \end{array}$ & $\begin{array}{l}\$ 480 \\
\$ 117.17 \times 2\end{array}$ & $\begin{array}{lr}\text { Labnet } & \text { Digital } \\
\text { Dry Bath } & \\
2 \quad \mathrm{x} & \text { Heating } \\
\text { Blocks } & \end{array}$ & $\begin{array}{l}\$ 480 \\
\$ 117.17 \times 2\end{array}$ \\
\hline Shaker & $\begin{array}{l}\text { Gas-Col Rugged } \\
\text { Rotator }\end{array}$ & $\$ 1206.05$ & $\begin{array}{l}\text { Rocker Platform } \\
\text { Bellco Glass Inc. }\end{array}$ & $\$ 713^{*}$ \\
\hline Spectrophotometer & $\begin{array}{lr}\text { Abraxis } & \text { LCC } \\
\text { model } & \text { no. } \\
108921-500 & \\
\end{array}$ & $\$ 5132$ & $\begin{array}{l}\text { Artel Inc. Model } \\
\text { DP }\end{array}$ & $\$ 1395$ \\
\hline $\begin{array}{l}\text { Top-loading } \\
\text { balance }\end{array}$ & $\begin{array}{l}\text { Explorer Pro } \\
\text { Ohaus EP2102C }\end{array}$ & $\$ 1900$ & $\begin{array}{l}\text { Explorer } \quad \text { Pro } \\
\text { Ohaus EP2102C }\end{array}$ & $\$ 1900^{*}$ \\
\hline Vortex Mixer & $\begin{array}{l}\text { ThermoScientific } \\
\text { MaxiMix } \\
\text { Labnet VX-100 }\end{array}$ & $\begin{array}{l}\$ 471.80 \\
\$ 290.20\end{array}$ & $\begin{array}{l}\text { ThermoScientific } \\
\text { MaxiMix }\end{array}$ & \$ 471.80* \\
\hline & & & $\begin{array}{l}\text { Provisional Dust } \\
\text { Particle Cabinet }\end{array}$ & $\$ 250$ \\
\hline Total: & & $\$ 41934.39$ & & $\$ 25892.99$ \\
\hline \multicolumn{3}{|c|}{ Total Costs Applied in this case study: } & & $\$ 17354.34$ \\
\hline
\end{tabular}

* Indicate instruments that were borrowed for experimentation. Costs were not incorporated into the total costs applied. 
Preliminary tests, which ran standards only, illustrated a need for a specific type of photometer that was capable of reading the specially engineered ELISA tubes. One major barrier encountered was that these tubes were not adaptable to generic multi-use photometers set at $450 \mathrm{~nm}$. The size and shape of ELISA tubes were too short to insert into two different photometers tested (Thermo Scientific Spectronic 20D+ and Thermo Scientific Genesys 10UV) and too small to refract and disperse the incoming beam of light. No results could be produced using these instruments. As a result, a photometer was manufactured specifically for these tubes and was purchased from Artel Inc. for approximately $\$ 1400$. This was one of the major capital costs attributed to this set up and was required for analysis of all samples.

The second major cost applied at the Ryerson University laboratory was the purchase of a nitrogen generator system required for solvent exchange and concentrating samples for analysis. This instrument is necessary for all experiments. As the cost for an instrument of this nature can be quite large, the laboratory employed a pre-owned system from Parker Balston. This system was more expensive than the one used at the OMOE. The Parker Balston Nitrovap System used at the OMOE is a non-electrical unit; however, requires the application of an existing external compressed air utility that are specifically built into many well established and permanent laboratories. As the space at Ryerson University does not have this infrastructure, the Parker NitroflowLab system was purchased. This unit is completely portable and only requires an electrical input. Despite being the more expensive option, this unit may be used in any type of facility that does not have access to permanent infrastructure; it also retains the qualities of being 
completely portable and transferable. This was the largest cost for the initiation of a bioassay laboratory; however, was a required piece of equipment needed for all experiments. The cost of the Nitroflow Lab system was \$14 995.

The construction of a provisional particle-dust cabinet had some successes in eliminating cross-contamination of dust. Prior to laboratory optimization, samples prepared and analyzed in the fume hood underwent a strong ventilation system that would re-circulate settled dust causing high levels of background contamination.

To illustrate the comparison of the background effect caused by the strong ventilation system, standards were created by diluting known amounts of pure crystalline TCDD in nonane, into $1 \mathrm{~mL}$ of toluene and $62.5 \mu \mathrm{L}$ Triton-X keeper, and compared to before and after the installation of a provisional particle-dust cabinet. Different concentrations were tested $\left(0 \operatorname{pgTEQg}^{-1}, 1.6 \operatorname{pgTEQg}^{-1}, 3.2 \operatorname{pgTEQg}^{-1}, 6.25 \operatorname{pgTEQg}^{-1}, 10\right.$ pgTEQg $^{-1}, 12$ $\operatorname{pgTEQg}^{-1}, 31.2 \mathrm{pgTEQg}^{-1}, 50 \mathrm{pgTEQg}^{-1}$, and $\left.100 \mathrm{pgTEQg}^{-1}\right)$. Samples were fully evaporated under a pure stream of nitrogen without the dust-particle cabinet (nonoptimal) and with the particle dust cabinet (optimal).

Samples conducted prior to laboratory optimization illustrated inconsistent and unreliable results below the $10 \mathrm{pgTEQg}^{-1}$ concentration range (Table 8). An upward bias had occurred, causing the sample concentration to be anywhere between two times to six times higher than expected. This was attributed to two main possibilities: (i) past projects conducted in the laboratory had left behind vast remnants of dust; and (ii) the fume hood 
being utilized had a heavy ventilation vacuum that allowed settled particulate to redistributed back into the air. Subsequent to laboratory optimization, crosscontamination was greatly reduced to produce results similar to those produced at the OMOE. The improvised particle-dust cabinet was successful in reducing the recirculation effect, while still maintaining the safety of a chemical fume hood to produce consistent and expected results.

Table 8. Recovery of ELISA standards prior to and post optimization.

\begin{tabular}{|c|c|c|c|}
\hline$\#$ & $\begin{array}{c}\text { Expected } \\
\text { Amount } \\
(\mathbf{p g})\end{array}$ & Recovery Before Optimization & Recovery After Optimization \\
\hline 1 & 0 & $239 \%$ & $0 \%$ \\
\hline 2 & 1.6 & $596 \%$ & - \\
\hline 3 & 3.12 & $0 \%$ & $80.0 \%$ \\
\hline 4 & 6.25 & $177 \%$ & $101.4 \%$ \\
\hline 5 & 10 & $569.5 \%$ & - \\
\hline 6 & 12.5 & - & $110.8 \%$ \\
\hline 7 & 25 & - & $95.7 \%$ \\
\hline 8 & 31.2 & $82 \%$ & - \\
\hline 9 & 50 & - & $103.8 \%$ \\
\hline 10 & 100 & $102 \%$ & $106.26 \%$ \\
\hline
\end{tabular}

* Dashes indicate standards that were not used during experimental run

The plan to establish a minimally resourced laboratory was deemed successful. Not only was the laboratory able to reproduce results similar to those produced at a fully resourced laboratory (OMOE); it was able to be initiated, constructed and operative within one year and within half the cost. Initiation and execution also used minimal staff with the employment of a maximum of two full-time staff at one time. Knowledge transfer was able to occur for technicians who had a minimum of a Bachelors of Science in a matter of weeks and were able to reproduce results similar to those conducted by a technician who had been practicing the methodology for a number of years. This plan for a bioassay 
laboratory is highly feasible for under-resourced areas, which can establish a high throughput dioxin laboratory for as low as $\$ 25000$ within a one year timeframe.

\subsection{Optimal Bioassay Laboratory Conditions and Laboratory Portability}

A list of optimal equipment for dioxin sample analysis in soil and sediment are listed in Table 9. The total cost for equipping an optimized laboratory (without labor costs) is approximately $\$ 60000$. This is a hundred times less than the estimated costs of a fully resource GC-HRMS laboratory quoted at $\$ 6.75$ million (USD) (Devlin-Foltz and Hoppes, 2010).

\subsubsection{Optimal Conditions for a Stationary Laboratory}

Conditions should be considered when constructing a stationary bioassay laboratory for the use of analyzing dioxins in soil and sediment. When possible, laboratories should be contained within one medium sized (approximately 600 square foot) laboratory, preferably located on the uppermost level of a building, isolated from considerable exterior traffic activity. Having the laboratory located on the top floor of a building would reduce the length of the fume hood exhaust, as well as reduce dust contamination that is increased at lower levels. When possible, traffic should be controlled as to not redistribute settled dust back into the testing condition environment. Making the room accessible only to authorized technicians could control this. The area should be cleaned daily to contain dust conditions by wiping all surfaces with an all-purpose cleaner. 
All sample preparation and analysis equipment should ideally be contained in one room. This laboratory should include a refrigerator designated only for dioxin sample containment as well as a running water system in which a reverse osmosis water purifier could be applied. Stationary laboratories may also consider using areas with an existing compressed air utility, as this would make purchasing a nitrogen generator system more cost effective, as the portable alternative would not be necessary. Large bench tops would be advantageous as they would be capable of accommodating large footprint equipment such as a refrigerated bench top centrifuge. Having a refrigerated bench top centrifuge capable of accommodating both $50 \mathrm{~mL}$ and $15 \mathrm{~mL}$ centrifuge tubes, located on the same lab bench used for ELISA analysis would ease a technicians analysis capabilities, as time would not be spent travelling back to the centrifuge during timesensitive applications.

All glassware, reagents and bottles should be sealed with aluminum foil and have sufficient space to be stored. Consideration of having separate airtight containers to store glassware would also assist in organizing the laboratory. Separate waste containers should also be made available for the containment of organic, acid, plastic and glass waste.

A separate small room should be considered, designated for soil homogenization only. As the practice of soil homogenization creates transient soil dust and particulate matter, having a separate area for the homogenization procedure would reduce potential cross contamination of ELISA analysis. 
Table 9. Optimized equipment, specifications and costs.

\begin{tabular}{|c|c|c|}
\hline Equipment & $\begin{array}{l}\text { Recommended Product Name and } \\
\text { Specifications }\end{array}$ & Costs \\
\hline Fume Hood & $\begin{array}{l}\text { Specifications: } \\
6 \text { foot exhaust fume hood } \\
61 \text { "W x } 26 " \mathrm{~S} \times 26 \text { × } \mathrm{H}\end{array}$ & $\$ 5000$ \\
\hline $\begin{array}{l}\text { Reverse Osmosis Water } \\
\text { Purifier }\end{array}$ & $\begin{array}{l}\text { Millipore Direct Q3 UV system } \\
\text { Specifications: } \\
\text { HPLC grade } \\
185 \text { and } 254 \mathrm{~nm} \text { UV lamp for production } \\
\text { of low TOC water } \\
\text { 10L of ultrapure water a day }\end{array}$ & $\$ 7000$ \\
\hline Benchtop Centrifuge & $\begin{array}{l}\text { Sorvall Legend RT } \\
\text { Specifications: } \\
\text { Speed Range - } 300-15,000 \\
\text { Temperature Range - }-9^{\circ} \mathrm{C} \text { to } 40^{\circ} \mathrm{C}, \mathrm{CFC}- \\
\text { free refrigerant } \\
\text { Standards - EN } 61010-1 \text {, EN } 61010-2- \\
020 \mathrm{CE} \text { marked, CSA approved } \\
\text { Electrical - } 120 \mathrm{~V}(60 \mathrm{~Hz}), 230 \mathrm{~V}(50 / 60 \\
\text { Hz) } \\
4 \text { x Buckets - } 7 \text { x } 50 \mathrm{ml} \text { disposable } \\
\text { conical tubes } \\
4 \text { x Buckets - } 17 \text { x } 15 \mathrm{ml} \text { disposable } \\
\text { conical tubes }\end{array}$ & $\$ 15955$ \\
\hline Repeator Pipettor & $\begin{array}{l}\text { Eppendorf Repeator Pipettor } \\
4 \times 10 \mathrm{~mL} \text { Tip } \\
2 \times 50 \mathrm{~mL} \text { Tip }\end{array}$ & $\begin{array}{l}\$ 492 \\
\$ 107 \times 4 \\
\$ 132 \times 2\end{array}$ \\
\hline Nitrogen Generator & $\begin{array}{l}\text { Parker Nitroflow Lab } \\
\text { Specifications: } \\
\text { Purity - } 99.5 \% \\
\text { Flow Rates - up to } 32 \mathrm{Ipm}\end{array}$ & $\$ 14995$ \\
\hline
\end{tabular}




\begin{tabular}{|c|c|c|}
\hline & $\begin{array}{l}\text { Delivery Pressure }-8 \text { bar } \\
\text { Outlet Connection }-1 / 4 \text { "' G } \\
\text { Electrical Requirements }-230 \text { VAC-50Hz } \\
\text { Power Consumption } 1400 \text { Watts } \\
\text { Dimensions }(\mathrm{HxWxD})- \\
\text { 700x310x900mm }\end{array}$ & \\
\hline $\begin{array}{l}\text { Positive Displacement } \\
\text { Microdispensers }\end{array}$ & $\begin{array}{l}\text { Drummond } \\
1 \times 25 \mathrm{~mL} \\
2 \times 50 \mathrm{~mL} \\
2 \times 100 \mathrm{~mL} \\
\end{array}$ & $\begin{array}{l}\$ 794.17 \\
\$ 794.17 \times 2 \\
\$ 794.17 \times 2 \\
\end{array}$ \\
\hline Sample Evaporation System & $\begin{array}{l}\text { Labnet Digital Dry Bath } \\
\text { Specifications: } \\
\text { Temperature range }-+5^{\circ} \mathrm{C} \text { to } 150^{\circ} \mathrm{C} \\
2 \times \text { Heating Blocks }\end{array}$ & $\$ 480$ \\
\hline Shaker & $\begin{array}{l}\text { Gas-Col Rugged Rotator } \\
\text { Specifications: } \\
\text { Speed Range }-2 \text { to } 83 \mathrm{rpm} \\
\end{array}$ & $\$ 1206.05$ \\
\hline Spectrophotometer & $\begin{array}{l}\text { Abraxis } L C C \text { model no. } 108921-500 \\
\text { Specifications: } \\
450 \mathrm{~nm} \text { interference filter } \\
\text { tube size }(12 \times 75 \mathrm{~mm}) \\
110 \text { Volts }\end{array}$ & $\$ 5132$ \\
\hline Top-loading balance & Explorer Pro Ohaus EP2102C & $\$ 1900$ \\
\hline Vortex Mixer & $\begin{array}{l}\text { ThermoScientific MaxiMixI } \\
\text { Specifications: } \\
\text { Speed Range }-3000 \text { rpm } \\
\text { Tube Capacity }-1 \text { to } 4 \\
\text { Labnet VX-100 } \\
\text { Specifications: } \\
\text { Speed Range }-0-3400 \text { rpm } \\
\text { Operating modes }- \text { tough or continuous }\end{array}$ & $\begin{array}{l}\$ 471.80 \\
\$ 290.20\end{array}$ \\
\hline
\end{tabular}




\subsubsection{Optimal Conditions for a Portable Laboratory}

All of the equipment used for the case study at Ryerson University can be installed and applied to a mobile unit. A portable laboratory would allow for dioxin testing to be brought directly to a contaminated site and allow for ELISA to be utilized in a more versatile, accessible and efficient means. Mobile labs can be transported and or dropshipped at specific research locations, or integrated into an existing lab facility for temporary capabilities. Portable laboratory trailers can be designed for on-site environmental testing which would be advantageous as analysis of dioxins in soil and sediment can be adapted as concentration gradients are elucidated. Equipment listed in Table 9 all have portable specifications that are only dependent on an electrical application that can be accessed through an attached generator.

As with the Ryerson University laboratory, HPLC grade water does not have to be accessible at all times. Canteens of HPLC grade water can be kept on-site as this is not necessary for every application. Necessary requirements for a portable laboratory for ELISA analysis are a fume hood, chemical resistant work-surfaces and electric generator.

The benefit of expanding this technology into a completely portable analysis system would be that the ELISA would be capable of being brought directly on to a contaminated site. This is not feasible with the instrumentation required for GC-HRMS. Sampling and sample processing would be able to be conducted simultaneously, and sample procurement can be adjusted directly to more accurately map a contaminated site. By having the accessibility to test and sample at the same site, a more precise 
determination of where samples should be taken can be determined, with areas of high concentrations having a greater emphasis in sample processing. Mapping dioxin samples on-site would also allow for flexibility and more strategic sampling to find the potential source of contamination. Portable analysis and on-site testing would not be feasible with GC-HRMS due to the magnitude, cost and sensitivity of the equipment involved. 


\section{APPLICATION}

\subsection{Application of ELISA in Marginalized Economies}

As the initiation, execution and optimization of a full scale bioassay laboratory with limited resources and a finite budget have shown feasible and successful results; it is recommended that this model be applied to marginalized economies and developed countries to aid in evaluating dioxin-contaminated areas worldwide. Affordable means of detection for dioxin-contaminated areas have been deemed as the limiting factor towards clean up in marginalized areas of the world, which as determined previously, are in no short supply of contaminated sites.

A primary example of where this methodology would likely be successful and highly impactful is in Vietnam. As stated earlier, Vietnam is one of the most devastated and impacted countries contaminated with dioxins and furans in the world. The need for detection of highly contaminated areas and affordable testing would be able to provide some protection for up to 3 to 7 million people (Nguyen, 2009). Dwernychuk (2005) describes several highly contaminated areas existing in Vietnam, and that a focus should be implemented on analyzing areas around former abandoned United States army bases. Several of these areas were former Agent Orange storage sites that had undergone spills and leaks and whereby extensive spraying had occurred to clear the area. These areas have since been resettled by local communities, which have readapted the former infrastructure to use as part of their current community. This is problematic as these areas are now sites of concentrated human activity, which continues to compromise the health of many local communities with unknown risk to the human population (Dwernychuk, 2005). 
Currently, there is a budget being proposed to build a $\$ 6.75$ million dollar (USD) stateof-the-art Vietnam Persistent Organic Pollutants Laboratory in Hanoi (Devlin-Foltz and Hoppes, 2010); which would allow for the country to analyze samples in house rather than outsourcing to laboratories in countries where GC-HRMS is available. A large part of this budget is allocated towards the purchase of GC-HRMS instrumentation. This is a significant budget being put forth towards environmental testing of organic pollutants and is capable of incorporating several moderately resourced bioassay laboratories in comparison to one GC-HRMS laboratory. With such an extensive budget, multiple bioassay laboratories may be initiated on-site of contaminated areas so that a backlog of sample processing and a reliance on the one GC-HRMS instrument in Vietnam is not induced as seen in several examples beforehand. Highly contaminated areas for soil and sediment samples could be detected within a short time frame, and resources could be saved and designated towards remediating these areas or providing safe alternatives to those most affected.

By creating a portable and transferrable laboratory system in marginalized areas, one can mobilize at least eighteen marginalized countries immediately to begin processing and detecting contaminated sites locally. As illustrated in Chapter 1, the demand for analysis worldwide would immediately empower at least eighteen countries if applied, and this does not include developed economies in need for environmental testing. As an alternative to increasing wait times, off loading sample analysis responsibility, and creating a financial dependency on well-established countries; marginalized and transient economies could apply this model and begin analysis with an affordable and achievable 
budget. With the cost of establishing a GC-HRMS laboratory averaging a few millions of dollars, an ELISA laboratory has shown to be a feasible, affordable and sustainable alternative that is able to provide similar results with a mere fraction of the cost.

\subsection{Application of ELISA in Developed Economies}

Coming full circle, it can also be justified that more environmental testing is required here in Canada. The likelihood that it will be ever increasing in the nearby future is evident with the recent release of several investigative reports conducted by the Toronto Star and the Globe and Mail. On February $28^{\text {th }}, 2011$, the Globe and Mail distributed the article, "Agent Orange used widely in Ontario over decades, Minister says," which described how Agent Orange was heavily used for more than three decades in many provinces and territories in Canada (Babbage, 2011). The article goes on to describe how there was no ban on Agent Orange in Canada until 1985 and that it was widely used by Hydro One, then Ontario Hydro, to clear way for transmission lines from 1950-1979 across Ontario. The Toronto Star's investigative report discussed how this is not just an issue faced by Hydro One; however, Agent Orange was also used by the Ministry of Transportation to clear roadsides and that a governmental probe conducted by the Ministry of Natural Resources is also widening its approach to include several municipalities as well as the Ministry of Agriculture (Zlomislic and Talaga, 2011).

An independent Fact Finding Panel has been constructed with the responsibilities to report the following to the public by the fall of 2012 (MacNeil, 2011). The responsibilities are to: 
- Investigate and document the scope and scale of the use of 2,4,5-T herbicide in the province by Ontario government ministries and agencies, including those acting as agents or as contractors.

- Determine the specific time period when 2,4,5-T was used in the province by Ontario government ministries and agencies.

- Determine the geographic area where 2,4,5-T herbicide was used in the province by Ontario government ministries and agencies.

- Examine whether exposure to 2,4,5-T herbicide in the affected areas may have potential health impacts.

- Document the methods 2,4,5-T herbicide was deployed by employees of provincial ministries and agencies, and the interaction of those employees and the general public with 2,4,5-T herbicide application operations in affected areas.

- Review the preparation, application and storage of 2,4,5-T herbicide as well as provincial occupational health and safety, and laws, standards and workplace practices including the use of personal protection equipment and applicable training.

- Referring, where appropriate, to the Workplace Safety and Insurance Board any findings that could assist its work.

The responsibilities and focus in this provincial probe are broadly defined. Under no responsibility within the Fact Finding Panel does it state that environmental testing will be conducted to determine whether past exposure to Agent Orange will be addressed. Focus of this probe appears to put the onus on mitigation of prior mistakes when an emphasis on further precautions and safeguarding should also be put into place at present. It is apparent that this dioxin-tainted herbicide was widely used across Canada. As the persistency and half-life of dioxin is unknown, it is likely that several of these areas may still pose a risk to the surrounding environment. With the population of Ontario almost tripling since the 1950s (Ontario Ministry of Finance [OMOF], 2010), it is unknown who may be at risk and to what severity. The bioassay plan should be suggested as an 
immediate detection method to be used by the Ministry of Natural Resources as part of the government wide probe to determine whether concentrations around targeted areas still pose a risk to the human population today. 


\section{CONCLUSIONS}

The findings of this thesis have illustrated that an uncertain dioxin-contaminated site can be characterized and mapped using the ELISA and that the ELISA is capable of producing a portable, feasible and low cost alternative for areas that cannot afford to employ a GC-HRMS laboratory. Correlation of a fully resourced laboratory and a minimally resourced laboratory that was optimized in less than a year, showed a strong correlation $\left(n=13, r^{2}=0.888\right.$, slope $\left.=0.87\right)$.

A concentration site map illustrated that the ELISA introduced into a new setting with minimal financial backing and dated resource was able to determine and map a contaminated site, producing similar concentration ranges as a fully resourced laboratory. Similar concentration patters and concentration spatial trends of the two laboratories also confirmed this.

The ELISA results obtained from the Welland site were accepted by the OMOT to assist in the biannual update for the Federal Contaminated Sites Inventory. With that, it can be deemed that the ELISA poses as a promising, sustainable, low cost alternative to be used on dioxin-contaminated sites in comparison to GC-HRMS in Canada.

With these successes, it should also be mentioned that by thoroughly screening a site and plotting a strategic sampling grid, the ELISA could begin to be seen as a potential source identifier for contamination. This was considered as the capital costs of building a laboratory and the cost of analysis per sample, were a mere fraction of that of GC- 
HRMS; and by analyzing more samples with the prospect of producing a pattern, may give explanation as to what the source of contamination might have been. This allows the ELISA to be more than a screening tool to determine if a site is dioxin-positive or dioxin-negative. This was seen in this case study, as the hypothesized suspect source of contamination, the contaminated borehole, illustrated no greater response in dioxin concentration than other areas of the sampling site. A concentration gradient was seen that projected concentrations being greatest in the south and moving north. It was then hypothesized that the contamination source likely occurred south of the site, and potentially transpired from either the use of coal-fuelled trains in the past, PCP-treated wood used as rail ties, or the use of Agent Orange to spray way for infrastructure.

The methodology of ELISA was deemed robust enough to be reproducible with underresourced spaces and equipment. Minimal requirements were necessary to produce an operational laboratory in under a year. To add to these successes, it was determined that this model may be used in provisional situations with capital costs averaging approximately \$25 000 with a one-year commitment for initiation and execution. The success of a minimally resourced laboratory was achieved as capital costs for initiation were half that of a fully resourced laboratory. 


\section{RECOMMENDATIONS}

Based on the success of the implementation of a bioassay plan at Ryerson University, it is recommended that the bioassay lab at Ryerson University be used to detect several contaminated areas located within Ontario and the Greater Toronto Area that have now been suggested to be dioxin positive due to mass spraying of Agent Orange in the 1950s, 1960s and 1970s. The current government-wide probe (MacNeil, 2011)is an indication that there are likely several undetected areas worth investigating, which are currently not included in the Federal Contaminated Sites Inventory (CCME, 2008). It is recommended that Ryerson University be used as a hub to detect for these areas, and be used to lessen government reliance on screening and detection with GC-HRMS. Ryerson University as a fully functional bioassay laboratory has the potential to detect and contribute new contaminated sites that should be flagged under the Federal Contaminated Sites Inventory and alternatively, be used to detect areas already flagged in the inventory where more information is required. Sites that have been thoroughly analyzed by ELISA at Ryerson University, that illustrate no threat to human health and the environment may then be delisted similarly to the actions put forth for the site used in this study.

A second recommendation would be to continue to optimize the laboratory at Ryerson University by, when feasible, purchasing more efficient equipment to increase the sensitivity of the procedure. One place to start would be purchasing a more efficient rotator to improve the level of extraction of the sample. Once this is achieved in soil samples, other matrixes should be explored such as sediment, vegetation and foods. 
As it was suggested in this study, the contribution of dioxin emissions from coal-fuelled trains may be an issue worth investigating. From the results illustrated from the Welland Site, there is a strong indication that past activities from the train track may have been the cause for dioxin contamination in this area. Currently there is no literature on dioxin emissions from coal-fuelled trains, which may be worth investigating.

Lastly, a final recommendation would be to solicit and encourage marginalized economies and transitional economies to use this plan as a model to implement a bioassay laboratory as a domestic and primary source of analysis within these countries. There are many advantages to this. Not only would this assist in several countries in working towards their Parties' implementation plan under the Stockholm Convention; it would also mobilize and give agency towards these countries economies. Implementing inhouse analysis rather than exporting to another country would create jobs and resources locally, as well as provide a feasible form of knowledge transfer. Making detection more accessible and available to areas would increase awareness amongst communities about health issues related to dioxins and furans, and allow for greater engagement and empowerment to those left victim to this legacy. 


\section{APPENDIXES}

Appendix A - Comparison of analytical methods used to detect of dioxins.

\begin{tabular}{|c|c|c|c|}
\hline Paper & $\begin{array}{l}\text { Environmental } \\
\text { Matrix }\end{array}$ & Method & $\begin{array}{l}\text { LOD* or }^{*} \\
\text { MDL** }\end{array}$ \\
\hline $\begin{array}{l}\text { Chuang, J. C., Van Emon, J. M., and Schrock, M. E. } \\
\text { (2009) }\end{array}$ & Soil and Sediment & ELISA & $\begin{array}{l}\mathrm{MDL}=10 \mathrm{pg} / \mathrm{g} \\
(\mathrm{ppt})\end{array}$ \\
\hline Elijarrate, E., and Barcelo, D. (2002) & $\mathrm{N} / \mathrm{A}$ & $\begin{array}{l}\text { Low Resolution-Mass } \\
\text { Spectrometry (LRMS) } \\
\text { High Resolution Mass } \\
\text { Spectrometry (HRMS) } \\
\text { Tandem Mass Spectrometry } \\
\text { (MS/MS) } \\
\text { Time-of-Flight Mass } \\
\text { Spectrometry (TOF) }\end{array}$ & $\begin{array}{l}\text { Low-pg range } \\
\text { MDL=0.003 } \\
\text { pg (TCDD) } \\
\text { MDL=0.2-0.6 } \\
\text { pg (TCDD) }\end{array}$ \\
\hline $\begin{array}{l}\text { Haglund, P., Sporring, S., Wilberg, K., and Bjorklund, E. } \\
\text { (2007) }\end{array}$ & Fish and Fish Oil & HRGC-HRMS & $\begin{array}{l}\mathrm{LOD}=2.4-2.8 \\
\mathrm{pg} / \mathrm{g}(\mathrm{ppt})\end{array}$ \\
\hline $\begin{array}{l}\text { Haglund, P., Korytar, P., Danielsson, C., Diaz, J., Wiberg, } \\
\text { K., Leonards, P., Brinkman, U. A. T., and de Boer, J. } \\
(2008)\end{array}$ & Food and Feed & $\begin{array}{l}\text { Comprehensive Two-Dimensional } \\
\text { GC-Micro Electron Capture } \\
\text { Detection (GCxGC-uECD) }\end{array}$ & $\begin{array}{l}\mathrm{LOD}=0.5 \mathrm{pg} / \mathrm{g} \\
(\mathrm{ppt})\end{array}$ \\
\hline $\begin{array}{l}\text { Helen, C., Lemasle, M., Laplanche, A., and Genin, E. } \\
(2001)\end{array}$ & $\mathrm{N} / \mathrm{A}$ & HRGC/MS/MS & $\begin{array}{l}\mathrm{MDL}=1 \\
\mathrm{pg} / \mathrm{mL} \text { (tetra- } \\
\text { hepta-CDD/Fs) } \\
=1 \mathrm{ng} / \mathrm{g}\end{array}$ \\
\hline
\end{tabular}




\begin{tabular}{|c|c|c|c|}
\hline & & $\mathrm{HRGC} / \mathrm{MS}^{3}$ & $\begin{array}{l}\mathrm{MDL}=5 \\
\mathrm{pg} / \mathrm{mL} \\
(\mathrm{OCDD} / \mathrm{F}) \\
=5 \mathrm{ng} / \mathrm{g}\end{array}$ \\
\hline $\begin{array}{l}\text { Hoh, E., Lehotay, S. J., Mastovska, K., and Huwe, J. K. } \\
\text { (2008) }\end{array}$ & Fish Oil & $\begin{array}{l}\text { Direct Sample Introduction } \\
\text { coupled to 2D GC/Time-of-Flight } \\
\text { MS (DSI-GCxGC/TOF-MS) }\end{array}$ & $\begin{array}{l}\text { LOQ }=0.019- \\
7.8 \mathrm{pg} / \mathrm{g} \text { TEQ } \\
(\mathrm{ppt})\end{array}$ \\
\hline Kishida, M., Maekawa, T., and Bandow, H. (2010) & Soil and Sediment & HRGC-HRMS & $\begin{array}{l}\mathrm{MDL}=0.12- \\
0.56 \mathrm{pg} / \mathrm{g}(\mathrm{ppt})\end{array}$ \\
\hline Kleinhenz, S., Jira, W., and Schwind, K. H. (2006) & Food & HRGC-HRMS & $\begin{array}{l}\mathrm{LOQ}=0.1 \mathrm{ng} \\
\mathrm{TEQ} / \mathrm{kg}(\mathrm{ppt})\end{array}$ \\
\hline $\begin{array}{l}\text { Korytar, P., Danielsson, C., Leonards, P. E. G., Haglund, } \\
\text { P., de Boer, J., and Brinkman, U. A. T. (2004) }\end{array}$ & Milk & $\begin{array}{l}\text { Two Dimensional Gas } \\
\text { Chromatography with Electron- } \\
\text { Capture Detection (GCxGC with } \\
\text { ECD) }\end{array}$ & $\begin{array}{l}\mathrm{LOD}=30-150 \\
\mathrm{fg}\end{array}$ \\
\hline $\begin{array}{l}\text { Malavia, J., Abalos, M., Santos, F. J., Abad, E., Rivera, J., } \\
\text { and Galceran, M. T. (2007) }\end{array}$ & Vegetable Oil & $\begin{array}{l}\text { Gas Chromatography-Ion Trap } \\
\text { Tandem Mass Spectrometry (GC- } \\
\text { MS-MS) }\end{array}$ & $\begin{array}{l}\mathrm{LOD}=0.04-0.2 \\
\mathrm{pg} / \mathrm{g}(\mathrm{ppt})\end{array}$ \\
\hline $\begin{array}{l}\text { Malavia, J., Abalos, M., Santos, F. J., Abad, E., Rivera, J., } \\
\text { and Galceran, M. T. (2007) }\end{array}$ & Food & $\begin{array}{l}\text { Ion-trap Tandem Mass } \\
\text { Spectrometry (GC/ITMS/MS) }\end{array}$ & $\begin{array}{l}\mathrm{LOD}=0.1-0.93 \\
\mathrm{pg} / \mathrm{g}(\mathrm{ppt})\end{array}$ \\
\hline $\begin{array}{l}\text { March, R. E., Splendore, M., Reiner, E. J., Mercer, R. S., } \\
\text { Plomley, J. B., Waddell, D. S., MacPherson, K. A. (2000) }\end{array}$ & $\mathrm{N} / \mathrm{A}$ & $\begin{array}{l}\text { HRMS } \\
\text { QIT (quadrupole ion trap) } \\
\text { TSQ (triple - stage quadrupole) }\end{array}$ & $\begin{array}{l}\mathrm{LOD}=10 \\
\mathrm{fg} / \mathrm{mL} \\
\mathrm{LOD}=100 \\
\mathrm{fg} / \mathrm{mL} \\
\mathrm{LOD}=150 \\
\mathrm{fg} / \mathrm{mL}\end{array}$ \\
\hline Miyawaki, T., Kawashima, A., and Honda, K. (2008) & Soil and Sediment & HRGC-HRMS & $\begin{array}{l}\mathrm{LOD}=0.3-10 \\
\mathrm{pg} / \mathrm{g}(\mathrm{ppt})\end{array}$ \\
\hline $\begin{array}{l}\text { Popp, P., Keil, P., Moder, M., Paschke, A., and Thuss, U. } \\
\text { (1997) }\end{array}$ & Solid Waste & $\begin{array}{l}\text { GC-MS (Finnigan MAT } 95 \text { mass } \\
\text { spectrometer) }\end{array}$ & Unstated \\
\hline
\end{tabular}




\begin{tabular}{|l|l|l|l|}
\hline Schrock, M., Dindal, A., and Billets, S. (2009) & Soil and Sediment & $\begin{array}{l}\text { Upper } \\
\text { calibration } \\
\text { limits of: } \\
0.4 \mathrm{ng} / \mathrm{g}(\mathrm{ppb})\end{array}$ \\
\hline $\begin{array}{l}\text { Trindade, M., Nording, M., Nichkova, M., Spinnel, E., } \\
\text { Haglund, P., Last, M. S., et al. (2008) }\end{array}$ & Soil & ELISA & $\begin{array}{l}\text { LOD=10.9pg/ } \\
\mathrm{mL}(\mathrm{ppt})\end{array}$ \\
\hline Van Leeuwen, S. P. J. and de Boer, J. (2008) & N/A & $\begin{array}{l}\text { Electron Capture Negative } \\
\text { Ionization-Low Resolution Mass } \\
\text { Spectrometry (ECNI-LRMS) }\end{array}$ & $\begin{array}{l}\text { LOD }=10-110 \\
\text { fg }\end{array}$ \\
\hline
\end{tabular}

*LOD - limit of detection, the smallest amount or concentration of an analyte in a sample that can be reliably distinguished from zero.

** MDL - the minimum concentration of analyte that can be reported with $99 \%$ confidence that the analyte is greater than zero 
Appendix B - High priority PCDD/F contaminated sites located in Ontario.

\begin{tabular}{|c|c|c|c|c|c|c|}
\hline & Region & $\begin{array}{l}\text { FCSI Identifier/ } \\
\text { Site Name } \\
\end{array}$ & $\begin{array}{c}\text { Reporting } \\
\text { Organization } \\
\end{array}$ & Media Type & Status & Classification \\
\hline 1 & Whitby, ON & $\begin{array}{c}00022940 \\
\text { Historical Inlet }\end{array}$ & $\begin{array}{l}\text { Department of } \\
\text { Fisheries and } \\
\text { Oceans }\end{array}$ & $\begin{array}{l}\text { Groundwater } \\
\text { Soil } \\
\text { Subsurface } \\
\text { Soil }\end{array}$ & $\begin{array}{l}\text { Historical Review/ Initial } \\
\text { Testing Underway }\end{array}$ & Historical Review \\
\hline 2 & Whitby, ON & $\begin{array}{c}00022941 \\
\text { Shoreline extension }\end{array}$ & $\begin{array}{l}\text { Department of } \\
\text { Fisheries and } \\
\text { Oceans }\end{array}$ & $\begin{array}{l}\text { Groundwater } \\
\text { Soil } \\
\text { Subsurface } \\
\text { Soil }\end{array}$ & $\begin{array}{l}\text { Historical Review/ Initial } \\
\text { Testing Underway }\end{array}$ & Historical Review \\
\hline 3 & $\begin{array}{l}\text { Thorold, } \\
\text { ON }\end{array}$ & $\begin{array}{c}10352004 \\
\text { Welland Canal }\end{array}$ & $\begin{array}{l}\text { Ministry of } \\
\text { Transportation }\end{array}$ & Soil & $\begin{array}{c}\text { Develop Remediation/ } \\
\text { Risk Management Strategy }\end{array}$ & Insufficient Data \\
\hline 4 & $\begin{array}{l}\text { Niagara-on- } \\
\text { the-Lake }\end{array}$ & $\begin{array}{c}10389001 \\
\text { Rifle Range } \\
\text { Former Dump } \\
\end{array}$ & $\begin{array}{c}\text { Department of } \\
\text { National Defence }\end{array}$ & $\begin{array}{l}\text { Groundwater } \\
\text { Soil }\end{array}$ & $\begin{array}{c}\text { Detailed Testing } \\
\text { Complete/ Remedial } \\
\text { action plan underway }\end{array}$ & Action Required \\
\hline 5 & $\begin{array}{c}\text { Lambton } \\
\text { Shores, ON }\end{array}$ & $\begin{array}{c}10829001 \\
\text { Camp Ipperwash }\end{array}$ & $\begin{array}{c}\text { Department of } \\
\text { National Defence }\end{array}$ & Soil & Initial Testing Underway & Historical Review \\
\hline 6 & Essa, ON & $\begin{array}{c}11022086 \\
\text { Fumigation Block }\end{array}$ & $\begin{array}{c}\text { Department of } \\
\text { National Defence }\end{array}$ & Soil & Initial Testing Program & Historical Review \\
\hline 7 & $\begin{array}{l}\text { Kingston, } \\
\text { ON }\end{array}$ & $\begin{array}{c}22905009 \\
\text { Kingston Harbour }\end{array}$ & $\begin{array}{c}\text { Ministry of } \\
\text { Transportation }\end{array}$ & Soil & $\begin{array}{c}\text { Initial Testing Completed/ } \\
\text { Detailed Testing } \\
\text { Underway }\end{array}$ & $\begin{array}{l}\text { High Priority for } \\
\text { Action }\end{array}$ \\
\hline 8 & $\begin{array}{c}\text { The } \\
\text { Archipelago } \\
\text {, ON }\end{array}$ & $\begin{array}{c}85124001 \\
\text { Vicinity of } \\
\text { Daymark-Metal }\end{array}$ & $\begin{array}{l}\text { Department of } \\
\text { Fisheries and } \\
\text { Oceans }\end{array}$ & Soil & $\begin{array}{c}\text { Initial Testing Complete/ } \\
\text { Detailed Testing } \\
\text { Underway }\end{array}$ & $\begin{array}{l}\text { Action likely } \\
\text { required }\end{array}$ \\
\hline
\end{tabular}




\section{Appendix C - Welland, Ontario site maps.}

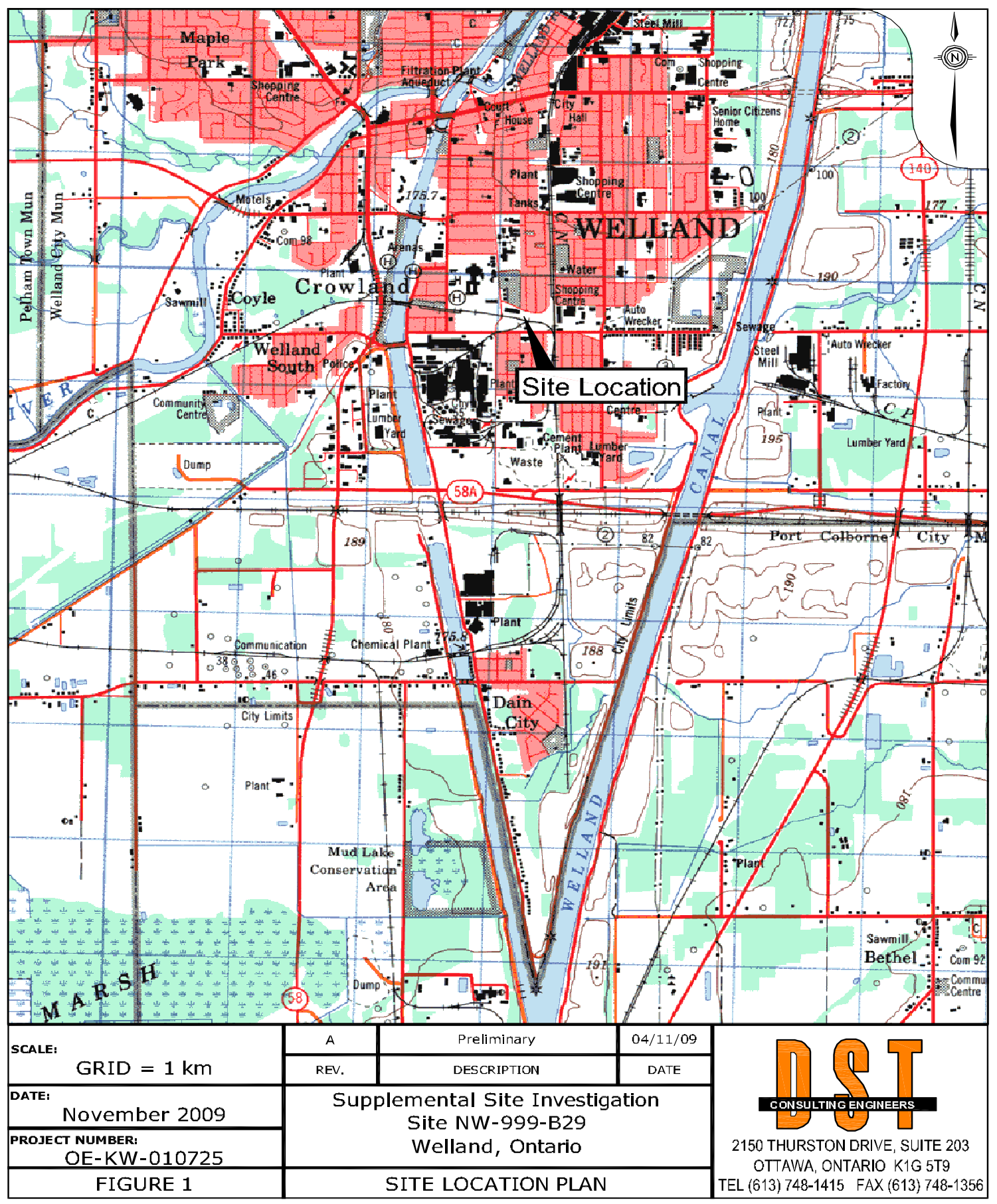

Source: OMOT personal communication, 2010 


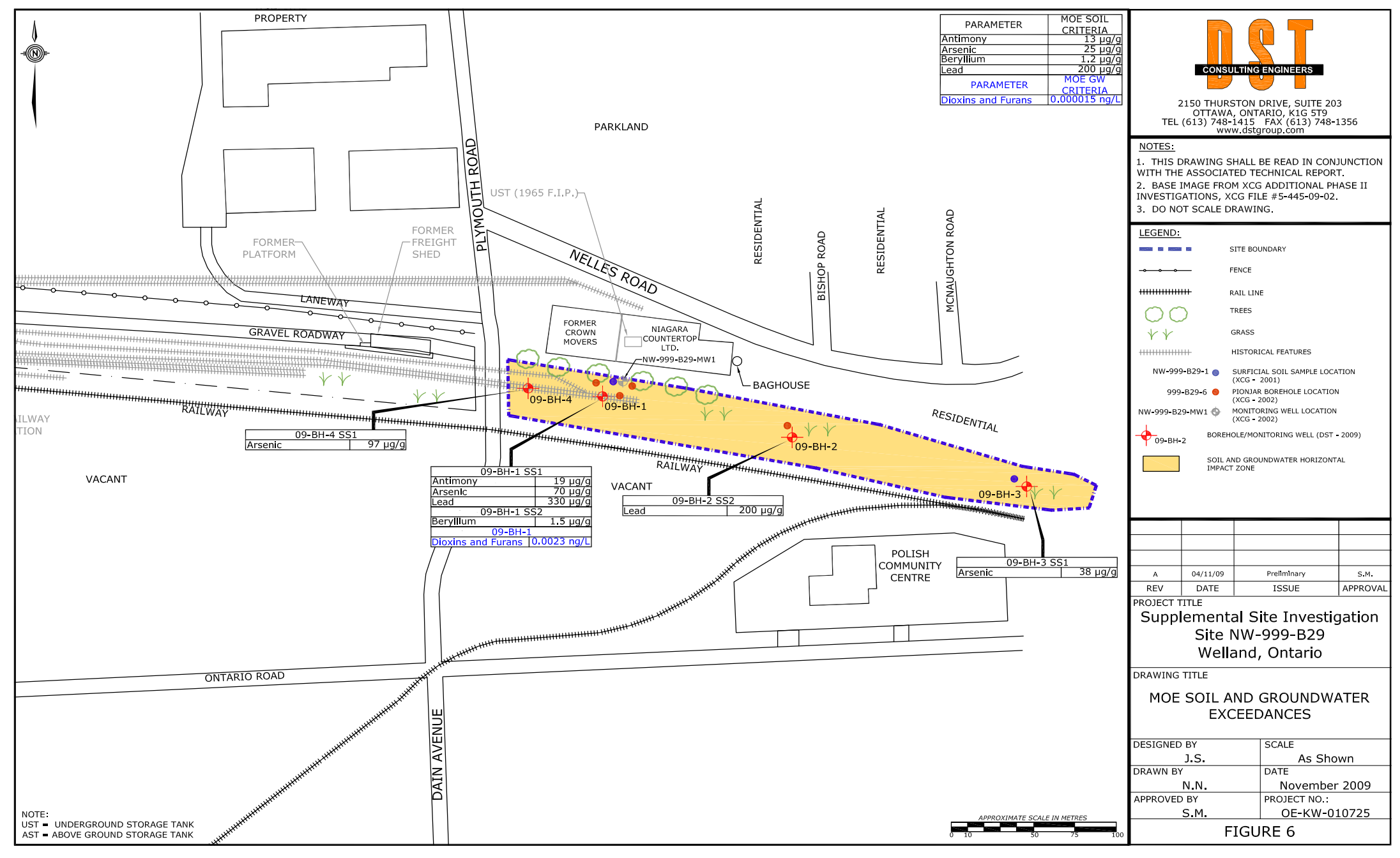

Source: OMOT, personal communication, 2010 


\section{Appendix D - Draft of a standard operating procedure for soil and sediment samples at the MOE}

This draft Standard Operating Procedure (SOP) describes the general methodology that has been developed to prepare samples in a soil or sediment matrix using Enzyme-Linked Immunosorbent Assay (ELISA). These steps are a modified version of the methodology presented by Cape Technologies (CAPE-Tech, 2002).

\section{APPARATUS}

\subsection{Equipment}

\subsubsection{Homogenization}

Oven

Mortar

Pestle

Sieve (2mm, US 10 mesh)

Sieve (355 mm, US $45 \mathrm{mesh}$ )

\subsubsection{Sample Weighing}

Digital scale - Explorer Pro Ohaus EP2102C

Calibration weights

Fume hood

1.1.3. Extraction and Oxidation

Rugged rotator or Orbital Platform Shaker

Centrifuge

Vortex mixer

Fume hood

\subsubsection{Evaporation}

Parker Balston Nitrovap Generator

Accublock Digital Dry Bath

Nitrogen drying apparatus

Fume hood

Vortex mixer 


\subsubsection{ELISA}

Centrifuge

Vortex Mixer

Fume hood

\subsection{Labware}

\subsubsection{Homogenization}
Aluminum foil
Gloves
Kimwipes
Metal scoopula
Protective breathing mask
Amber glass jar (250g) - 1 for each sample

\subsubsection{Sample Weighing}

Centrifuge tube $(50 \mathrm{~mL})-1$ for each sample

Gloves

Kimwipes

Labeling tape

Metal scoopula

Protective breathing mask

Small $50 \mathrm{~mL}$ beaker

Teflon-capped glass vial - 1 for each sample

\subsubsection{Extraction and Oxidation}

$16 \mathrm{~mm}$ borosilicate glass vial -1 per sample plus 2 additional $16 \mathrm{~mm}$ borosilicate glass vial with $2 \mathrm{~mL}$ marking $16 \mathrm{~mm}$ borosilicate glass vial with $6 \mathrm{~mL}$ marking $16 \mathrm{~mm}$ borosilicate glass vial with $10 \mathrm{~mL}$ marking $16 \mathrm{~mm}$ borosilicate glass vials M1, M2 and M3 for pipette cleaning Aluminum foil

Centrifuge tube $(50 \mathrm{~mL})-1$ for each sample Clean $100 \mathrm{~mL}$ beaker for DMF

Glass beads -6 per sample

Gloves

Kimwipes

Metal scoopula

Parafilm

Pasteur pipettes -2 per sample plus one additional 
Pipettes serological sterile $1 \mathrm{~mL}-1$ per sample

Positive displacement pipettor $100 \mu \mathrm{L}$ range

Positive displacement pipettor replacement bores -4 per sample

Protective Eyewear

Teflon-capped borosilicate glass vials - 1 per sample

Teflon-capped vial with $15 \mathrm{~mL}$ marking

\subsubsection{Evaporation}

$16 \mathrm{~mm}$ borosilicate glass vials M1, M2 and M3 for pipette cleaning $16 \mathrm{~mm}$ borosilicate glass vial -1 per standard plus one extra

Aluminum foil

Gloves

Kimwipes

Parafilm

Pasteur pipettes to connect to the drying apparatus -1 per sample

Pipette serological sterile $1 \mathrm{~mL}-1$ for toluene transfer

Positive displacement pipettor $25 \mu \mathrm{L}, 50 \mu \mathrm{L}, 100 \mu \mathrm{L}$ range

Positive displacement pipettor replacement bores -4 per sample

Protective Eyewear

\subsection{Reagents}

\subsubsection{Homogenization}

Acetone

\subsubsection{Sample Weighing}

Anhydrous Sodium Sulphate

\subsubsection{Extraction and Oxidation}

Dimethylformamide (DMF)

Fuming sulphuric acid

Hexane

Keeper solution

Methanol

\subsubsection{Evaporation}

Toluene

Keeper solution

Methanol 


\section{GENERAL CONSIDERATIONS}

The sample weighing, extraction, oxidation and evaporation steps are written for the preparation of one soil sample at a time. However, 30 samples can be extracted and oxidized at once and 24 can be evaporated at once. Samples can be sealed with parafilm and stored in the fridge at any point in the procedure listed here. This SOP was written for soil samples that do not require clean up before ELISA analysis. It was also written to take the sample algorithm into consideration.

\section{PROCEDURE}

Note: as samples may contain high levels of dioxins and other contaminants, be sure to always wear gloves and a protective breathing mask and always work in a fume hood.

\subsection{Sample Homogenization}

3.1.1. Empty sampling jar contents into an aluminum foil bin. Loosely cover with aluminum foil and allow to air-dry at room temperature for 48 hours.

3.1.2. Transfer the soil from the aluminum foil bin in approximately $10 \mathrm{~g}$ aliquots into a pre-cleaned, acetone-rinsed ceramic mortar. Disaggregated the sample with a pre-cleaned, acetone-rinsed pestle. Do not grind the sample.

3.1.3. Transfer the sample into a pre-cleaned, acetone-soaked and oven dried sieve (2mm, US 10 mesh). Sieve the sample onto a piece of clean aluminum foil. Discard contents larger than $2 \mathrm{~mm}$. Do this for the remaining soil in the aluminum foil bin.

3.1.4. Transfer the sieved sample back into the mortar. Using a pestle, grind the contents.

3.1.5. Transfer the ground soil into a second sieve (355 mm, US $45 \mathrm{mesh}$ ). Sieve contents onto a new piece of aluminum foil. Transfer any soil particles larger than $355 \mathrm{~mm}$ back into the mortar. Re-grind any particles larger than $355 \mathrm{~mm}$. 
3.1.6. Transfer homogenized soil into a clean, solvent rinsed, amber glass jar. Label with date sampled and date homogenized. Store in a refrigerated environment until analysis.

\subsection{Sample Weighing}

3.2.1. Tare a teflon-capped vial being held upright in a small $50 \mathrm{~mL}$ beaker on a digital scale. Use a metal scoopula to measure $4 \mathrm{~g}$ of anhydrous sodium sulphate into the tube. Record the weight. Be sure to wipe the scoopula clean before proceeding to the next step.

3.2.2. Tare a centrifuge tube $(50 \mathrm{~mL})$ vial being held upright in a $250 \mathrm{~mL}$ beaker on a digital scale.

3.2.3. Retrieve a soil sample and using a metal scoopula, weigh out $5 \mathrm{~g}$ of soil into the centrifuge tube and record the exact weight.

3.2.4. Wipe off the scoopula with a clean Kimwipe or wash if necessary.

\subsection{Extraction and Oxidation}

3.3.1. Empty the anhydrous sodium sulphate from the Teflon-capped vial into the centrifuge tube containing the soil sample. Cap the centrifuge tube and shake gently until the contents are homogenous and free-flowing.

3.3.2. In a fume hood, carefully decant DMF into a clean $100 \mathrm{~mL}$ beaker. Pour $15 \mathrm{~mL}$ of DMF into an empty Teflon-capped glass vial using the Tefloncapped vial with the $15 \mathrm{~mL}$ marking as a guide. Caution: DMF is a hazardous substance. Wear gloves and safety glasses and proceed with care.

3.3.3. Add the DMF and six glass mixing beads into the soil mixture.

3.3.4. After ensuring that the cap is tightened, attach the vial to the rugged rotator. To keep the wheel balanced, ensure that vials are attached in pairs across the wheel from each other.

3.3.5. Select a rotation speed that allows the solid mixture inside to tumble. To allow for complete extraction, the sample should remain on the wheel for 2 hours.

3.3.6. Check periodically to make sure that the solid mixture continues to tumble inside the vial and does not start to stick to the bottom. 
Note: Be sure to also check that the tubes do not leak during the entire 2 hour extraction.

3.3.7. Centrifuge the sample for 15 minutes at $1000 \times \mathrm{g}$ to fully separate the different fractions. To keep the centrifuge balanced, ensure that vials are placed in pairs across the centrifuge from each other.

3.3.8. In a fume hood, carefully pour $6 \mathrm{~mL}$ hexane into a new borosilicate glass tube using the borosilicate glass tube with the $6 \mathrm{~mL}$ marking as a guide. Using a clean Pasteur pipette, transfer the hexane into a new centrifuge tube.

3.3.9. Using a positive displacement pipettor, transfer either $200 \mu \mathrm{L}$ or $1 \mathrm{~mL}$ of DMF extract to the centrifuge tube containing $6 \mathrm{~mL}$ hexane. Inject the DMF below the surface of the hexane. The amount of extract to be transferred is dependant on which test level is being followed.

3.3.10. Using a Pasteur pipette, transfer the remaining DMF into a Teflon-capped borosilicate glass vial for storage. Store in a refrigerated environment. Extracts are stable for one month at room temperature in a tightly sealed vial. The soil mixture can now be discarded in the proper waste container.

3.3.11. In a fume hood, carefully pour either $2 \mathrm{~mL}$ or $10 \mathrm{~mL}$ fuming sulphuric acid into a new borosilicate glass tube using either the borosilicate glass tube with the $2 \mathrm{~mL}$ marking or $10 \mathrm{~mL}$ marking as a guide. The amount of acid to be poured is dependant on which dioxin decision level test is selected. Caution: fuming sulphuric acid is corrosive and hygroscopic. Wear gloves and safety glasses and proceed with care.

3.3.12. Using a Pasteur pipette, slowly transfer the acid into the centrifuge tube containing hexane and DMF extract. The acid should not be exposed in air for too long as this may lead to adsorption of water which will decrease the $\mathrm{SO}_{3}$ concentration in solution and cause incomplete oxidation of the sample.

3.3.13. Tightly cap the vial and reattach the sample to the rugged rotator. To keep the wheel balanced, ensure that vials are attached in pairs across the wheel from each other. The sample should be spun for 15 minutes to allow for complete oxidation. At the end of the oxidation, the vial should be warm but not hot.

3.3.14. Centrifuge the sample at $2000 \times \mathrm{g}$ for 5 minutes to achieve full separation of phases.

Note: At this point, the acid phase should be dark reddish brown and should have a clean separation from the hexane layer. If the DMF extract 
was originally dark than the acid layer may also be black or dark grey. If the interface between the hexane and the acid is not sharp and shows signs of cloudiness or flocculation, oxidation was incomplete and steps 3.2.11 to 3.2.14 should be repeated.

3.3.15. Using a positive displacement pipettor, dispense $150 \mu \mathrm{L}$ PEG-Triton Keeper solution into the bottom of a new borosilicate glass tube.

3.3.16. Using a Pasteur pipette, transfer as much of the sample's oxidized upper hexane layer as possible into the tube with the Keeper solution. Be sure not to transfer any of the lower layer as this contamination will carry through into the ELISA analysis.

3.3.17. Cover the top of the tube in aluminum foil and wrap in parafilm. Store in a refrigerator until sample is to be evaporated. Typically the evaporation is performed one day before ELISA is run.

\subsection{Evaporation}

3.4.1. Turn on the air supply so that the input pressure is 80 psi. Leave the air running for 10 minutes to purge the system of any dust.

3.4.2. Attach a new Pasteur pipette for each sample that is to be evaporated to one of 24 hose endings coming from the drying apparatus connected to the dry bath. Make sure that all unused hose endings also have Pasteur pipettes attached and are sealed with parafilm, as to prevent nitrogen from leaking from an open ending.

3.4.3. After purging the air stream for 10 minutes, turn the lever on the Nitrovap system from 'Standby' to 'Nitrogen On'. Nitrogen should now be flowing to the drying apparatus.

3.4.4. Adjust the nitrogen flowrate to 0.1 psi using the pressure gauge next to the drying apparatus.

3.4.5. Turn on the dry bath and adjust the temperature to $55^{\circ} \mathrm{C}$.

3.4.6. Place the sample tube in a dry bath slot and slip the clean Pasteur pipette connected to the hose ending through the slotted scaffolding supports so that the pipette tip is blowing nitrogen onto the top of the sample tube.

3.4.7. Readjust the pressure so that the nitrogen is swirling the liquid in the tube but the surface appears undisturbed. Blowing too much nitrogen will evaporate the sample too quickly and will lead to an excess loss of analyte. 
3.4.8. Wrap the dry bath with a layer of tin foil to conserve the heat and protect the sample from any dust.

3.4.9. Periodically check the sample so that it can be removed as soon as it is finished evaporating. It is finished when there is only a small portion of Keeper remaining on the bottom of the tube and there is no detectable hexane odour from the tube. Do not overdry the sample.

3.4.10. Once the sample has evaporated, remove it from the bath, seal it with an aluminum foil cover and parafilm.

3.4.11. At this point, standards can be prepared. Using a positive displacement pipettor, dispense $62.5 \mu \mathrm{L}$ PEG-Triton Keeper solution into the bottom of eight new borosilicate glass tubes.

3.4.12. Using a pipette transfer $1 \mathrm{~mL}$ of toluene into each of the eight test tubes.

3.4.13. Using the $25 \mu \mathrm{L}, 50 \mu \mathrm{L}$ and $100 \mu \mathrm{L}$ variable positive displacement pipettor, dispense the allocated amount of TCDD in nonane directly into the toluene.

3.4.14. Adjust the dry bath to $80^{\circ} \mathrm{C}$ and repeat steps 3.3 .6 to 3.3 .10 for all standards.

3.4.15. Turn off the dry bath, close the air valve feeding into the Nitrovap system and turn the lever on the Nitrovap system from 'Nitrogen On' to 'Standby'.

\subsection{ELISA}

3.5.1. The night prior to the ELISA test, take out one set of ELISA tubes and the bottle of sample diluent out of the refrigerator. This allows the ELISA tubes and the sample diluent to reach room temperature prior to us. All contents in the ELISA kit must be used at room temperature; however, stored in the refrigerator when not in use.

3.5.2. The morning of the ELISA test, put all evaporated borosilicate glass tubes ( 8 standards and 12 samples) into the centrifuge; centrifuge at $2000 \mathrm{xg}$ for 30 minutes.

3.5.3. Prepare three borosilicate glass tubes with approximately $12 \mathrm{~mL}$ of methanol. Wash microdispensers with methanol, rinsing and wiping with a fresh kimwipe four times per methanol tube. 
3.5.4. Take the 20 ELISA tubes out of the pouch and place them on the ELISA tube magnetic rack; label them from 1 to 20 (1-2 are for negative controls; 3-8 are standards; 9-20 are samples to be tested).

3.5.5. Rinse an Eppendorf Repeator Pipettor tip $(50 \mathrm{~mL})$ with distilled water. Attach the tip to the Eppendorf Repeator Pipettor and pipette $5 \mathrm{~mL}$ of reverse osmosis, autoclaved water into each ELISA tube. Let the tubes sit for at least 5 minutes. Use a different tip for each reagent dispensed with the Eppendorf Repeator pipettor to avoid reagent cross-contamination. Note: Refer to the table in the Eppendorf booklet to determine what setting coordinates with the size of tip and amount of liquid pipetted.

3.5.6. Detach the $50 \mathrm{~mL}$ tip designated for double distilled water. Rinse a $10 \mathrm{~mL}$ tip designated for "Sample Diluent" with distilled water. Attach the tip to the Eppendorf Repeator Pipettor and set aside.

3.5.7. Pour the water out of the tubes and tap inverted tube onto absorbent material to remove excess water.

3.5.8. Dispense the $500 \mathrm{~mL}$ sample diluent into each tube. Return any remaining diluent to the reagent bottle. ELISA tubes are now ready for sample addition.

3.5.9. Reconstitute the samples first. Prepare a borosilicate glass tube with 10 $\mathrm{mL}$ of methanol.

3.5.10. Use a methanol-washed variable $100 \mathrm{~mL}$ microdispenser to transfer either $70 \mathrm{~mL}$ or $100 \mathrm{~mL}$ of methanol to the first out of the twelve sample tubes. Dispense the methanol just above the evaporated keeper residue. Vortex the borosilicate glass tube for 15 seconds to dissolve the keeper and the sample completely. The tube should be held upright to minimize any splashing of the solution onto the sides of the tube. Cover with a piece of foil and place back in the test tube rack. The amount of methanol to be transferred is dependant on which test level is being followed.

3.5.11. Use a methanol-washed variable $100 \mathrm{~mL}$ microdispenser to transfer either $70 \mathrm{~mL}$ or $100 \mathrm{~mL}$ of methanol to the second sample tube. Vortex the borosilicate glass tube for 15 seconds to dissolve the keeper and the sample completely. The tube should be held upright to minimize any splashing of the solution onto the sides of the tube. Cover with a piece of foil and place back in the test tube rack. The amount of methanol to be transferred is dependant on which test level is being followed.

3.5.12. Put the two borosilicate glass tubes with methanol, keeper and dioxin extract in the centrifuge; centrifuge the tubes at $1000 \times$ g for 2 minutes. Take the two centrifuged tubes out, and place them on the test tube rack. 
3.5.13. Use a clean fixed $50 \mathrm{~mL}$ microdispenser, transfer $50 \mathrm{~mL}$ of the sample into the corresponding ELISA tube. Dispense the sample directly into the sample diluent. Record the time the first sample enters the ELISA tube.

3.5.14. Immediately after sample addition, vortex each ELISA tube for 10 seconds. The appearance of the solution should be homogeneous.

3.5.15. Repeat steps 3.5.11 through 3.5.15 for the rest of the samples.

3.5.16. After, the samples are reconstituted and transferred into ELISA tubes; standards are reconstituted in a similar manner. Transfer $50 \mathrm{~mL}$ of methanol using a clean fixed $50 \mathrm{~mL}$ microdispenser to dissolve the keeper residue. Centrifuge the borosilicate test tube and transfer all contents into the ELISA tube using a variable $100 \mathrm{~mL}$ microdispenser. Standards are reconstituted in pairs, in the same manner as sample reconstitution.

3.5.17. After all the 20 samples and standards are transferred into ELISA tubes, use small pieces of parafilm to cover each of the 20 ELISA tubes. Cover the entire magnetic rack with a piece of aluminum foil and set aside.

3.5.18. Record the time. The incubation lasts 2 hours.

3.5.19. After the first hour of the incubation time has surpassed, vortex each of the ELISA tubes for 5 seconds. Return to the magnetic rack. Recover with aluminum foil and set aside for the remaining hour.

3.5.20. Make the Wash I solution during the incubation time. Pipette $20 \mathrm{~mL}$ of Triton $\mathrm{x}-100$ to $100 \mathrm{~mL}$ of double distilled water and stir on a magnetic stirrer. Pipette slowly due to thick quality of Triton $x-100$.

3.5.21. Record the end time of the incubation period. Rinse an Eppendorf Repeator Pipettor tip $(50 \mathrm{~mL})$ with distilled water. Attach the tip to the Eppendorf Repeator Pipettor and fill with Wash I solution.

3.5.22. Pour out the ELISA tube contents into an appropriate waste container. Tap the inverted tubes onto absorbent material to remove excess liquid.

3.5.23. Dispense $1 \mathrm{~mL}$ of Wash I solution (100 ppm) into each ELISA tube using the Repeator pipettor equipped with the $50 \mathrm{~mL}$ pipette tip. Vortex the tubes briefly ( $\sim 5$ seconds). Pour out the ELISA tube contents into an appropriate waste container. Remove hanging drops by tapping the inverted tubes on absorbent material. Repeat this wash procedure three more times for a total of four washes. Change absorbent material before every new ELISA test. Be sure to shake or tap out as much Wash I solution as possible at each wash step, especially the last one. 
3.5.24. Rinse an Eppendorf Repeator Pipettor tip $(10 \mathrm{~mL})$ with distilled water. Attach the tip to the Eppendorf Repeator Pipettor and fill with CompetitorHRP Conjugate solution.

3.5.25. Add $500 \mathrm{~mL}$ of Competitor-HRP Conjugate into each ELISA tube. Return any unused portion into the conjugate bottle. Record CompetitorHRP Conjugate lot number.

3.5.26. Tubes are vortexed $(\sim 5 \mathrm{sec})$ and covered with a piece of aluminum foil. Tubes are set aside and allowed to stand at room temperature for 20 minutes. Rapid and accurate addition of the conjugate, as well as consistent incubation times, are necessary to maintain equal treatment within and among runs. Dump tube contents after 20 minutes.

3.5.27. Repeat the wash procedure for a total of four washes as described in steps 3.5.21 to 3.5.23, using $2 \mathrm{~mL}$ of double distilled water. At this time using the pipette, place $1 \mathrm{~mL}$ of double distilled water into an ELISA tube to be designated as a Blank.

3.5.28. Rinse an Eppendorf Repeator Pipettor tip $(10 \mathrm{~mL})$ with distilled water. Attach the tip to the Eppendorf Repeator Pipettor and fill with HRPSubstrate Solution.

3.5.29. Dispense $500 \mathrm{~mL}$ of HRP-Substrate Solution into each ELISA tube. Return unused portion into the substrate bottle. Vortex the tubes briefly ( $\sim 5$ seconds). Record HRP Substrate Solution lot number. If substrate is blue before addition to the ELISA tubes, do not use. Contact the manufacturer.

3.5.30. Use a piece of aluminum foil to cover the whole rack, and incubate tubes at room temperature for 40 minutes in the dark.

3.5.31. During the incubation period, rinse an Eppendorf Repeator Pipettor tip (10 $\mathrm{mL}$ ) with distilled water. Attach the tip to the Eppendorf Repeator Pipettor and fill with Stop Solution.

3.5.32. After the incubation period, add $500 \mathrm{~mL}$ of Stop Solution into each ELISA tube. Vortex the tubes briefly ( $\sim 5$ seconds). The stop solution converts the developed colour to yellow. Record Stop Solution lot number. If the stop solution is not added, all tubes will eventually turn dark blue.

3.5.33. Read OD values as soon as possible after stop solution has been added; the yellow colour is stable for 30 minutes.

3.5.34. Enter absorbance readings into an ELISA worksheet for analysis. 


\section{Appendix E - Summary of Raw Data}

\begin{tabular}{|c|c|c|c|c|c|c|}
\hline Sample & Sample Description & $\begin{array}{c}\text { Test } \\
\text { Location }\end{array}$ & $\begin{array}{c}\text { Test } \\
\text { Level }\end{array}$ & Absorbance & $\begin{array}{l}\text { Uncorrected } \\
\text { pgTEQ/tube }\end{array}$ & $\begin{array}{c}\text { Corrected }(\mathrm{pg} / \mathrm{g}) \\
\text { of each sample }\end{array}$ \\
\hline Welland 1 & Welland Quadrant 1, Replicate 1 & MOE & $900 \mathrm{pg} / \mathrm{g}$ & 1.753 & 1.523 & 0 \\
\hline Welland 1 & Welland Quadrant 1, Replicate 2 & MOE & $900 \mathrm{pg} / \mathrm{g}$ & 1.791 & 0 & 0 \\
\hline Welland 1 & Welland Quadrant 1, Replicate 3 & MOE & $900 \mathrm{pg} / \mathrm{g}$ & 1.815 & 0 & 0 \\
\hline Welland 1 & Welland Quadrant 1, Replicate 1 & RYE & $120 \mathrm{pg} / \mathrm{g}$ & 1.67 & 2.49 & 7.55 \\
\hline Welland 2 & Welland Quadrant 2, Replicate 1 & MOE & $120 \mathrm{pg} / \mathrm{g}$ & 1.404 & 11.54 & 69.36 \\
\hline Welland 2 & Welland Quadrant 2, Replicate 2 & MOE & $120 \mathrm{pg} / \mathrm{g}$ & 1.578 & 4.18 & 25.11 \\
\hline Welland 2 & Welland Quadrant 2, Replicate 1 & RYE & $120 \mathrm{pg} / \mathrm{g}$ & 1.58 & 6.85 & 44.61 \\
\hline Welland 3 & Welland Quadrant 3, Replicate 1 & MOE & $120 \mathrm{pg} / \mathrm{g}$ & 1.427 & 10.43 & 62.56 \\
\hline Welland 3 & Welland Quadrant 3, Replicate 2 & MOE & $120 \mathrm{pg} / \mathrm{g}$ & 1.451 & 9.32 & 56.04 \\
\hline Welland 3 & Welland Quadrant 3, Replicate 1 & RYE & $120 \mathrm{pg} / \mathrm{g}$ & 1.50 & 11.40 & 83.89 \\
\hline Welland 4 & Welland Quadrant 4, Replicate 1 & MOE & $120 \mathrm{pg} / \mathrm{g}$ & 1.505 & 7.01 & 42.12 \\
\hline Welland 4 & Welland Quadrant 4, Replicate 2 & MOE & $120 \mathrm{pg} / \mathrm{g}$ & 1.509 & 6.84 & 41.14 \\
\hline Welland 4 & Welland Quadrant 4, Replicate 1 & RYE & $120 \mathrm{pg} / \mathrm{g}$ & 1.65 & 3.41 & 15.40 \\
\hline Welland 5 & Welland Quadrant 5, Replicate 1 & MOE & $120 \mathrm{pg} / \mathrm{g}$ & 1.469 & 12.34 & 72.15 \\
\hline Welland 5 & Welland Quadrant 5, Replicate 2 & MOE & $120 \mathrm{pg} / \mathrm{g}$ & 1.545 & 7.70 & 46.21 \\
\hline Welland 5 & Welland Quadrant 5, Replicate 1 & RYE & $120 \mathrm{pg} / \mathrm{g}$ & 1.51 & 8.14 & 42.85 \\
\hline Welland 6 & Welland Quadrant 6, Replicate 1 & MOE & $120 \mathrm{pg} / \mathrm{g}$ & 1.456 & 13.14 & 79.00 \\
\hline Welland 6 & Welland Quadrant 6, Replicate 2 & MOE & $120 \mathrm{pg} / \mathrm{g}$ & 1.509 & 9.90 & 59.40 \\
\hline Welland 6 & Welland Quadrant 6, Replicate 1 & RYE & $120 \mathrm{pg} / \mathrm{g}$ & 1.51 & 8.14 & 51.57 \\
\hline Welland 7 & Welland Quadrant 7, Replicate 1 & MOE & $120 \mathrm{pg} / \mathrm{g}$ & 1.530 & 8.62 & 51.63 \\
\hline Welland 7 & Welland Quadrant 7, Replicate 2 & MOE & $120 \mathrm{pg} / \mathrm{g}$ & 1.533 & 8.44 & 50.74 \\
\hline Welland 7 & Welland Quadrant 7, Replicate 1 & RYE & $120 \mathrm{pg} / \mathrm{g}$ & 1.59 & 4.57 & 19.00 \\
\hline Welland 8 & Welland Quadrant 8, Replicate 1 & MOE & $120 \mathrm{pg} / \mathrm{g}$ & 1.527 & 8.81 & 52.94 \\
\hline Welland 8 & Welland Quadrant 8, Replicate 2 & MOE & $120 \mathrm{pg} / \mathrm{g}$ & 1.511 & 9.78 & 58.09 \\
\hline Welland 8 & Welland Quadrant 8, Replicate 1 & RYE & $120 \mathrm{pg} / \mathrm{g}$ & 1.58 & 4.98 & 22.39 \\
\hline Welland 9 & Welland Quadrant 9, Replicate 1 & MOE & $120 \mathrm{pg} / \mathrm{g}$ & 1.295 & 28.33 & 154.71 \\
\hline
\end{tabular}




\begin{tabular}{|c|c|c|c|c|c|c|}
\hline Welland 9 & Welland Quadrant 9, Replicate 2 & MOE & $120 \mathrm{pg} / \mathrm{g}$ & 1.267 & 31.22 & 171.69 \\
\hline Welland 9 & Welland Quadrant 9, Replicate 1 & RYE & $120 \mathrm{pg} / \mathrm{g}$ & 1.33 & 19.02 & 120.26 \\
\hline Welland 10 & Welland Quadrant 10, Replicate 1 & MOE & $120 \mathrm{pg} / \mathrm{g}$ & 1.618 & 6.50 & 23.79 \\
\hline Welland 10 & Welland Quadrant 10, Replicate 2 & MOE & $120 \mathrm{pg} / \mathrm{g}$ & 1.499 & 12.60 & 60.32 \\
\hline Welland 10 & Welland Quadrant 10, Replicate 1 & RYE & $120 \mathrm{pg} / \mathrm{g}$ & 1.6 & 4.16 & 14.08 \\
\hline Welland 11 & Welland Quadrant 11, Replicate 1 & MOE & $120 \mathrm{pg} / \mathrm{g}$ & 1.428 & 17.18 & 87.65 \\
\hline Welland 11 & Welland Quadrant 11, Replicate 2 & MOE & $120 \mathrm{pg} / \mathrm{g}$ & 1.575 & 8.50 & 35.66 \\
\hline Welland 11 & Welland Quadrant 11, Replicate 1 & RYE & $120 \mathrm{pg} / \mathrm{g}$ & 1.55 & 3.23 & 22.06 \\
\hline Welland 12 & Welland Quadrant 12, Replicate 1 & MOE & $120 \mathrm{pg} / \mathrm{g}$ & 1.475 & 14.12 & 69.46 \\
\hline Welland 12 & Welland Quadrant 12, Replicate 2 & MOE & $120 \mathrm{pg} / \mathrm{g}$ & 1.400 & 19.22 & 100.08 \\
\hline Welland 12 & Welland Quadrant 12, Replicate 1 & RYE & $120 \mathrm{pg} / \mathrm{g}$ & 1.49 & 6.17 & 44.88 \\
\hline Welland 13 & Welland Quadrant 13, Replicate 1 & MOE & $120 \mathrm{pg} / \mathrm{g}$ & 1.544 & 5.67 & 34.03 \\
\hline Welland 13 & Welland Quadrant 13, Replicate 2 & MOE & $120 \mathrm{pg} / \mathrm{g}$ & 1.555 & 5.12 & 30.73 \\
\hline Welland 13 & Welland Quadrant 13, Replicate 1 & RYE & $120 \mathrm{pg} / \mathrm{g}$ & 1.66 & 0.05 & 0 \\
\hline Welland 14 & Welland Quadrant 14, Replicate 1 & $\mathrm{MOE}$ & $120 \mathrm{pg} / \mathrm{g}$ & 1.404 & 14.44 & 86.63 \\
\hline Welland 14 & Welland Quadrant 14, Replicate 2 & MOE & $120 \mathrm{pg} / \mathrm{g}$ & 1.449 & 11.23 & 67.37 \\
\hline Welland 14 & Welland Quadrant 14, Replicate 1 & MOE & $120 \mathrm{pg} / \mathrm{g}$ & 1.147 & 7.32 & 54.90 \\
\hline Welland 15 & Welland Quadrant 15, Replicate 1 & MOE & $120 \mathrm{pg} / \mathrm{g}$ & 1.349 & 18.97 & 113.82 \\
\hline Welland 15 & Welland Quadrant 15, Replicate 2 & MOE & $120 \mathrm{pg} / \mathrm{g}$ & 1.463 & 10.56 & 63.36 \\
\hline Welland 15 & Welland Quadrant 15, Replicate 1 & RYE & $120 \mathrm{pg} / \mathrm{g}$ & 1.45 & 8.56 & 64.20 \\
\hline
\end{tabular}




\begin{tabular}{|c|c|c|c|c|c|c|}
\hline Sample & Sample Description & $\begin{array}{c}\text { Test } \\
\text { Location }\end{array}$ & Test Level & Absorbance & $\begin{array}{l}\text { Uncorrected } \\
\text { pgTEQ/tube }\end{array}$ & $\begin{array}{c}\text { Corrected }(\mathrm{pg} / \mathrm{g}) \\
\text { of each sample }\end{array}$ \\
\hline $\mathrm{PC}$ & Positive Control, Replicate 1 & MOE & $900 \mathrm{pg} / \mathrm{g}$ & 1.39 & 45.20 & 1618 \\
\hline $\mathrm{PC}$ & Positive Control, Replicate 2 & MOE & $900 \mathrm{pg} / \mathrm{g}$ & 1.17 & 41.25 & 1470 \\
\hline $\mathrm{PC}$ & Positive Control, Replicate 3 & MOE & $900 \mathrm{pg} / \mathrm{g}$ & 1.39 & 22.13 & 720 \\
\hline $\mathrm{PC}$ & Positive Control, Replicate 4 & MOE & $900 \mathrm{pg} / \mathrm{g}$ & 1.115 & 33.05 & 1685 \\
\hline $\mathrm{PC}$ & Positive Control, Replicate 5 & MOE & $900 \mathrm{pg} / \mathrm{g}$ & 1.112 & 32.49 & 1660 \\
\hline $\mathrm{PC}$ & Positive Control, Replicate 6 & MOE & $900 \mathrm{pg} / \mathrm{g}$ & 1.219 & 27.48 & 1066 \\
\hline $\mathrm{PC}$ & Positive Control, Replicate 7 & MOE & $900 \mathrm{pg} / \mathrm{g}$ & 1.215 & 37.21 & 1344 \\
\hline $\mathrm{PC}$ & Positive Control, Replicate 8 & MOE & $900 \mathrm{pg} / \mathrm{g}$ & 1.18 & 41.24 & 1546 \\
\hline $\mathrm{PC}$ & Positive Control, Replicate 9 & MOE & $900 \mathrm{pg} / \mathrm{g}$ & 1.13 & 38.69 & 1416 \\
\hline $\mathrm{PC}$ & Positive Control, Replicate 10 & MOE & $900 \mathrm{pg} / \mathrm{g}$ & 1.17 & 37.61 & 1454 \\
\hline
\end{tabular}




\title{
Appendix F - Statement sent requesting that No Further Action Required
}

By Electronic Correspondence: adriennekristin.lee@ryerson.ca

\author{
Heather Osborne \\ clo Environmental Affairs \\ Transport Canada \\ Place de Ville, Tower C \\ 330 Sparks St. \\ Ottawa ON K1A 0N5 \\ Heather.Osborne@tc.gc.ca
}

Thorold, Ontario - Welland Supplemental Site Investigation

Project Number: OE-KW-010725

Site number: NW-999-B29

\section{No Further Action Required}

\section{Dear Ms. Osborne:}

Ryerson University have reviewed the "Welland Supplemental Investigative Site" received on August $10^{\text {th }}, 2010$ and concludes that enough investigation has been conducted to provide reasonable assurance that the soil contamination from dioxins and furans pose no immediate or long term threat to human health and the environment. Fifteen soil samples were taken encompassing borehole \#1 (09-BH-01) previously analyzed to be dioxin and furan positive. Soil samples analyzed by Enzyme-linked Immunosorbent Assay (ELISA) illustrated that the maximum concentration found on site

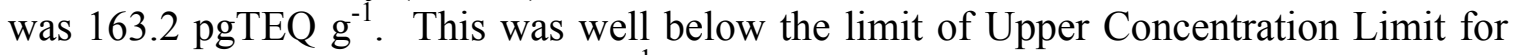
Soil in Ontario of 10, 000 pgTEQ $\mathrm{g}^{-1}$ as well as below the Action Level set out by the United States Agency for Toxic Substances and Disease Registry (ATSDR) of 1000 $\operatorname{pgTEQ~} \mathrm{g}^{-1}$. The concentration gradient of this site has been mapped and can be found as an attachments to this letter. It has been hypothesized that dioxin contamination has occurred due to air deposition of a source originating from the south and moving northwards.

If you have any questions concerning this correspondence, please contact Adrienne Lee at Ryerson University by email at adriennekristin.lee@,ryerson.ca.

Sincerely,

Adrienne Lee

M.ASc. Environmental Applied Science and Management Candidate

Ryerson University 


\section{REFERENCES}

Agapkina, G. I., Brodskii, E. S., Shelepchikov, A. A., Feshin, D. B., \& Efimenko, E. S. (2010). Polychlorinated dibenzo-p-dioxins and dibenzofurans in Moscow soils. Moscow University Science Bulletin, 65, 114-118.

Ahlborg, U., Becking, G., Birnbaum, L., Brouwer, A., Derks, H., Feeley, M., Golor, G., Hanberg, A., Larsen, J. C., Liem, A. K. D., Safe, S. H., Schlatter, C., Waern, F., Younes, M., \& Yrjanheikki, E. (1994). Toxic equivalency factors for dioxin-like PCBs. Chemosphere, 28, 1049-1067.

Alawi, M. A., Wichmann, H., Bahadir, M., \& Lorenz, W. (1996). Dioxins and furans in the Jordanian environment part 1: preliminary study on a municipal landfill site with open combustion nearby Amman - Jordan. Chemosphere, 32, 907-912.

Alcantara, C. (2005). The Harmonization Accord: stakeholder influence on the Canadawide standard for dioxins and furans. Journal of Canadian Studies, 39, 156-178.

Aoki, Y. (2001). Polychlorinated dibenzofurans as endocrine disrupters-what we have learned from Yusho disease. Environmental Research Section A, 86, 2-11.

Aristizabal, B., Cobo, M., Hoyos, A., Montes de Correa, C., Abalos, M., Martinez, K., Abad, E., \& Rivera, J. (2008). Baseline levels of dioxin and furan emissions from waste thermal treatment in Colombia. Chemosphere, 73, 171-175.

Babbage, M. (2011, February 28). Agent Orange used widely in Ontario over decades, Minister says. The Globe and Mail. Retrieved February 28, 2011 from: www.globeandmail.com

Bakoglu, M., Karademir, A., \& Durmusoglu, E. (2005). Evaluation of PCDD/F levels in ambient air and soils and estimation of deposition rates in Kocaeli, Turkey. Chemosphere, 59, 1373-1385.

Barra, R., Colombo, J. C., Eguren, G., Gamboa, N., Jardim, W. F., \& Mendoza, G. (2006). Persistent organic pollutants (POPs) in eastern and western South American countries. 185, 1-33.

Baughman, R., \& Meselson, M. (1973). An analytical method for detecting TCDD (Dioxin): levels of TCDD in samples from Vietnam. Environmental Health Prespectives, $5,27-35$

Bertazzi, P. A., Zocchetti, C., Guercilena, S., Consonni, D., Tironi, A., \& Landi, M. T. (1997). Dioxin exposure and cancer risk: A 15-year mortality study after the "Seveso Accident". Epidemiology , 8, 646-652. 
Bertazzi, P. A., Bernucci, I., Brambilla, G., Consonni, D., \& Pesatori, A. C. (1998). The Seveso studies on early and long-term effects of dioxin exposure: A review. Environmental Health Perspectives, 106, 625-633.

Billets, S. (2004). In Site - The Newsletter of the Superfund Monitoring and Measurement Technology Verification Program. Las Vegas: United States Environmental Protection Agency.

Billets, S. (2005). Innovative Technology Verification Report Technologies for Monitoring and Measurement of Dioxin and Dioxin-like Compounds in Soil and Sediment. Columbus: United States Environmental Protection Agency.

Bouwman, H. (2004). South Africa and the Stockholm Convention on Persistent Organic Polluntants. South African Journal of Science, 100, 323-329.

Brann, E. (1990). The association of selected cancer with service in the US military in Vietnam. I. Non-Hodgkin's Lymphoma. Archives of Internal Medicine, 150, 2473-2483.

Buan, E. (2009). Development of a laboratory analytical method beneficial to the policies of the Canada-wide standards for dioxins and furans. Toronto: Ryerson University.

Canadian Council of Ministers of the Environment [CCME]. (2001). Canada-Wide Standards for Dioxins and Furans. Winnepeg: CCME.

Canadian Council of Ministers of the Environment [CCME]. (1999). Canadian Environmental Quality Guidelines for the Protection of Environmental and Human Health: Dioxins and Furans. Winnepeg: CCME.

Canadian Council of Ministers of the Environment [CCME]. (2008). National Classification System for Contaminated Sites Guidance Document. Gatineau: Environment Canada.

Canadian Council of Ministers of the Environment [CCME]. (2011, March 16). Our Work: Dioxins and Furans. Retrieved 2011, March 31 from : http://www.ccme.ca/ourwork/air.html?category_id=91

Canadian Environmental Protection Act [CEPA]. (1999). Strategic Options for the Management of CEPA-Toxic Substances from the Wood Preservation Sector. Ottawa: CEPA.

CAPE-Technologies. (n.d.). Schematic Diagram of DF1 Dioxin/Furan Immunoassay Protocol. From CAPE-Technologies: http://www.cape-tech.com/

Chandler, J. (2007). Review of Dioxins and Furans from Incineration In Support of a Canada-wide Standard Review. Willowdale: CCME. 
Chao, H.-R., Wang, Y.-F., Lin, D.-Y., Cheng, Y.-T., \& Tsou, T.-C. (2011). Fast cleanup system combined with a dioxin-responsive element-driven luciferase bioassay for analysis of polychlorinated dibenzo-p-dioxins/furans in sediments and soils. Bulletin of Environmental Contamination and Toxicology, 1-5.

Chuang, J. C., Van Emon, J. M., \& Schrock, M. E. (2009). High-throughput screening of dioxins in sediment and soil using selective pressurized liquid extraction with immunochemical detection. Chemosphere, 77, 1217 - 223.

Consonni, D., Pesatori, A. C., Zocchetti, C., Sindaco, R., Cavalieri, D., Rubagotti, M., \& Bertazzi, P.A. (2008). Mortality in the population exposed to dioxin after the Seveso, Italy, accident in 1976: 25 years of follow-up. American Journal of Epidemiology, 167, 947-858.

Devlin-Foltz, D., and Hoppes, J. (2010). U.S.-Vietnam Dialogue Group on Agent Orange. Washington, DC: The Aspen Institute.

Dwernychuk, W. L. (2005). Dioxin hot spots in Vietnam. Chemosphere, 60, 998-999.

Eadon, G., Kaminsky, L., Silkworth, J., Aldous, K., Hilker, D., O'Keefe, P., Smith, R., Gierthy, J., Hawley, J., Kim, N., \& DeCaprio, A. (1986). Calculation of 2,3,7,8-TCDD equivalent concentrations of complex environmental contaminant mixtures. Environmental Health Perspectives, 70, 221-227.

Eduljee, G. (1999). Secondary exposure to dioxins through exposure to PCP and its derivatives. The Science and the Total Environment, 232, 193-214.

Elijarrat, E., \& Barcelo, D. (2002). Congener-specific determination of dioxins and related compounds by gas chromatography coupled to LRMS, HRMS, MS/MS and TOFMS. Journal of Mass Spectometry, 37, 1105-1117.

Environment Canada. (2007). Air Pollutant Emissions. Retrieved 2009, Retrieved October 14, 2009 from Environment Canada:

http://ec.gc.ca/pdb/websol/emissions/ap/ap_result_e.cfm?year=2007\&substance=df\&loca tion $=$ CA\&submit $=$ Search

Environment Canada. (2010). Implementation Plan for Canada-Wide Standards on Federal Incinerators: Dioxins/Furans and Mercury. Retrieved July 24, 2010 from Environment Canada:

http://www.ec.gc.ca/lcpe-cepa/default.asp?lang=En\&n=3000B00C-1

Evans, G. R., Webb, K. B., Knutsen, A. P., Roodman, S. T., Roberts, D. W., \& Bagby, J. R. (1988). A medical follow-up of the health effects of long-term exposure to 2,3,7,8tetrachlorodibenzo-p-dioxin. Archives of Environmental Health, 43, 273-278. 
Evans, R., Shadel, B., Roberts, D., Clardy, S., Jordan-Izaguirre, D., \& Patterson, D. (2000). Dioxin incinerator emissions exposure study Times Beach, Missouri. Chemosphere, 40, 1063-1074.

Fiedler, H. (1999). Dioxin and Furan Inventories National and Regional Emissions of $P C D D / P C D F$. Geneva: UNEP Chemicals.

Garcia-Nieto, E., Nichkova, M., Yanez, L., Costilla-Salazar, R., Torres-Dosal, A., Gee, S. J., Hammock, B. D., Juarez-Santacruz, L., \& Diaz-Barriga, F. (2009). Assessment of dioxin-like soil contamination in Mexico by enzyme-linked immunosorbent assay. Archive in Environmental Contamation and Toxicology, 1-9.

Guo, Y. L., Lambert, G. H., Hsu, C.-C., \& Hsu, M. M. (2004). Yucheng: health effects of prenatal exposure to polychlorainted biphenyls and dibenzofurans. International Archives of Occupational and Environmental Health, 77, 153-158.

Haglund, P., Sporring, S., Wiberg, K., \& Bjorklund, E. (2007). Shape-selective extraction of PCBs and dioxins from fish and fish oil using in-cell carbon fractionation pressurized liquid extraction. Analytical Chemistry, 79, 29345-2951.

Harrison, R. O., \& Eduljee, G. H. (1999). Immunochemical analysis for dioxins- progress and prospects. The Science of the Total Environment, 239, 1-18.

Hites, R. A. (1997). Gas chromatography mass spectometry. In F. Settle, Handbook of Instrumental Techniques for Analytical Chemistry (pp. 609-626). Indiana: Prentice Hall.

Hodge, V. J., and Austin, J. (2004). A survey of outlier detection methodologies. Artificial Intelligence Review, 22, 85-126.

Hoffman, R. E., Stehr-Green, P., \& Webb, K. (1986). Health effects of long-term exposure to 2,3,7,8-tetrachlorodibenzo-p-dioxin. Journal of the American Medical Association, 255, 2031-2038.

Homberger, E., Reggiani, G., Sambeth, J., \& Wipf, H. (1979). The Seveso accident: its nature, extent and consequences. Annals of Occupational Hygiene, 22, 327-367.

Ishankulov, M. (2008). Preliminary assessment of situation related to dioxins and furans releases in Kazakhstan. The Fate of Persistent Organic Pollutants in the Environment, 443-456.

Kaisarevic, S., Andric, N., Bobic, S., Trickovic, J., Teodorovic, I., Vojinovic-Miloradov, M., \& Kovacevic, R. Z. (2007). Detection of dioxin-like contaminants in soil from the area of oil refineries in Vojvodina region of Serbia. Bulletin of Environmetal Contamination and Toxicology, 79, 422-426. 
Kennedy, J., Delaney, L., Hudson, E. M., McGloin, A., \& Wall, P. G. (2010). Public preceptions of the dioxin incident in Irish pork. Journal of Risk Research, 13, 937-949.

Kimbrough, R. D., Carter, C., Liddle, J. A., \& Cline, R. E. (1977). Epidemiology and pathology of a tetrachlorodibenzodioxin poisoning episode. Archives of Environmental Health, 77-86.

Kimbrough, R. D., Krouskas, C. A., Carson, M. L., Long, T. F., Bevan, C., \& Tardiff, R. G. (2010). Human uptake of persistent chemicals from contaminated soil: PCDD/Fs and PCBs. Regulatory Toxicolgoy and Pharmacology, 1-9.

Kishida, M., Maekawa, T., \& Bandow, H. (2010). Effect of extraction temperature on pressurized liquid extraction of polychlorinated dibenzo-p-dioxins, polychlorinated dibenzofurans, and dioxin-like polychlorinated biphenyls from a sediment sample using polar and non-polar solvents. Analytica Chimica Acta, 659, 186-193.

Kleinhenz, S., Jira, W., \& Schwind, K.H. (2006). Dioxin and polychlorinated biphenyls analysis: automationn and improvement of clean-up established by example of spices. Molecular Nutrition Food Research, 50, 362-367.

Kohler, P. M., \& Ashton, M. (2010). Paying for POPs: negotiating the implementation of the Stockholm Convention in developing countries. International Negotiations, 15, 459484 .

Kulkarni, P. S., Crespo, J. G., \& Afonso, C. A. (2008). Dioxins sources and current remediation technologies - A review. Environment International, 34, 139 - 153.

Kumar, K. S., Yamamuro, M., Pitaksintorn, S., \& Masunaga, S. (2003). Dioxins/furans and polychlorinated biphenyls (PCBs) in dugongs from the Thailand coast. Bulletin of Environmental Contamination Toxicology, 70, 198-204.

Lal, V. V., Mueller, J. F., \& Aalbersberg, W. G. (2010). Monitoring POPs in pacific region: a case study for OCDD contamination in Fiji Islands. Dioxin 2010 (pp. 1-4). Fiji: Institute of Applied Sciences, the University of the South Pacific.

Legashvili, I. (2008). Presistent organic pollutants (POPs) management in Georgia. The Fate of Persistent Organic Pollutants in the Environmen, 65-79.

Liem, D., Furst, P., \& Rapper, C. (2000). Exposure of populations to dioxins and related compounds. Food Additives and Contaminants, 17, 241-259.

Li-Muller, A., Fleming, S., \& Marsh, M. (1996). Guidance on Site Specific Risk Assessment for Use of Contaminated Sites in Ontario. Toronto: Ontario Ministry of the Environment and Energy. 
Lohmann, R., \& Jones, K. C. (1998). Dioxins and furans in air and deposition: a review of levels, behaviour and processes. The Science of the Total Environment, 219, 53-81.

MacNeil, G. (2011). Newsroom: Chair Named To Lead Independent Panel On Herbicide. Retrieved April 11, 2011 from Ministry of Natural Resources:

http://news.ontario.ca/mnr/en/2011/03/chair-named-to-lead-independent-panel-onherbicide.html

Mai, T. A., Doan, T. V., Tarradellas, J., de Alencastro, L. F., \& Grandjean, D. (2007). Dioxin contamination in soils of South Vietnam. Chemosphere, 67, 1802-1807.

Mandal, P. K. (2005). Dioxin: a review of its environmental effects and its aryl hydrocarbon receptor biology. Journal of Compartive Physiology B, 175, 221 - 230.

Marsh, M., Lall, R., Capstick, S., Lewis, A., Pastorek, L., \& Kuja, A. (1996). Guidance on Sampling and Analytical Methods for Use at Contaminated Sites in Ontario. Toronto: Ontario Ministry of the Environment and Energy Standards Development Branch.

Masuda, Y. (1996). Approach to risk assessment of chlorinated dioxins from Yusho PCB poisoning. Chemosphere, 32, 583-594.

McKay, G. (2002). Dioxin characterisation, formation and minimisation during municipal solid waste (MSW) incineration: review. Chemical Engineering Journal, 86, 343-368.

Minh, N. H., Boivin, T., Canh, P. N., \& Son, L. K. (2009). Comprehensive assessment of dioxin contamination in Da Nang airbase and its vicinities: environmental levels, human exposure and options for mitigating impacts. Interdisciplinary Studies on Environmental Chemistry - Environmental Research in Asia, 21-29.

Miyawaki, T., Kawashima, A., \& Honda, K. (2008). Development of supercritical carbon dioxide extraction with a solid phase trap for dioxins in soils and sediment. Chemosphere, 70, 648-655.

Muntean, N., Jermini, M., Small, I., Falzon, D., Furst, P., Migliorati, G., Scortichini, G., Forti, A.F., Anklam, E., von Holst, C., Niyazmatov, B., Bahkridinov, S., Aertgeerts, R., Bertollini, R., Tirado, C., \& Kolb, A. (2003). Assessment of dietary exposure to some persistent organic pollutants in the Republic of Karakalpakstan of Uzbekistan. Environmental Health Perspectives, 111, 1306-1311.

Nguyen, T. T. (2009). Environmental consequences of dioxin from the war in Vietnam: what has been done and what else could be done? International Journal of Environmental Studies, 66, 9-26. 
Nichkova, M., Park, E.-K., Koivunen, M. E., Kamita, S. G., Gee, S. J., Chuang, J., Van Emon, J.M., \& Hammock, B. D. (2004). Immunochemical determination of dioxins in sediment and serum samples. Talanta, 63, 1213-1223.

Nieuwoudt, C., Quinn, L. P., Pieters, R., Jordann, I., Visser, M., Kylin, H., Borgen, A.R., Giesy, J.P., \& Bouwman, H. (2009). Dioxin-like chemicals in soil and sediment from residential and industrial areas in central South Africa. Chemosphere, 76, 774-783.

Olie, K., Schecter, A., Constable, J., Kooke, R., Serne, P., Slot, P., \& de Vries, P. (1989). Chlorinated dioxin and dibenzofuran levels in food and wildlife samples in the North and South of Vietnam. Chemosphere, 19, 493-496.

Ontario Ministry of Finance [OMOF]. (2010). Ontario Population Projections Update. Retrieved April 14, 2011 from:

http://www.fin.gov.on.ca/en/economy/demographics/projections/

Papadopoulos, A., Vassiliadou, I., Costopoulou, D., Papanicolaou, C., \& Leondiadis, L. (2004). Levels of dioxins and dioxin-like PCBs in food samples on the Greek market. Chemosphere, 57, 413-419.

Persistent Bioaccumulative and Toxic (PBT) Chemical Program. (2008). Retrieved October 17, 2009 from the United States Environmental Protection Agency: http://www.epa.gov/opptintr/pbt/pubs/dioxins.htm

Picer, M., Kovacevic, R., Picer, N., Kobasic, V. H., Calic, V., \& Zoric, S. (2006). Characterization of soil and sediment samples collected from the Zadar Area, Croatia, by GC-ECD PCB analysis and bioassay. Bulletin on Environmental Contaminaiton and Toxicolology, 77, 687-693.

Popp, P., Keil, P., Moder, M., Paschke, A., and Thuss, U. (1997). Application of accelerated solvent extraction followed by gas chromatography, high-performance liquid chromatography and gas chromatography-mass spectrometry for the determination of polycyclic aromatic hydrocarbons, chlorinated pesticides and polychlorinated dibenzo-pdioxins and dibenzofurans in solid wastes. Journal of Chromatography, 774, 203-211.

Reiner, E., Clement, R., Okey, A., \& Marvin, C. (2006). Advances in analytical techniques for polychlorainated dibenzo-p-dioxins, polychlorinated dibenzofurans and dioxin-like PCBs. Analytical and Bioanalytical Chemistry, 386, 791-806.

Richmond, M. (2000). Examples of Uncertainty Calculations. Retrieved April 24, 2011 from: http://spiff.rit.edu/classes/phys377/uncert.html

Rogan, W. J., Gladen, B. C., Hung, K.-L., Koong, S.-L., Shih, L.-Y., Taylor, J. S., Wu, Y., Yang, D., Ragan, N., \& Hsu, C. (1988). Congential poisoning by polychlorinated biphenyls and their contaminants in Taiwan. Science, 241, 334-341. 
Rong, Z., Li, K., \& Yin, H. (2010). Pilot study of the polychlorinated dibenzo-p-dioxins and dibenzofurans level in agricultural soil in Shanghai, China. Environmental Monitoring and Assessment, 1-8.

Ruan, D., Chen, G., Kerre, E., \& Wets, G. (2005). Intelligent data mining: techniques and applications. Studies in Computational Intelligence, 5, 318.

Schecter, A., Birnbaum, L., Ryan, J. J., \& Constable, J. D. (2006). Dioxins: an overview. Environmental Research, 101, 419 - 428.

Schecter, A., Dai, L. C., Thuy, L. T., Quynh, H. T., Minh, D. Q., \& Cau, H. D. (1995). Agent Orange and the Vietnamese: the persistence of elevated dioxin levels in human tissues. American Journal of Public Health, 85, 516-522.

Schecter, A., Quynh, H. T., Pavuk, M., Papke, O., Malisch, R., \& Constable, J. D. (2003). Food as a source of dioxin exposure in the residents of Bien Hoa City, Vietnam. Journal of Occupational and Environmental Medicine , 45, 781-788.

Schrock, M., Dindal, A., \& Billets, S. (2009). Evaluation of alternative approaches for screening contaminated sediments and soils for polychlorinated dibenzo-p-dioxins and polychlorinated dibenzofurans. Journal of Environmental Management, 90, 1289 - 1295.

Secretariat of the Stockholm Convention on Persistent Organic Pollutants. (2004). Stockholm Convention on Persistent Organic Pollutants. Geneva: Secretariat of the Stockholm Convention on Persistent Organic Pollutants.

Sorg, O., Zennegg, M., Schmid, P., Fedosyuk, R., Valikhnovskyi, R., Gaide, O., Kniazevych, V., \& Saurat, J.H. (2009). 2,3,7,8-tetrachlorodibenzo-p-dioxin (TCDD) poisoning in Victor Yushchenko: identification and measurment of TCDD metabolites. The Lancet, 1-7.

Steenland, K., \& Deddens, J. (2003). Dioxin: Exposure-response analyses and risk assessment. Industrial Health, 41, 175-180.

Sweeney, M. H., \& Mocarelli, P. (2000). Human health effects after exposure to 2,3,7,8TCDD. Food Additives and Contaminants, 17, 303-316.

Takazawa, Y., Verdugo, R., Richter, P., Kitamura, K., Choi, J.-W., Hashimoto, S., Ito, H., Shibata, Y., \& Morita, M. (2004). Current levels of dioxins in surface soils from Santiago Chile. Bulletin of Environmental Contamination and Toxicology, 75, 543-550.

Tang, X., Zhu, Y., Shan, X., McLaren, R., \& Duan, J. (2007). The ageing effect on the bioaccessibility and fractionation of arsenic in soils from China. Chemosphere, 66, 11831190. 
The World Bank. (2010). Data Country and Lending Groups. Retrieved October 16, 1010 from: http://data.worldbank.org/about/country-classifications/country-and-lendinggroups

Thesleff, I., Pohjanvirta, R., Viluksela, M., Vartianinen, T., \& Miettinen, H. (2008). Dioxins. Retrieved June 21, 2010 from:

http://www.helsinki.fi/science/dentenv/AhR\%20pathway.jpg

Treasury Board of Canada Secretariat. (2010). Federal Contaminated Sites Inventory. Retrieved June 20, 2010 from: http://www.tbs-sct.gc.ca/fcsi-rscf/numbersnumeros.aspx?qid $=298088 \&$ sTheme $=\&$ tab $=$ cm $\&$ sSortOrder $=\&$ sSortDirection $=\& p g=$

Trindade, M., Nording, M., Nichkova, M., Spinnel, E., Haglund, P., Last, M. S., Gee, S., Hammock, B., Last, J.A., Gonzalex-Sapienza, G., \& Brena, B.M. (2008). Enzyme-linked immunosorbent assay for screening dioxin soil contamination by uncontrolled combustion during informal recycling in slums. Environmental Toxicology and Chemistry, 27, 2224 - 2232.

Tsukimori, K., Tokunaga, S., Shibata, S., Uchi, H., Nakayama, D., Ishimaru, T., Nakano, H., Wake, N., Yoshimura, T., \& Masutaka, F. (2008). Long-term effects of polychlorinated biphenyls and dioxins on pregnancy outcomes in women affected by the Yusho incident. Environmental Health Perspectives, 626-630.

Tundo, P., Raccanelli, S., Reda, L., \& Ahmed, M. T. (2004). Distribution of polychlorinated dibenzo-p-dioxins, polychlorinated dibenzofurans, dioxin-like polychlorinated biphenyl and polycyclic aromatic hydrocarbons in the sediment of Temsah Lake, Suex Canal, Egypt. Chemistry and Ecology, 20, 257-265.

Tuyet, L. T., \& Johansson, A. (2001). Impact of chemical warfare with Agent Orange on women's reproductive lives in Vietnam: A pilot study. Reproductive Health Matters, 9, 156-164.

Van den Berg, M., Birnbaum, L. S., Denison, M., De Vito, M., Farland, W., Feeley, M., Giesy, J.P., Hanber, A., Hasegawa, R., Kennedy, S., Kubiak, T., Laren, J.C., van Leeuwen, R., Liem, A.K., Nolt, C., Peterson, R.E., Poellinger, L., Safe, S., Schrenk, D., Tillitt, D., Tysklind, M., Younes, M., Waern, F., \& Zacharewski, T. (2006). The 2005 World Health Organization reevaluation of human and mammalian toxic equivalency factors for dioxins and dioxin-like compounds. Toxicological Sciences, 93, 223-241.

Van Emon, J. M., Chuang, J. C., Lordo, R. A., Schrock, M. E., Nichkova, M., Gee, S. J., Hammock B.D. (2008). An enzyme-linked immuosorbent assay for the determination of dioxins in contaminated sediment and soil samples. Chemoshere, 72, 95-103.

Vassiliadou, I., Papadopoulos, A., Costopoulou, D., Vasiliadou, S., Christoforou, S., \& Leondiadis, L. (2009). Dioxin contamination after an accidental fire in municipal landfill of Tagarades, Thessaloniki, Greece. Chemosphere, 74, 879-884. 
Vollmuth, S., Zajc, A., \& Niessner, R. (1994). Formation of polychlorinated dibenzo-pdioxins and polychlorinated dibenzofurans during the photolysis of pentachlorophenolcontaining water. Environmental Science and Technology, 28, 1145-1149.

Watanabe-Ezoe, Y., Li, X., Imasaka, T., Uchimura, T., \& Imasaka, T. (2010). Gas chromatography/femtosecond multiphoto ionization/time-of-flight mass spectrometry of dioxins. Analytical Chemistry, 82, 6519-6525.

Wolfe, W., Michalek, J., Miner, J., Rahe, A., Silva, J., Thomas, W., Grubbs, W.D., Lustik, M.B., Karrison, T.G., \& Roegner R.H. (1990). Health status of Air Force veterans occupationally exposed to herbicides in Vietnam. I. Physical Health. Journal of the American Medical Association, 264, 1824-1831.

Wyrzykowska, B., Hanari, N., Orlikowska, A., Yamashita, N., \& Falandysz, J. (2009). Dioxin-like compound compositional profiles of furnace bottom ashes from household combustion in Poland and their possible associations with contamination status of agricultural soil and pine needles. Chemosphere, 76, 255-263.

Yao, Y., Takasuga, T., Masunaga, S., \& Nakanishi, J. (2002). Detailed study on the levels of polychlorinated dibenzo-p-dioxins, polychlorinated dibenzofurans and polychlorinated biphenyls in Yusho rice oil. Chemosphere, 46, 1461-1469.

Zhang, W. (2008). Principles and techniques towards successful development of enzyme-linked immunosorbent assay (ELISA) for dioxin analysis. Toronto: Ryerson University.

Ziomislic, D. (2011, February 26). Ontario Hyrdro sprayed Agent Orange to clear corridors. Toronto Star. Retrieved on March 1, 2011 from: www.torontostar.com

Ziomislic, D. (2011, February 17). Star Exclusive: Agent Orange "soaked" Ontario teens. Toronto Star. Retrieved on March 1, 2011 from: www.torontostar.com

Zlomislic, D., \& Talaga, T. (2011, February 28). Minister calls for national probe of Agent Orange. Toronto Star. Retrieved on March 1, 2011 from: www.torontostar.com 